INTER NATIONAL MONETARY FUND
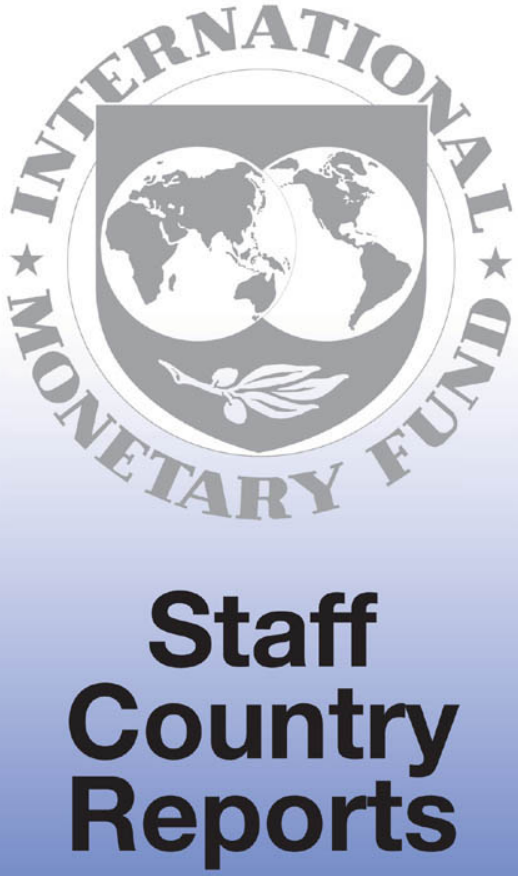


\title{
Euro Area Policies: Staff Report; Staff Supplement; Public Information Notice on the Executive Board Discussion; and Statement by the Executive Director on Euro Area Policies
}

Under Article IV of the IMF's Articles of Agreement, the IMF holds bilateral discussions with members, usually every year. In the context of the 2006 Article IV consultation with countries forming the euro area, the following documents have been released and are included in this package:

- $\quad$ the staff report on euro area policies (including the trade policies of the European Union), prepared by a staff team of the IMF, following discussions that ended on May 19, 2006 with the officials at EU institutions in the context of the Article IV consultations with countries forming the euro area. Based on information available at the time of these discussions, the staff report was completed on June 30, 2006. The views expressed in the staff report are those of the staff team and do not necessarily reflect the views of the Executive Board of the IMF.

- $\quad$ a staff supplement of July 25, 2006 updating information on recent developments.

- $\quad$ a Public Information Notice (PIN) summarizing the views of the Executive Board as expressed during its July 26, 2006 discussion of the staff report on euro area policies.

- a statement by the Executive Director for the country currently holding the Presidency of the European Council, on behalf of the euro-area countries.

The document listed below has been or will be separately released.

Selected Issues Paper

The policy of publication of staff reports and other documents allows for the deletion of market-sensitive information.

To assist the IMF in evaluating the publication policy, reader comments are invited and may be sent by e-mail to publicationpolicy@imf.org.

\author{
Copies of this report are available to the public from \\ International Monetary Fund • Publication Services \\ $70019^{\text {th }}$ Street, N.W. • Washington, D.C. 20431 \\ Telephone: (202) 623-7430 • Telefax: (202) 623-7201 \\ E-mail: publications@imf.org • Internet: http://www.imf.org
}

Price: $\$ 15.00$ a copy

\section{International Monetary Fund Washington, D.C.}


This page intentionally left blank 


\title{
INTERNATIONAL MONETARY FUND
}

\section{EURO AREA POLICIES}

\section{Staff Report for the 2006 Article IV Consultation}

\author{
Prepared by the European Department \\ Approved by Michael Deppler and Adnan Mazarei
}

June 30, 2006

- A staff team held discussions at the European Central Bank (ECB) and the European Commission (EC) as well as with trade union (ETUC), employer (UNICE), and various financial sector representatives during May 9-19, 2006.

- Meetings were held at the ECB with President Trichet, Vice President Papademos, Mr. Bini Smaghi, Mr. González-Páramo, Mr. Issing, Ms. TumpelGugerell, and senior staff. At the EC, the mission met with Commissioner Almunia, Mr. Regling (Director General for Economic and Financial Affairs), and other senior officials. Mr. Saarenheimo (Executive Director) and Mr. Wijnholds (ECB Observer at the Executive Board) attended most of the meetings. Mr. Deppler also met Eurogroup President Juncker, discussed the mission's preliminary findings at the May 29 Euro Working Group meeting, and presented the mission's concluding statement to the Eurogroup on June 6.

- The team comprised Messrs. Deppler (Head), Annett, Decressin, Faruqee, Fonteyne, Stavrev (all EUR), and Mr. Dhonte, the Fund's Special Representative to the EU. Mr. Lankes (PDR) joined the mission at the EC to cover EU trade issues.

- The authorities released the mission's concluding statement and have agreed to the publication of the staff report.

- $\quad$ Appendices I and II, respectively, discuss statistical issues and provide a listing of past and present pertinent Selected Issues and Working Papers. 
Contents

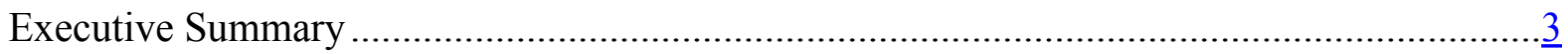

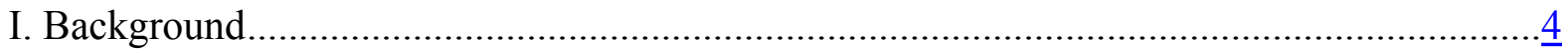

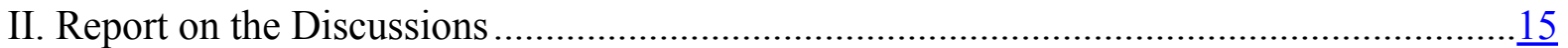

A. Prospects for Activity and Risks .........................................................

B. Monetary Policy: What are the Risks to Price Stability? ................................. $\frac{17}{24}$

C. Structural Policy Issues and Challenges.........................................................

D. International Spillovers, Trade Policy, and Imbalances .....................................

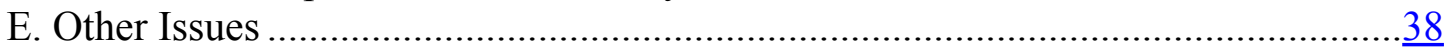

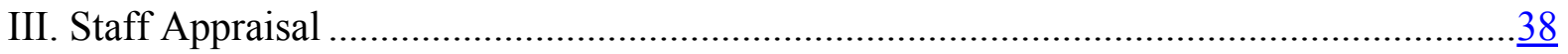

Tables

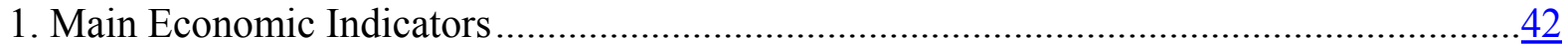

2. Macro-Prudential Indicators for the Banking Sector, 1999-2004 …..............................43

3. Balance of Payments .......................................................................................... 44

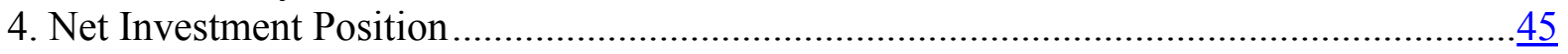

Figures

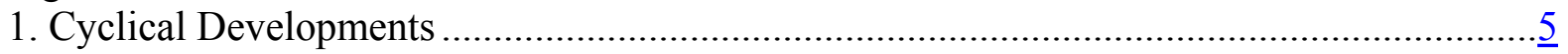

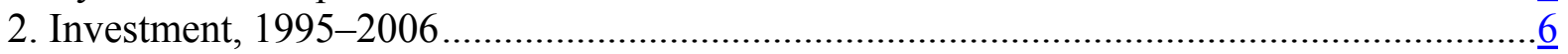

3. Corporate Sector Financial Developments, 1992-2005 …........................................

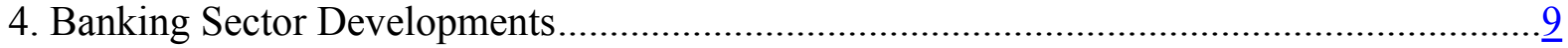

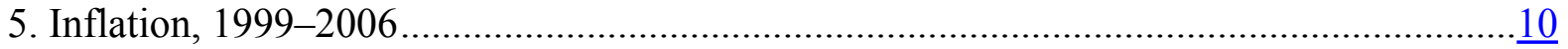

6. Households and Consumption .......................................................................... $\frac{12}{12}$

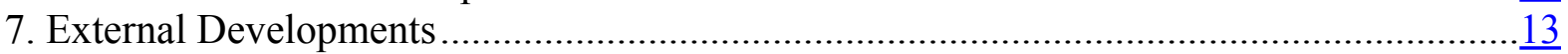

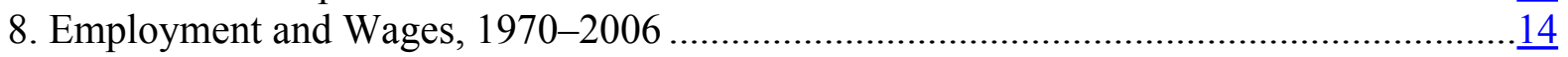

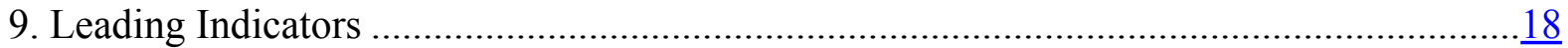

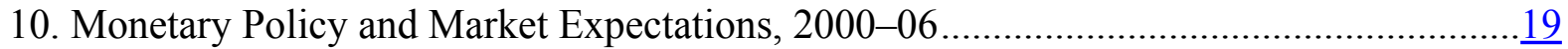

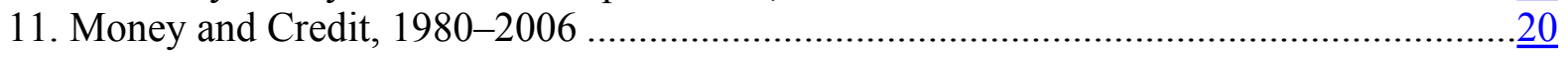

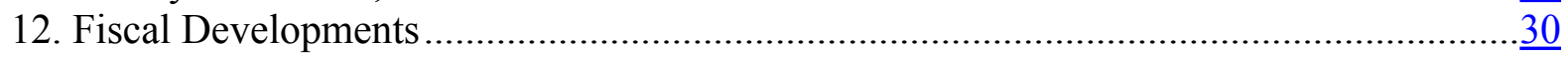

Boxes

1. Effectiveness and Role of Fund Surveillance ........................................................... 15

2. Declining Neutral Interest Rates and ECB Monetary Policy...................................... $\frac{23}{26}$

3. Euro Area Divergence........................................................................................ $\frac{26}{29}$

4. The Updated Demographic Perspective ................................................................

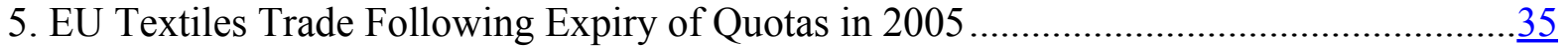

6. Reforms in the Euro Area and Global Imbalances ...................................................

Appendixes

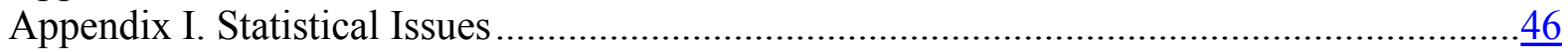

Appendix II. EU Policies Staff Research, 2003-05 ..................................................... 


\section{EXECUTIVE SUMMARY}

The recovery is gaining traction but prospects beyond the near term are less assured. While the euro area has been trailing the global upswing more than on previous occasions, activity is gradually strengthening and may even surprise on the upside during 2006. Further ahead, however, the risks move to the downside, given uncertainties in oil, currency, and financial markets. Inflation is running above the ECB's objective and is projected to continue doing so into 2007 on account of exogenous shocks. However, these shocks have not triggered significant indirect or second-round effects and staff project inflation to fall back below 2 percent in 2008 .

There was broad agreement on the economic outlook but the ECB saw the risks to price stability more skewed to the upside than the staff. The latest ECB rate hike is consistent with staff's views but further withdrawal of accommodation should await a broadening of the upswing — as evidenced by quickening employment—or signs of accelerating underlying price pressures.

Key concerns focused on the area's capacity to simultaneously stage solid employment and productivity growth over the medium run. A marked slowdown in productivity growth has offset a significant part of the increased labor utilization of the past decade; and population decline is set to start around 2010. Adjusting Europe's welfare states remains an uphill struggle. The discussions focused on the need for mutually re-enforcing fiscal and structural policies, specifically:

- $\quad$ Taking advantage of the recovery to make significant progress toward achieving broadly balanced fiscal positions by 2010 , preferably by cutting expenditure in a manner that fosters labor supply. Adjustment in 2005 has exceeded projections and there was agreement that the reformed Stability and Growth Pact was gaining traction over fiscal policies in high deficit countries. Countries plan to move toward balanced budgets over the medium run, but plans are vague and prospects remain uncertain.

- $\quad$ Accelerating the reform of product and services markets to ensure that labor market restructuring translates into more employment rather than higher rents. In this regard, the National Reform Programs under the reformed Lisbon Agenda offer an avenue for designing consistent structural policies and developing national ownership of the Agenda. The authorities also pointed to the adoption of a directive that opens EU services markets to competition, even if less than originally sought.

- Unlocking the potential of financial integration, which could provide a fillip to the area's growth prospects, while safeguarding stability. The Commission drew attention to the major progress that has been achieved since EMU and new initiatives to foster supervisory collaboration and coordination. Staff advocated tackling more decisively the vested interests that, among others, hold up the integration of financial infrastructure and add nation-specific layers to EU-wide regulations; and argued for a clarification and further integration of supervisory powers over complex cross-border groups to improve financial stability policies. 


\section{BACKGROUND}

\section{After several years of disappointments, growth has picked up and broadened} over the past twelve months. In marked contrast to the previous global upswing, euro-

Average Annual GDP Growth (in percent) area real GDP and domestic demand growth averaged only about $1 \frac{1 / 2}{2}$ percent during 2003-05 (Figure 1, Table 1). Since last summer, however, the pace has accelerated somewhat and, more importantly, the recovery has gradually been broadening: notwithstanding significant quarterly volatility, real GDP, final domestic demand, and household consumption all grew between $13 / 4-2$ percent in the year through 2006:Q1 and the recovery has been gaining some traction in weaker parts of the area. Nonetheless, the pick up in activity remains fragile, relying on strong global growth. Employment and consumption continue to lag.

\section{Besides supportive external demand and financial conditions, the recovery reflects in part improved fundamentals in the corporate sector:}

- $\quad$ Nonfinancial corporate profitability has been strong and leverage has been brought under control (Figures 2, 3). Market-based financing activities have begun to recover from recent lows and, thus far, are not expected to be set back significantly by the latest market turbulence. Bank-based borrowing, which picked up more than a year ago, remains robust. While enterprise loans have largely funded restructuring and consolidation, lending surveys now indicate that capital expendituresheretofore stuck in a holding pattern, outside construction - are no longer a drag.

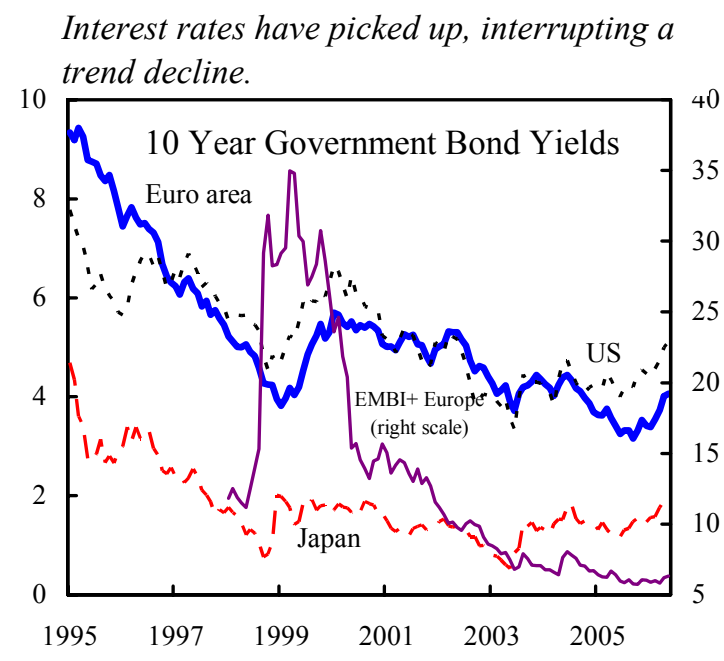


Figure 1. Euro Area: Cyclical Developments

(Annualized quarter-on-quarter percent change, unless otherwise specified)

The area's recovery lags a maturing global

...including in per capita terms.
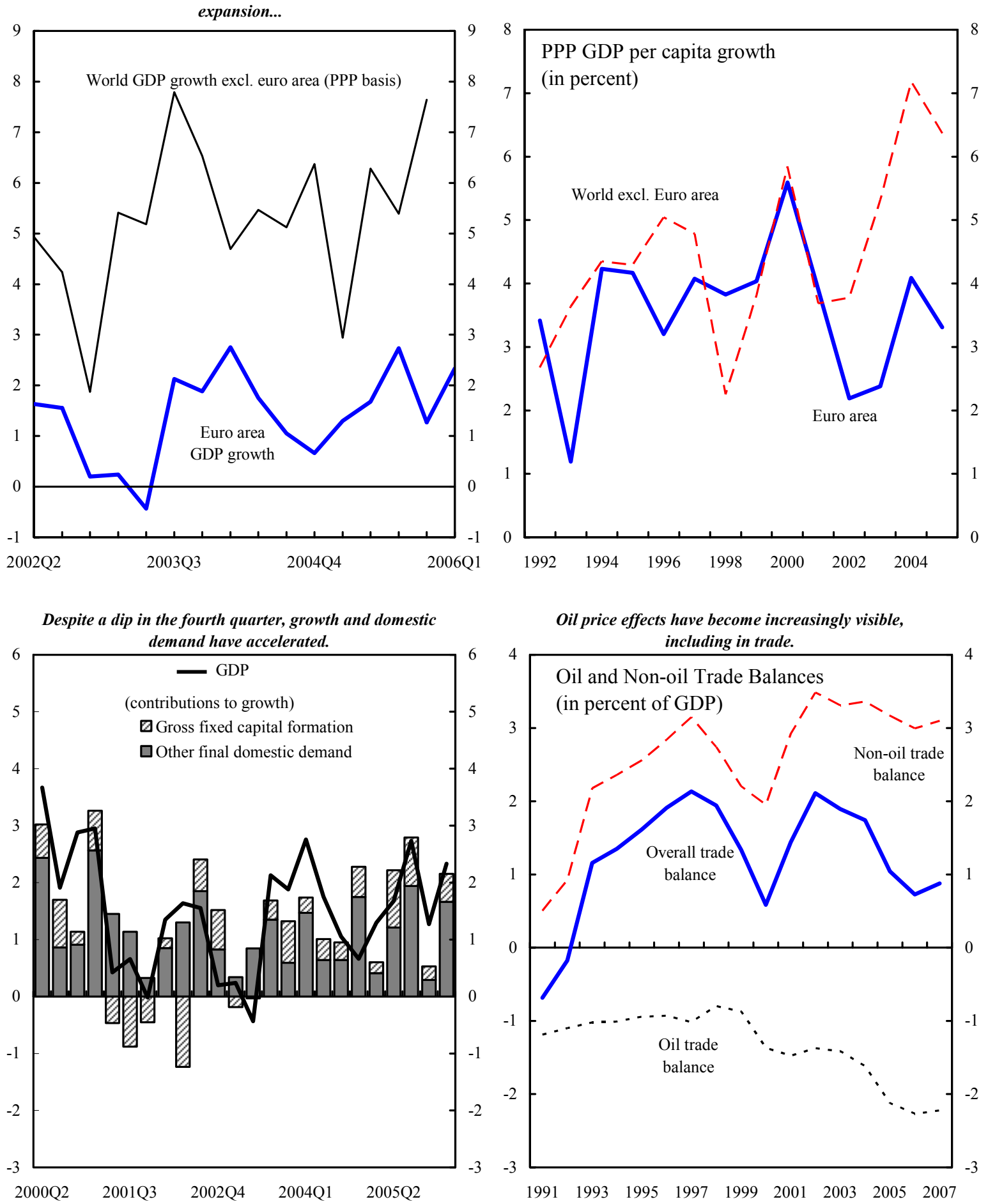

Sources: Eurostat; Datastream; and IMF, World Economic Outlook. 
Figure 2. Euro Area: Investment, 1995-2006

(in percent, unless otherwise specified)
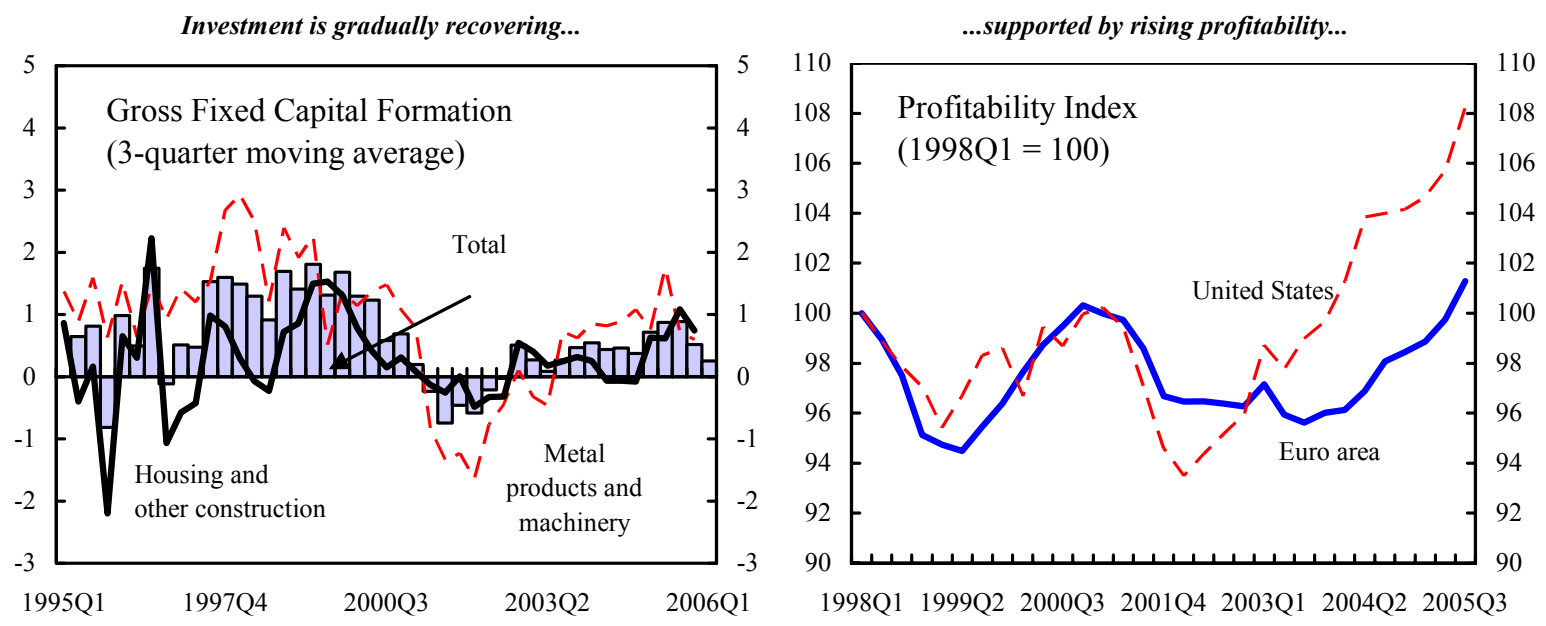

...and improving financial market conditions.

However, limited retrenchment since the peak may curb investment growth going forward.
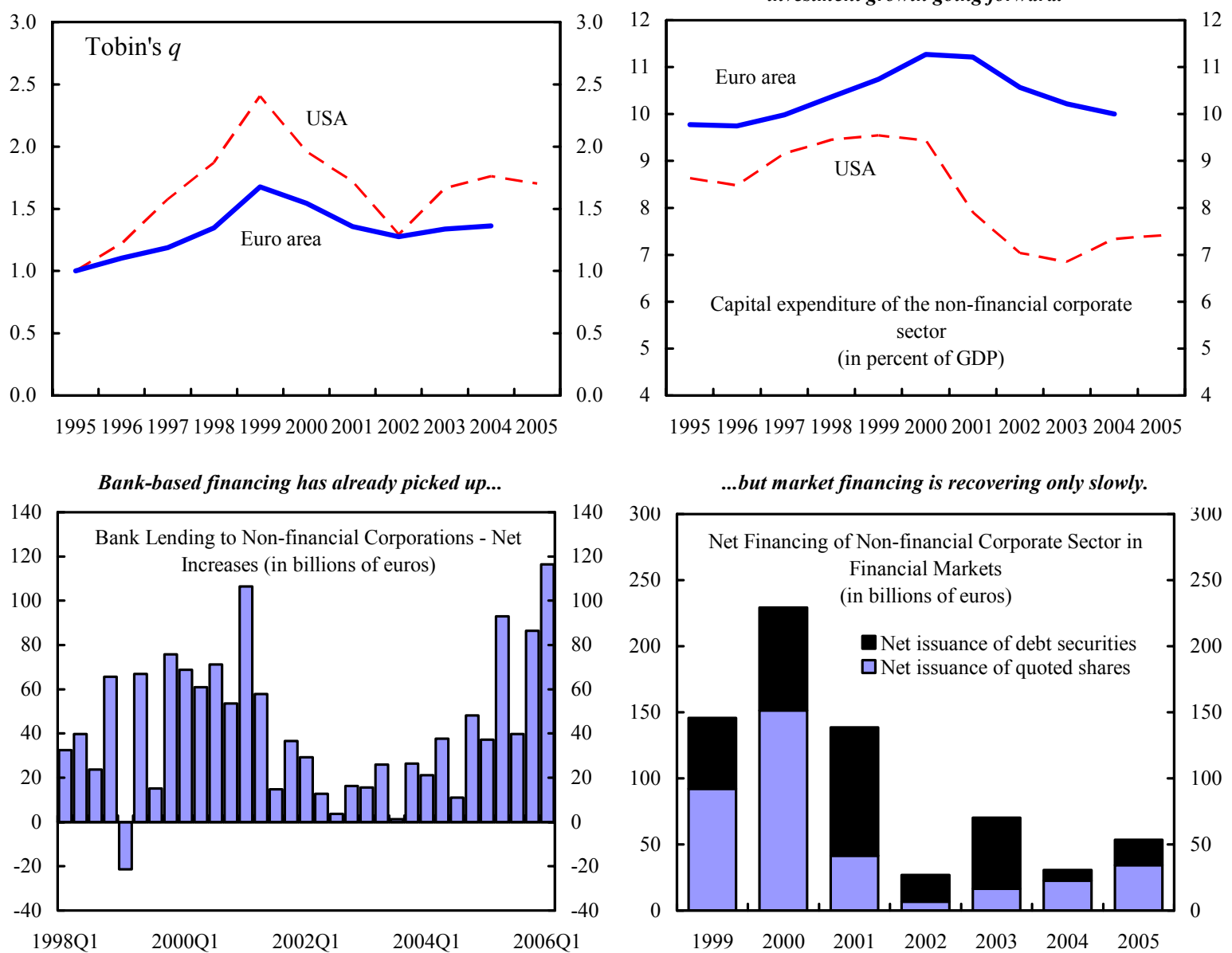

Sources: Eurostat; ECB; Haver Analytics; and IMF staff calculations. 
Figure 3. Euro Area: Corporate Sector Financial Developments, 1992-2005

The gross financing needs of corporations remain well below their most recent peaks..

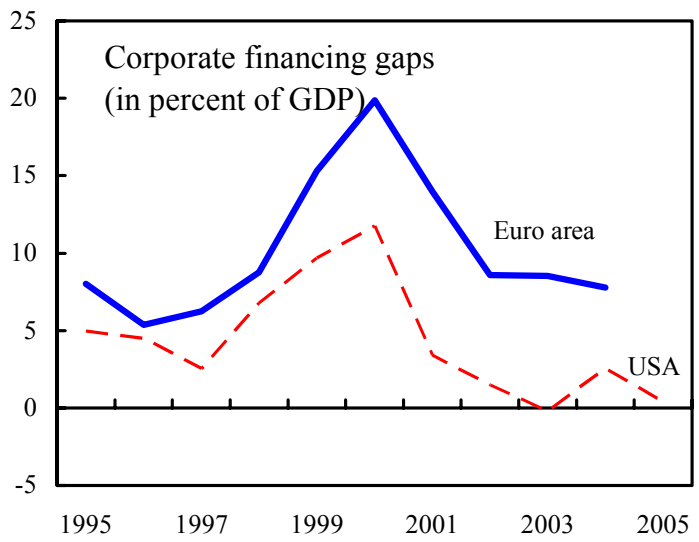

Corporations' net financing needs have been easily covered by households.

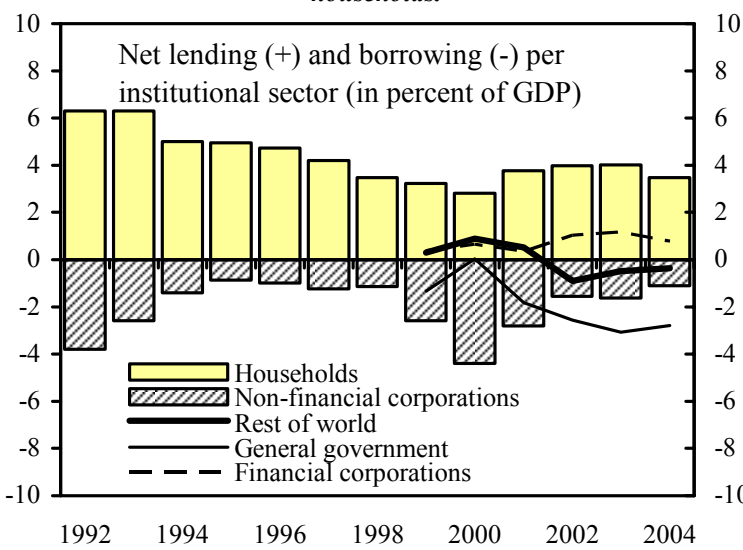

...while recovering equity markets have helped reduce balance

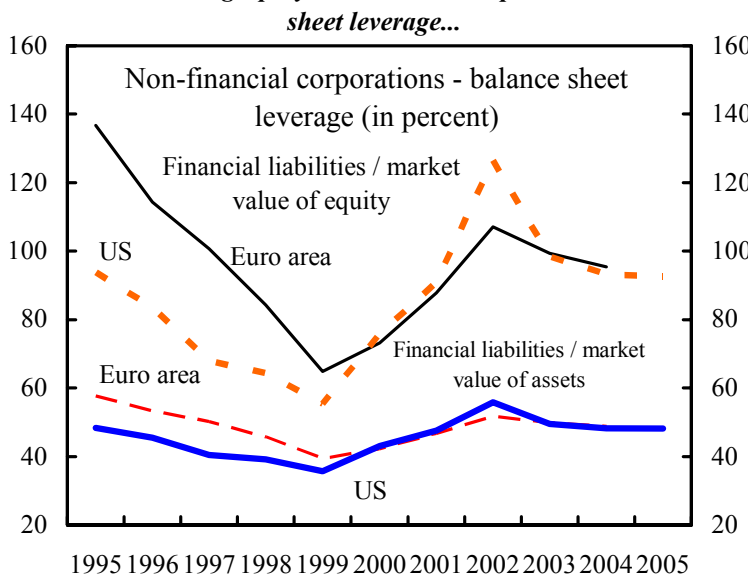

19951996199719981999200020012002200320042005 ...reflecting in particular reduced appetite for financial assets.

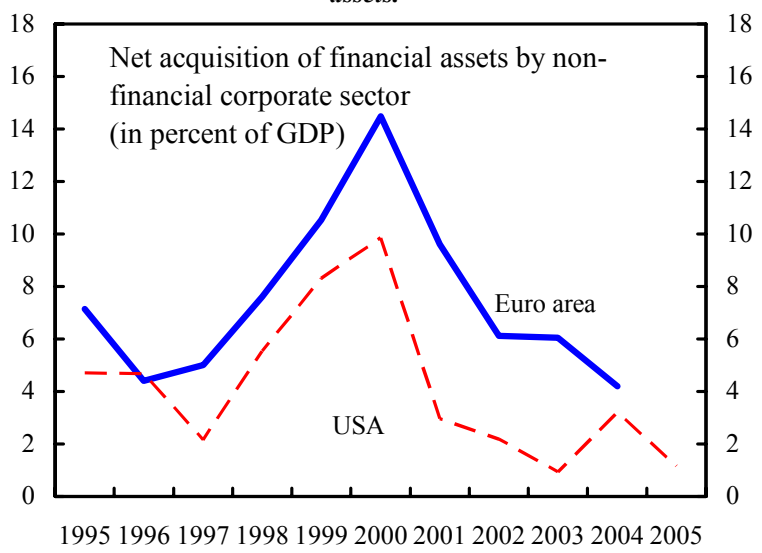

Lower debt accumulation and improving profitability are bringing down income leverage...

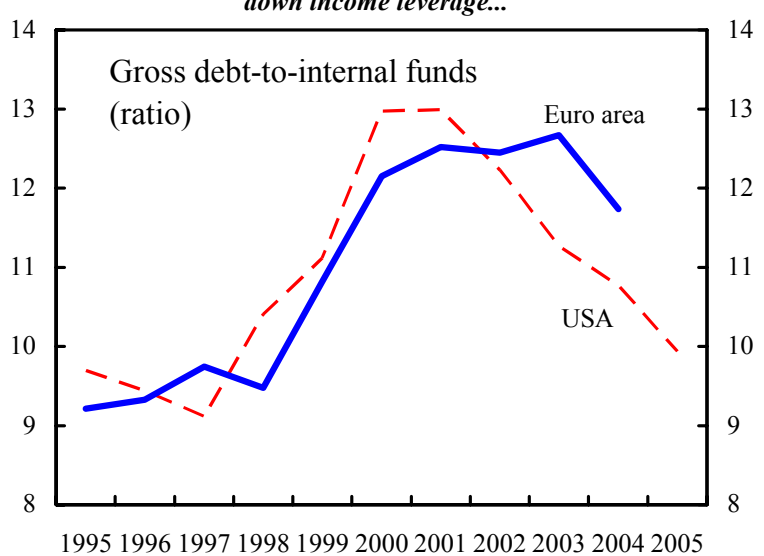

...and corporations have accumulated cash.

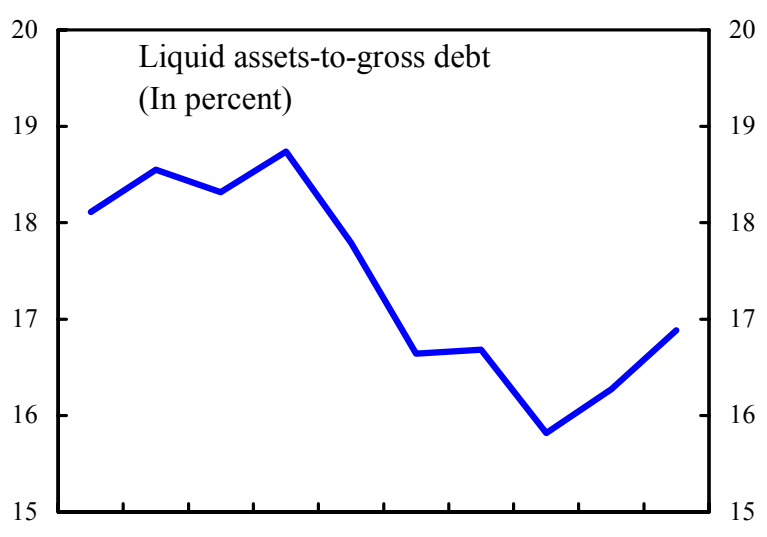

1995199619971998199920002001200220032004

Sources: ECB; and IMF staff calculations. 
- $\quad$ Financial sector indicators also point to improving positions (Figure 4, Table 2). Many banks are well capitalized and booking record profits, buoyed by favorable financial market developments, low interest rates, low costs of risk, cost containment, and booming demand for mortgage loans. Fundamental soundness has also been supported by improvements in governance, risk management, and regulation and supervision. ${ }^{1}$
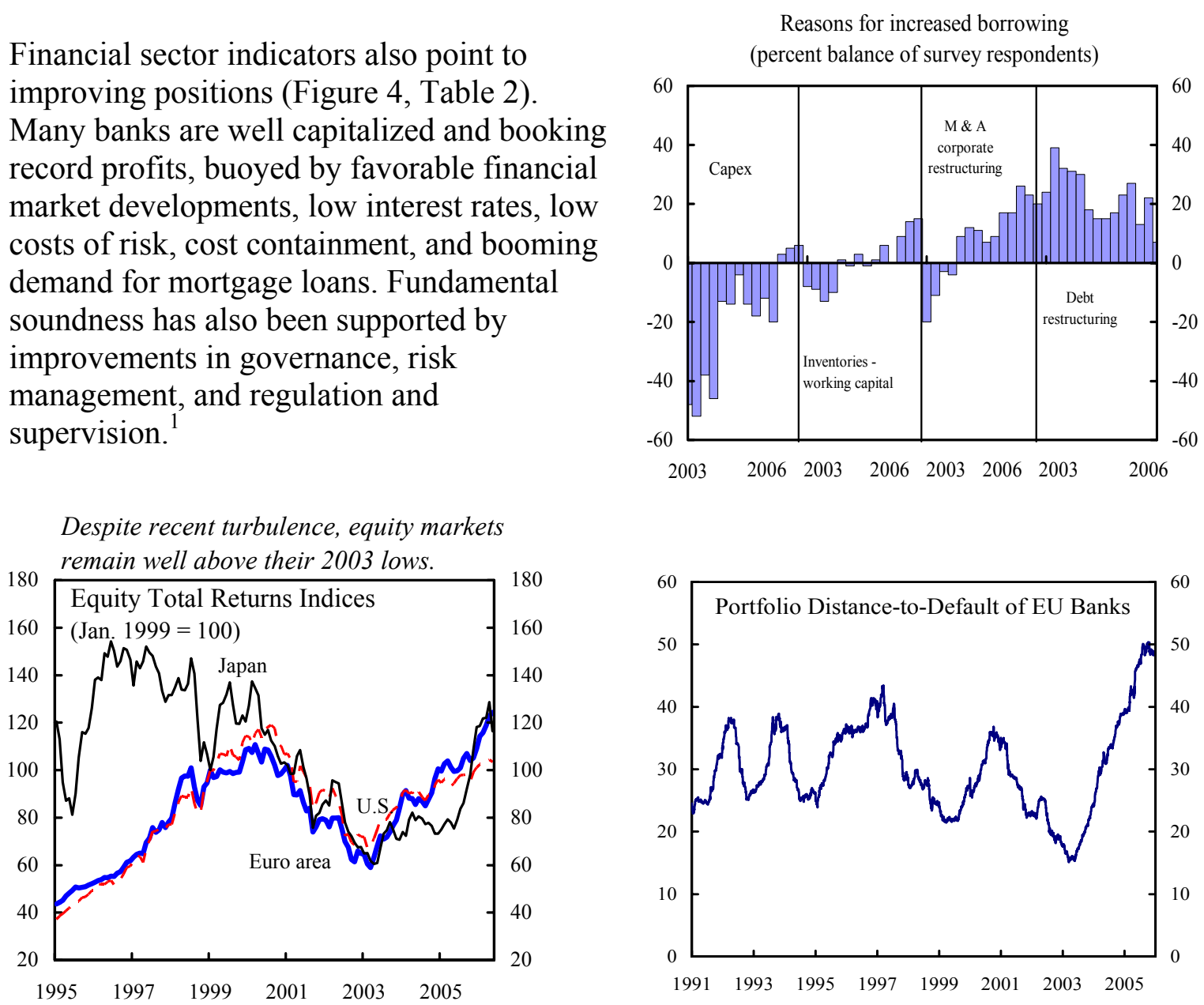

Source: Fund staff calculations.

\section{Price pressures appear contained,} notwithstanding sharply rising oil and administrative prices (Figure 5). Headline HICP inflation reached 2.5 percent in May and is likely to stay above 2 percent for some time due to energy prices, further administered price hikes, and the expected VAT increase in Germany in 2007. However, core inflation (HICP excluding energy and unprocessed food) is running around $1 \frac{1}{2}$ percent, reflecting limited indirect effects and the absence of second-round effects. And services price inflation is easing. This enhanced overall performance likely reflects enhanced central bank credibility, better functioning labor markets, global competition, and

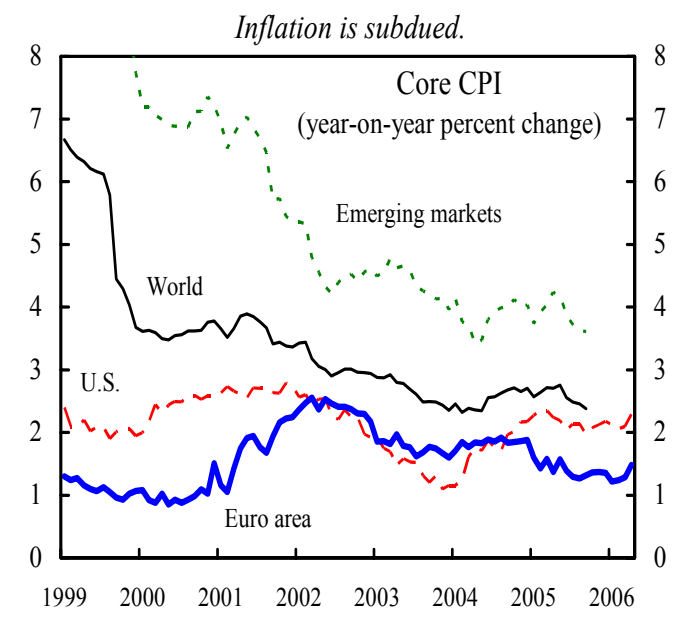
cyclical slack.

\footnotetext{
${ }^{1}$ The picture is generally less strong in the insurance sector, which has benefited from positive financial market developments, but is suffering record catastrophe claims (reinsurers) and negative repercussions from low interest rates (although life insurers have recently either lowered or phased out guaranteed rates of return).
} 
Figure 4. Euro Area: Banking Sector Developments (100 Largest Banks; in percent, unless otherwise noted)

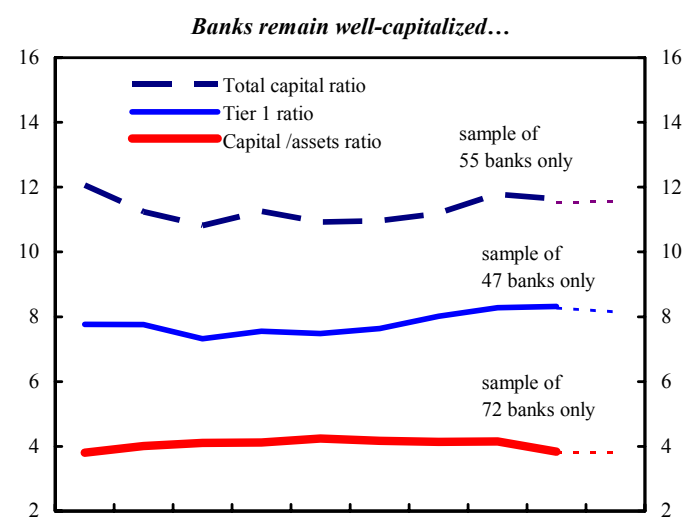

$\begin{array}{llllllllll}1996 & 1997 & 1998 & 1999 & 2000 & 2001 & 2002 & 2003 & 2004 & 2005\end{array}$ ...and profitability has recovered...
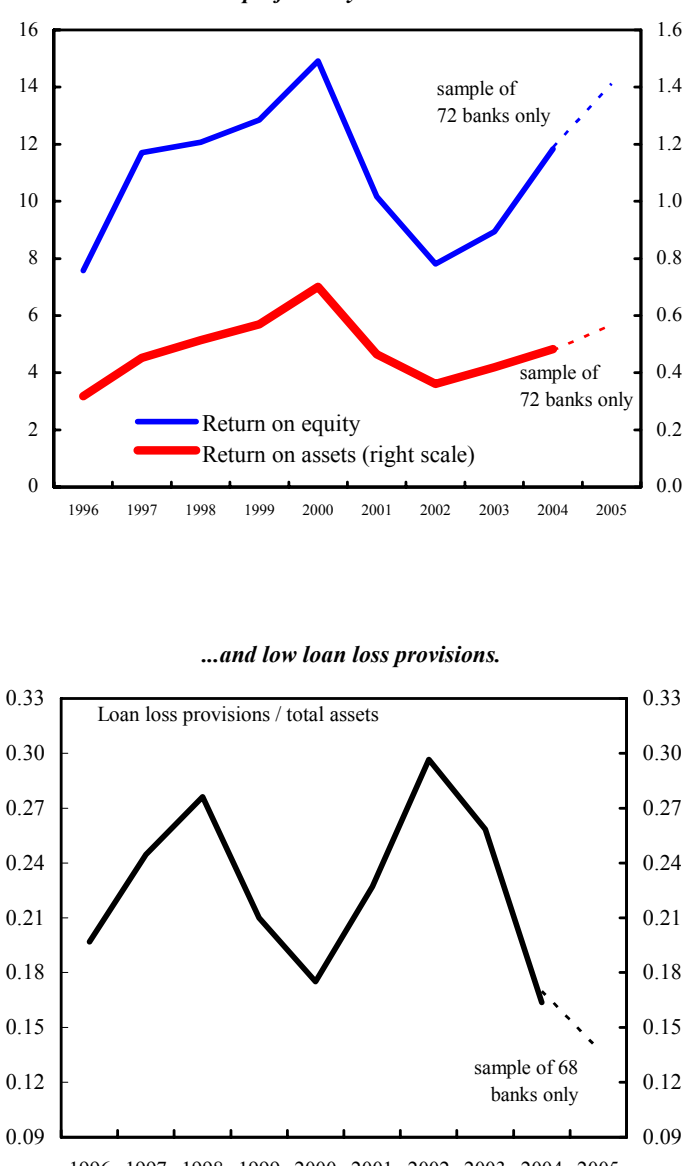

Increasing profitability and a positive outlook have supported banks' share prices.

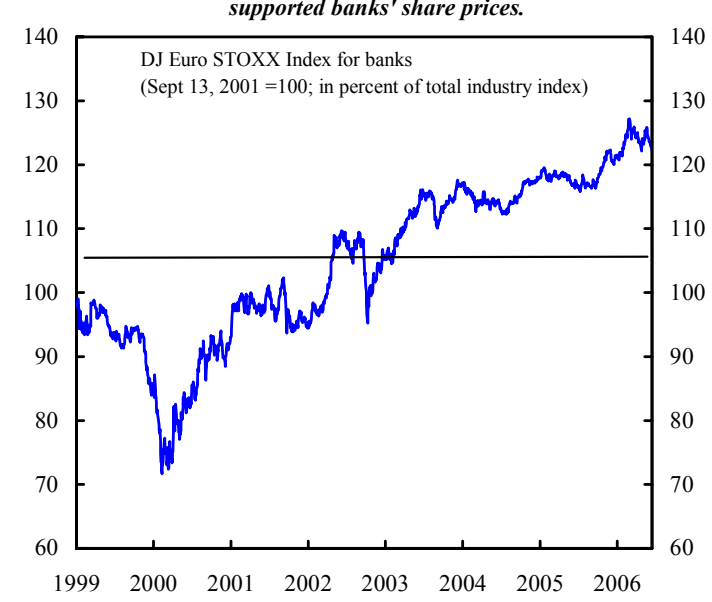

199719981999200020012002200320042005

Sources: BankScope; Datastream; and Fund staff calculations. 
Figure 5. Euro Area: Inflation and Labor Costs, 1999-2006 (in percent, unless otherwise specified)
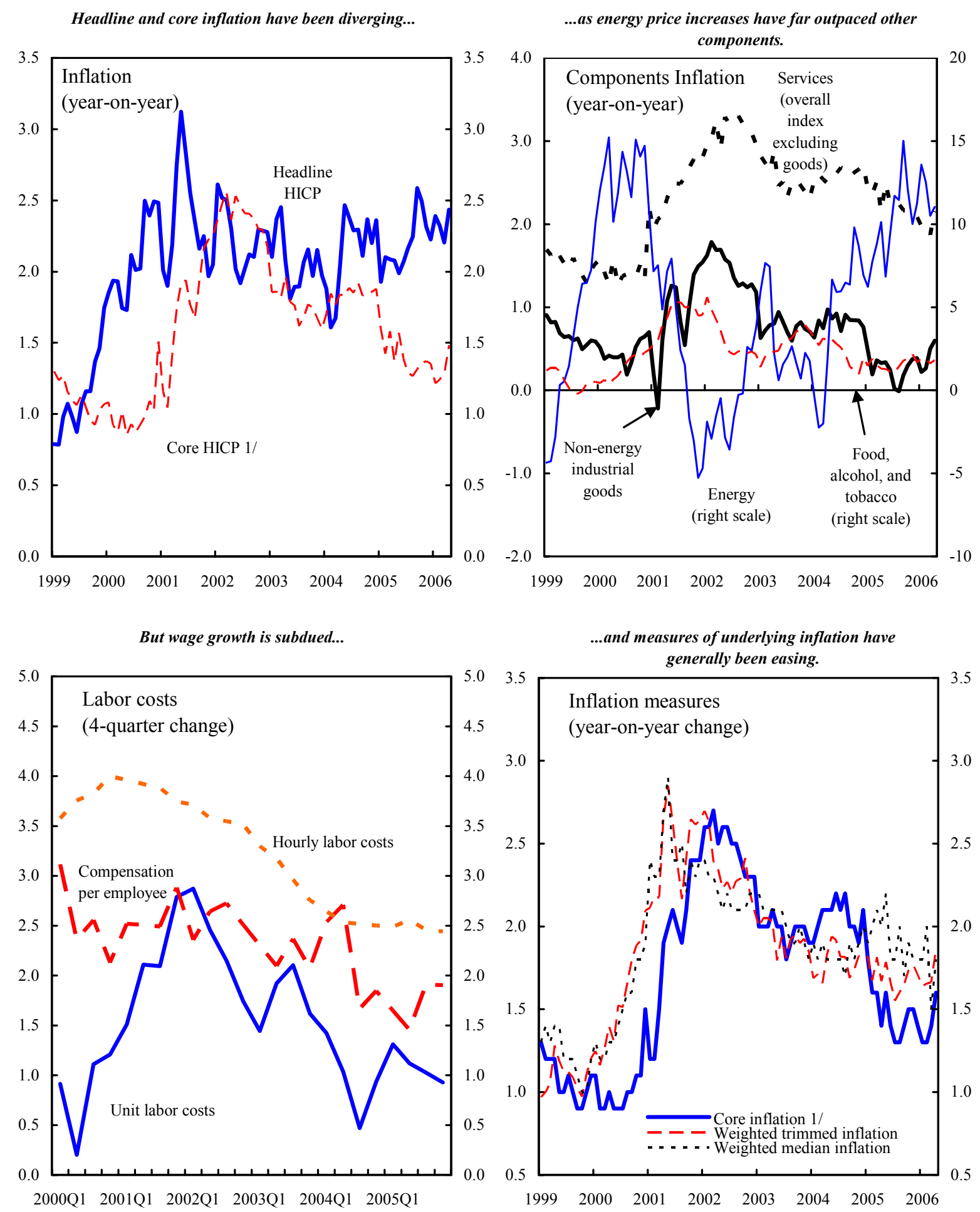

Sources: Eurostat; ECB; and Haver Analytics.

1/ Excludes alcohol, food, energy, and tobacco. 


\section{The area's external position and exchange rate appear broadly aligned with}

fundamentals. Household savings remain stable and, while balance sheets might be overstretched in some regions, this is not the case for the area as a whole, with the burden of rising indebtedness offset by larger holdings of assets and low interest rates (Figure 6). Combined with modest net borrowing by the corporate and public sectors, the external current account is broadly balanced. Following an appreciation during 2002-03, supported by significant net FDI and portfolio inflows, the real effective exchange rate of the euro has been moving broadly sideways around 5 percent above its long-term average over the past couple of years. Considering the area's relative cyclical position and developments in net foreign liabilities and the terms of trade, staff estimates suggest that the effective exchange rate is within a range compatible with (or slightly above) medium-term equilibrium (Figure 7, Tables 3, 4). ${ }^{2}$

Euro Area: Assessments of Real Exchange Rates 1/ (Percentage deviations from estimated medium-run equilibrium levels)

\begin{tabular}{|c|c|c|}
\hline & \multicolumn{2}{|c|}{ Multilateral } \\
\hline & Macro Balance & $\begin{array}{c}\text { Equilibrium exchange } \\
\text { rate }\end{array}$ \\
\hline Full pass-through & 5 & 5 \\
\hline Low pass-through & 8 & 3 \\
\hline
\end{tabular}

\section{However, medium-term trends are} not promising. Area productivity growth has been disappointing and thus improving corporate performance is rooted largely in cost containment, supported by wage moderation and outsourcing, and reduced corporate taxation (Figure 8). Moreover, population growth is decelerating sharply and is expected to turn negative around the turn of the decade. As a result, staff has marked down potential real GDP growth to a meager 1.8 percent.

\begin{tabular}{|c|c|c|c|c|c|c|c|}
\hline \multicolumn{8}{|c|}{$\begin{array}{l}\text { Summary Estimates of Productivity Growth } \\
\text { (In percent) }\end{array}$} \\
\hline & $\begin{array}{l}\text { United } \\
\text { States } \\
\end{array}$ & $\begin{array}{r}\text { Euro } \\
\text { area }\end{array}$ & EU-15 & EU-10 & Japan & China $1 /$ & India $1 /$ \\
\hline \multicolumn{8}{|c|}{ Labor Productivity Growth (GDP per hour, annual average, percent) } \\
\hline 1987-1995 & 1.1 & 2.4 & 2.3 & - & 2.8 & 4.7 & 4.3 \\
\hline $1996-2005$ & 2.4 & 1.2 & 1.4 & 4.4 & 2.0 & 5.6 & 3.9 \\
\hline \multicolumn{8}{|l|}{ of which: } \\
\hline $2000-2005$ & 2.6 & 1.0 & 1.0 & 4.7 & 1.9 & 8.7 & 4.1 \\
\hline 2003 & 3.2 & 0.3 & 0.7 & 4.3 & 1.4 & 6.4 & 6.4 \\
\hline 2004 & 3.0 & 1.1 & 1.4 & 4.1 & 3.2 & 8.4 & 4.4 \\
\hline 2005 & 1.8 & 0.3 & 0.5 & 6.2 & 1.9 & - & - \\
\hline \multicolumn{8}{|l|}{ Memorandum item: } \\
\hline \multicolumn{8}{|l|}{ Acceleration/deceleration } \\
\hline $1996-2005$ over $1987-1995$ & 1.2 & -1.2 & -0.9 & - & -0.8 & 0.9 & -0.5 \\
\hline
\end{tabular}

Euro Area: Potential Output Growth Estimates, 2005

\begin{tabular}{cc}
\hline WEO vintage & Estimate (in percent) \\
\hline 2001 & 2.6 \\
2002 & 2.4 \\
2003 & 2.1 \\
2004 & 2.1 \\
2005 & 1.8 \\
\hline
\end{tabular}

-

\footnotetext{
2 The exchange rate assessment is done based on two different approaches- the macroeconomic balance approach and equilibrium exchange rate approach. The macroeconomic balance approach consists of two steps: first, econometric estimation of the determinants of the equilibrium medium-term current account balance and estimates of the current account "norms"; and, second, determination of the exchange rate misalignment by comparing the current account norms with the current account balances that would emerge at prevailing exchange rates. The equilibrium exchange rate approach uses a reduced form model that relates the real effective exchange rate to a set of underlying fundamentals.
} 
Figure 6. Euro Area: Households and Consumption (in percent, unless otherwise specified)
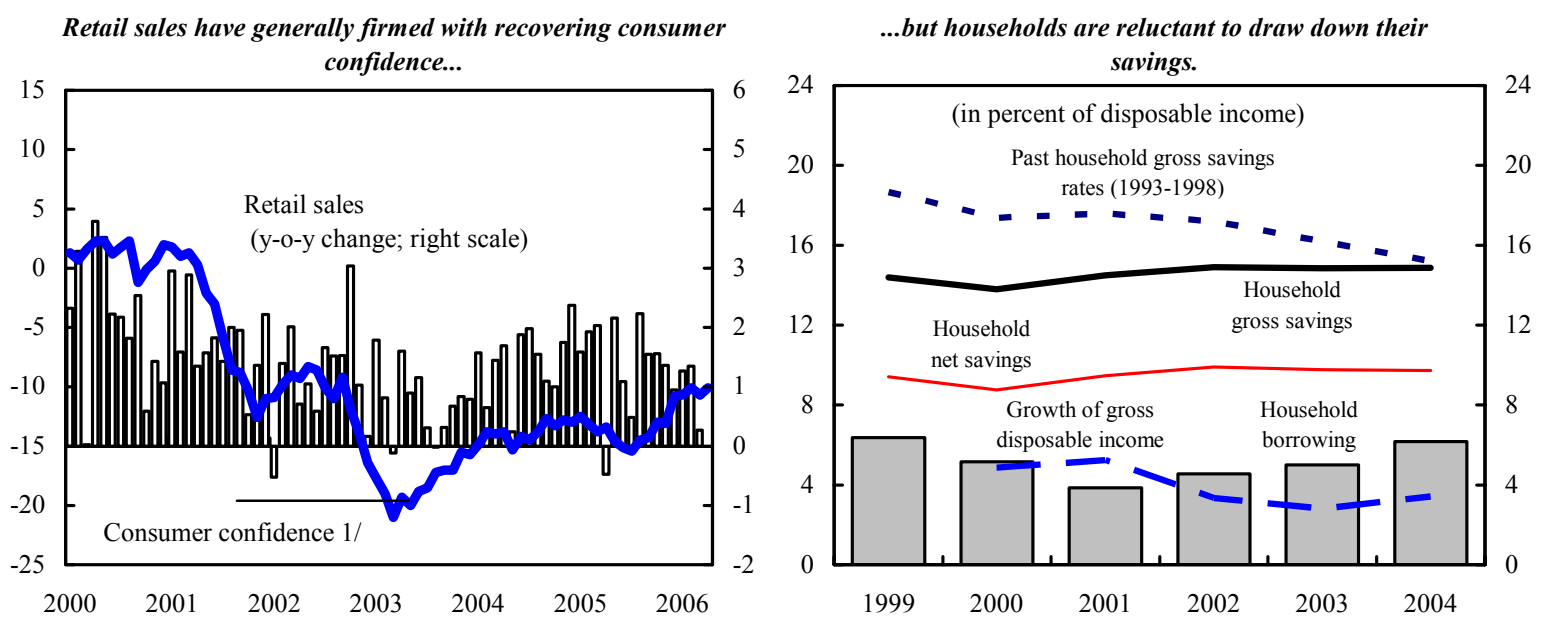

Low interest rates have dramatically increased housing affordability...
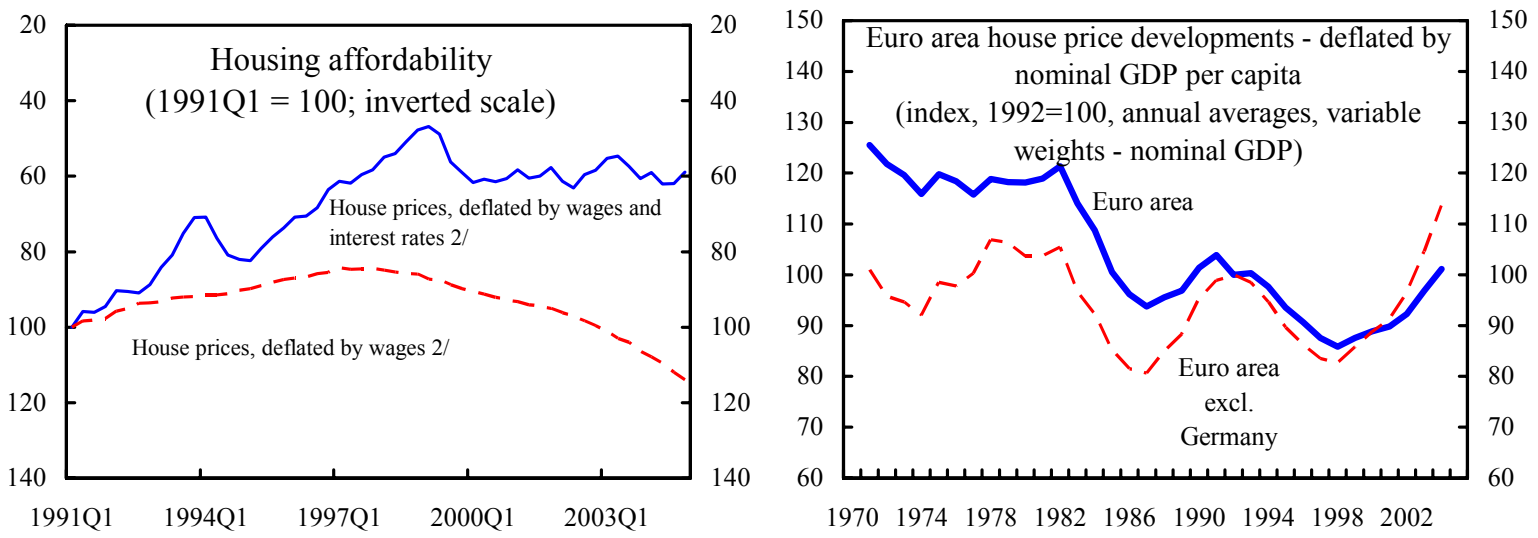

... and mortgage borrowing...

....although household indebtedness is relatively modest.

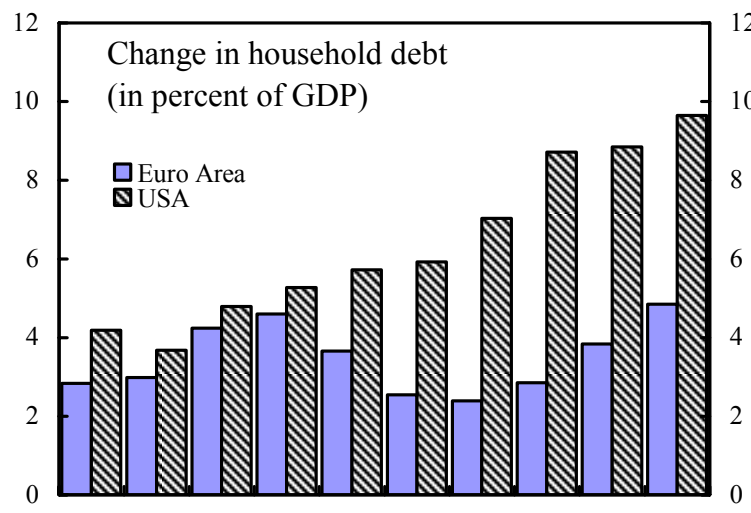

1996199719981999200020012002200320042005

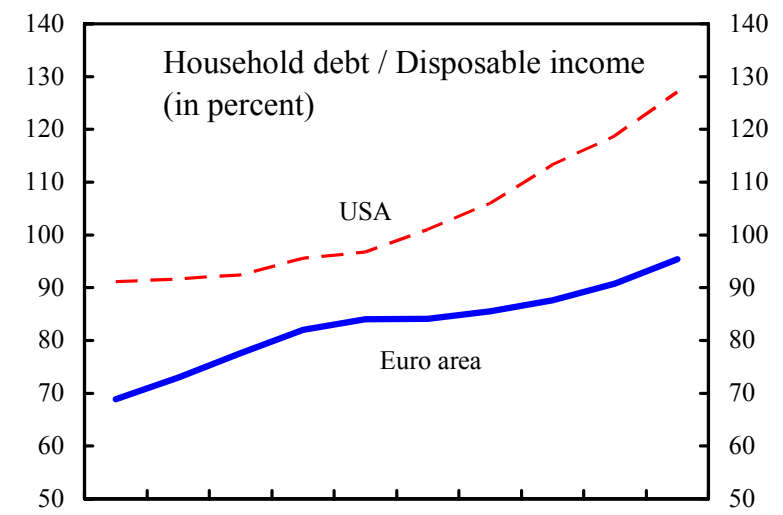

1996199719981999200020012002200320042005

Sources: OECD and Haver Analytics.

$1 /$ Balance of opinion on financial and general economic situation.

2/ Based on nominal compensation per employee and changes in the debt service of a 20 -year fixed-rate mortgage. 
Figure 7. Euro Area: External Developments (in billions of U.S. dollars; unless otherwise specified)
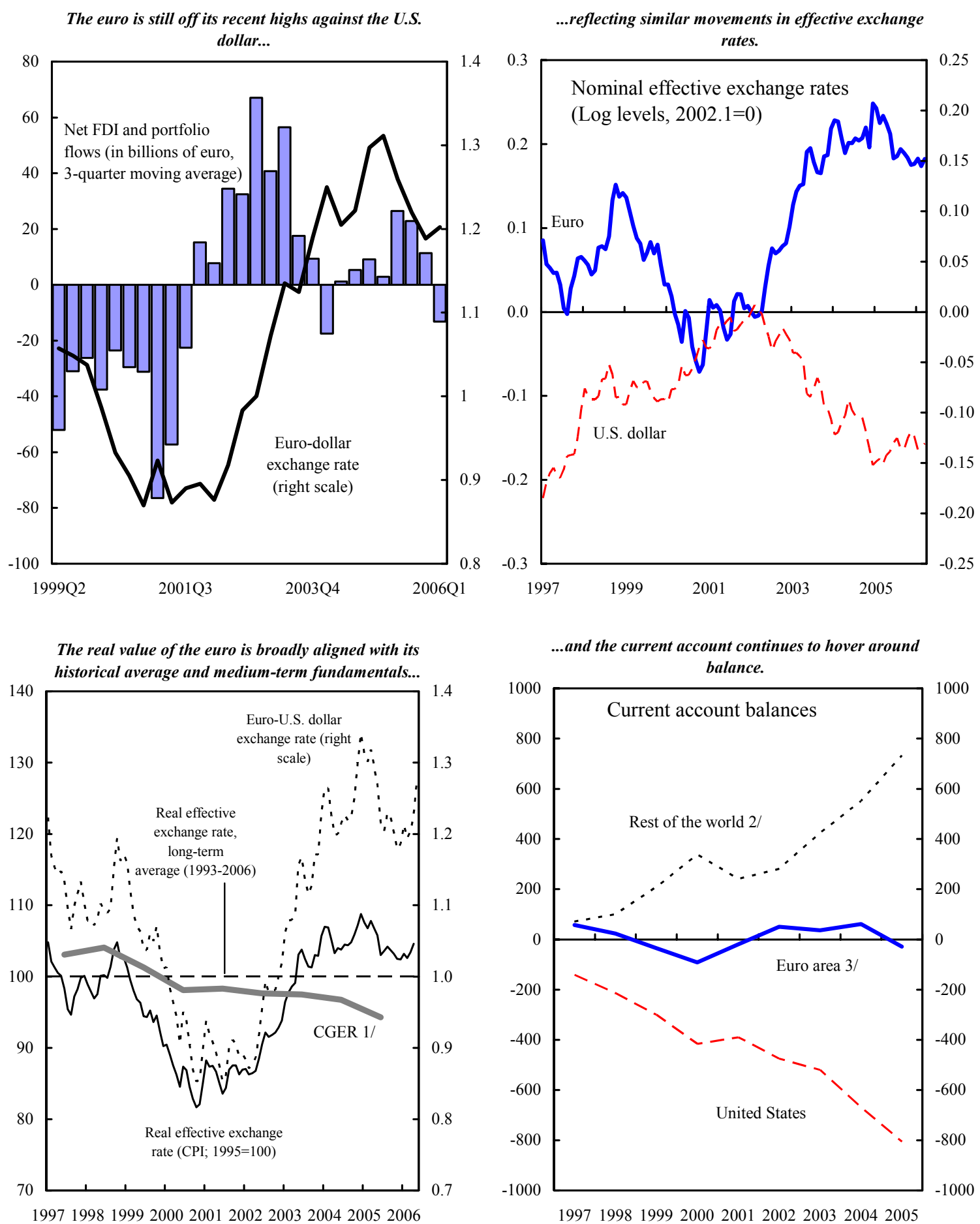

Sources: ECB; Haver Analytics; IMF, World Economic Outlook.

1/ Staff estimate of medium-term equilibrium real effective exchange rate (multilateral basis).

2/ Rest of the world calculated as residual (excludes global discrepancy).

3/ Excludes intra-area trade (ECB data). 
Figure 8. Euro Area: Employment and Wages, 1970-2006
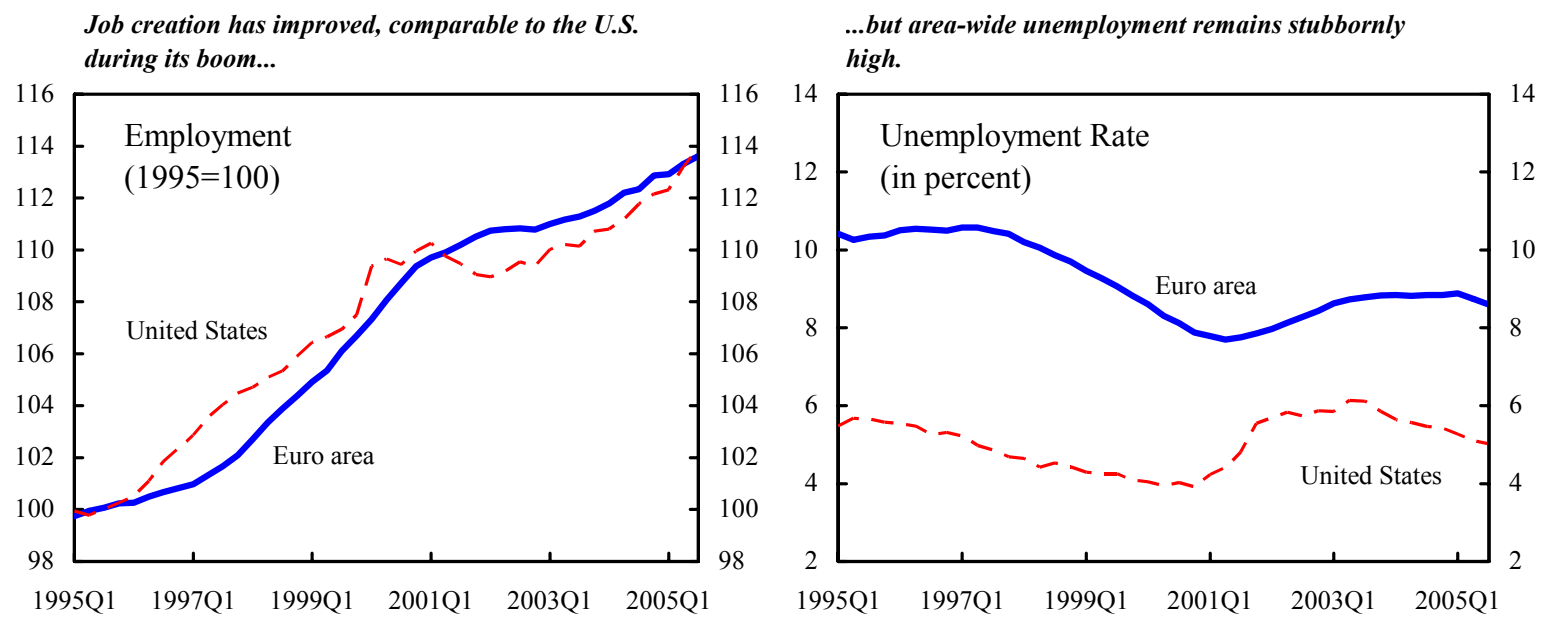

To maintain competitiveness, labor cost pressures have been contained...

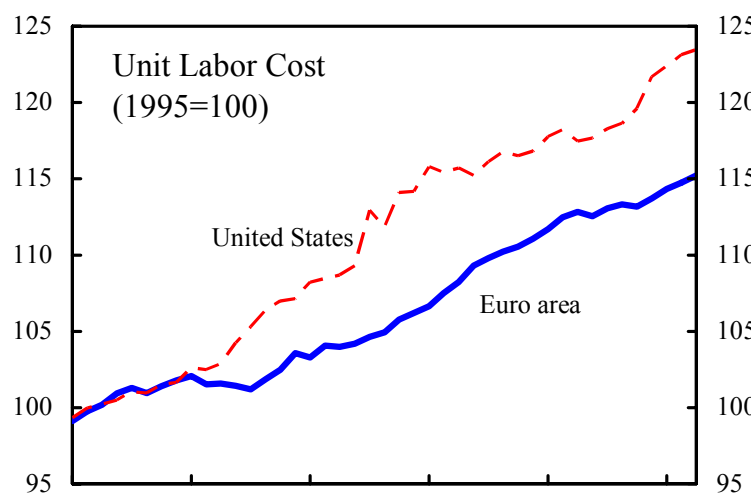

1995Q1 1996Q4 1998Q3 2000Q2 2002Q1 2003Q4 2005Q3

Thus, safeguarding cost competitiveness has been more redistributive...
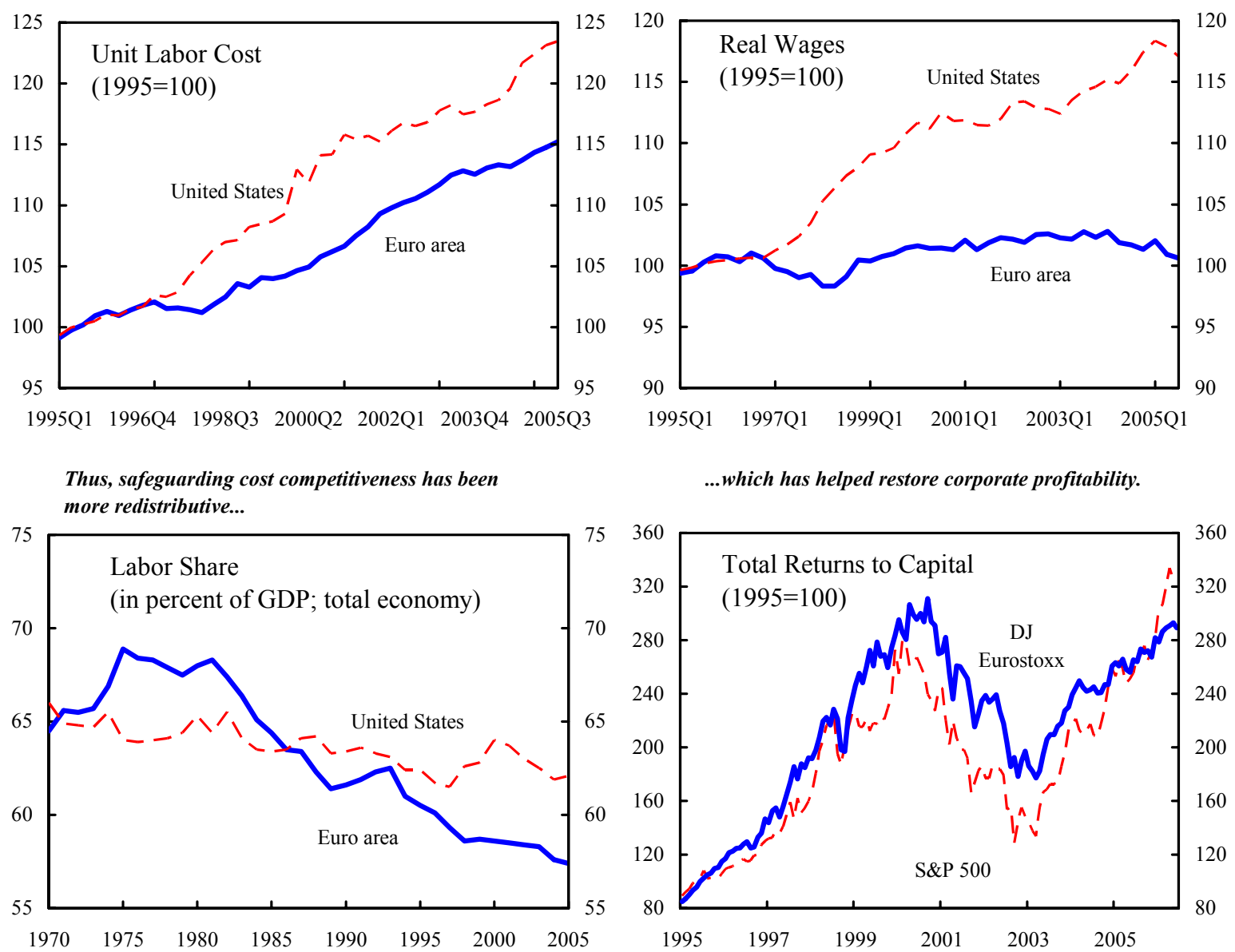

...which has helped restore corporate profitability.

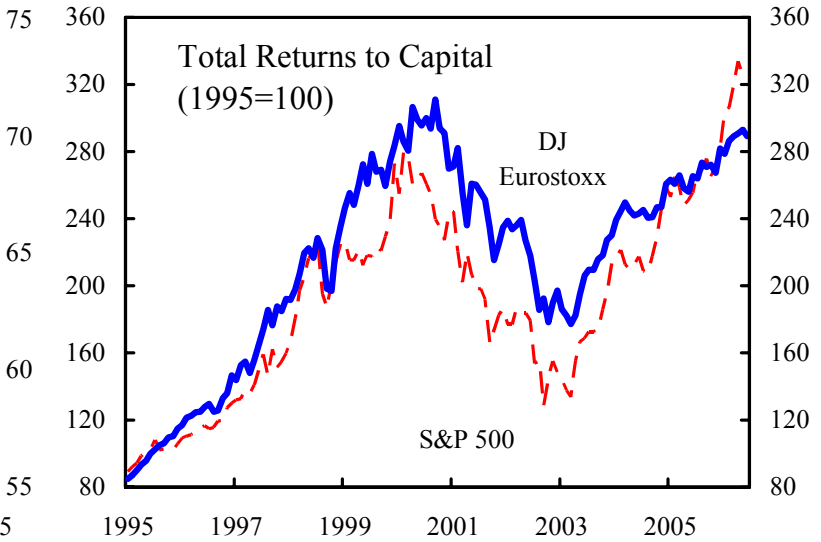

Sources: OECD; AMECO database; Datastream; IMF, World Economic Outlook; and IMF staff calculations.

1/ Labor cost data refer to hourly labor compensation. 


\section{REPORT ON THE DISCUSSIONS}

\section{With only modest prospects in sight even under favorable scenarios, the} discussions revolved around how to strengthen medium term growth, including from the perspective of alleviating external risks. In this regard, there was agreement that past reforms, while effective in strengthening employment, had disappointed in terms of growth because of the enduring weakness of productivity. To address that issue, and with the overriding importance of labor market reform well understood in official circles, product and services markets, as well as the interactions between macroeconomic adjustment and various structural reforms, featured more prominently than in the past (Box 1). Among services market reforms, the discussions centered on the financial sector, which appears to explain a significant part of Europe's productivity gap and where there is a need for the financial stability framework to keep up with growing cross-border activities.

\section{Box 1. Effectiveness and Role of Fund Surveillance}

\section{Past Fund advice.}

- Monetary policy: Over the past few consultations, Fund staff has argued that, given the outlook for price stability, monetary policy should remain accommodative until the recovery became more sustained. The ECB kept rates unchanged for $2 \frac{1}{2}$ years and then raised them from 2 to $23 / 4$ percent starting in December 2005 .

- $\quad$ Fiscal policy: Staff has been advising eliminating fiscal deficits through annual structural adjustments of at least $1 / 2$ percentage point of GDP. Staff welcomed the 2005 SGP reform but cautioned that it made transparent and evenhanded implementation of the Pact more challenging. Staff also advocated improvements in domestic fiscal governance institutions to support adjustment. Implementation of the revised Pact, thus far, has circumscribed discretion and led to some restoration of credibility.

- $\quad$ Structural policy: Staff has been arguing that the reformed Lisbon Strategy offers the right vehicle to increase national ownership of fiscal and structural policies, and thereby improve chances of successful delivery, but was concerned that absent some form of public benchmarking this policy framework would have no teeth. At the current, early stage, progress with National Reform Programs has been mixed.

- $\quad$ Financial sector issues: Staff has argued for further integration of regulation and supervision to ensure that Europe's financial stability framework keeps pace with cross-border business.

Effectiveness of Fund staff advice. In general, fiscal and structural reforms have proceeded but in a much less decisive manner than advocated by the staff. On specific advice: (i) staff's $1 / 2$ percent fiscal adjustment "benchmark" is a feature of the reformed SGP; (ii) staff's advice on domestic fiscal governance has been met with strong skepticism but is now on the agenda of the Finnish Presidency; (iii) benchmarking was not adopted in the reformed Lisbon Agenda, contrary to staff's views; and (iv) staff's advice on further integration of regulation and supervision was given a mixed reception but has now been cited in motivating new ECOFIN initiatives in this domain. 


\section{A. Prospects for Activity and Risks}

7. The general view was that the recovery had gained traction. But, staff thought that it remained fragile looking beyond this year and the Commission pointed to growing uncertainties over time. Pipeline effects from past oil price hikes are fading and external demand is widely forecast to remain robust over the foreseeable future, which should help propel activity. Moreover, the 2007 VAT hikes in
Latest Growth Projections (in percent)

\begin{tabular}{|c|c|c|c|c|c|c|}
\hline & \multicolumn{2}{|c|}{$\begin{array}{l}\text { EC Forecast } \\
\text { (May 2006) }\end{array}$} & \multicolumn{2}{|c|}{$\begin{array}{c}\text { Eurosystem Staff Projection } \\
\text { (June 2006) } \\
\end{array}$} & \multicolumn{2}{|c|}{$\begin{array}{l}\text { IMF WEO Projection } \\
\text { (June 2006) }\end{array}$} \\
\hline & 2006 & 2007 & 2006 & 2007 & 2006 & 2007 \\
\hline$\overline{\text { GDP }}$ & & & $1.8-2.4$ & $1.3-2.3$ & & \\
\hline Growth & 2.1 & 1.8 & 2.1 & 1.8 & 2.0 & 1.8 \\
\hline $\begin{array}{l}\text { Assumed oil } \\
\text { price increase 1/ }\end{array}$ & 27.4 & 3.0 & 29.1 & 5.1 & 24.6 & 4.9 \\
\hline $\begin{array}{l}\text { VAT effect on } \\
\text { GDP } 2 /\end{array}$ & $\ldots$ & $\ldots$ & $\ldots$ & $\ldots$ & 0.1 & -0.3 \\
\hline
\end{tabular}

1/ EC and Eurosystem forecasts are based on Brent crude oil prices; IMF forecasts are based on a simple average of spot prices of U.K. Brent, Dubai, and West Texas Intermediate crude oil.

2/ Based on staff calculations of the substitution effect using the Oxford Economic Forecasting model.

Germany should lead agents to advance purchases to 2006, albeit at the expense of 2007. However, underlying developments on the household side remain soft. Employment growth remains sluggish, partly because of the weakness of productivity that inhibits hiring, and real wages are stagnating. Without a more rapid expansion of payrolls, consumption will weigh on the recovery's dynamics. ${ }^{3}$ Staff thus foresees actual growth around 2 percent in 2006 , broadly in line with other projections. For 2007, staff and others forecast a strengthening of the underlying momentum (adjusting for the substitution effect of the VAT hike in Germany), with excess capacity being slowly eliminated in the outer years.

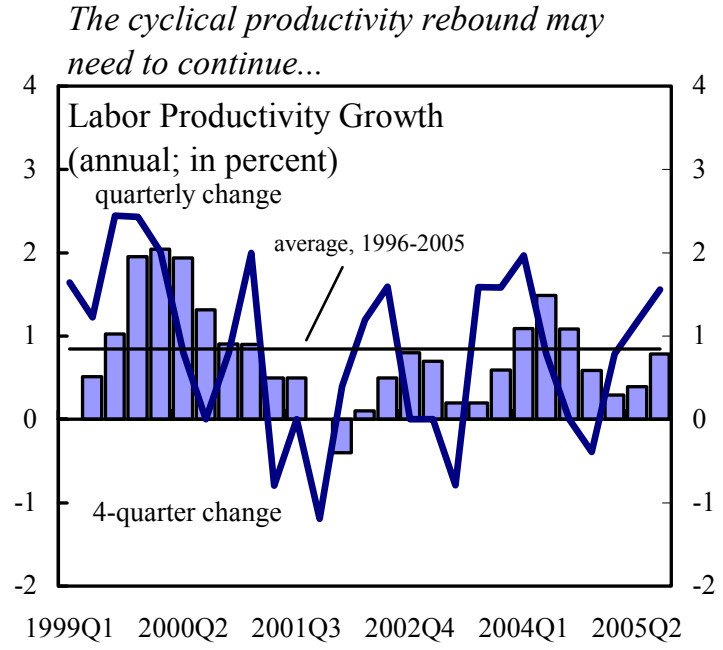

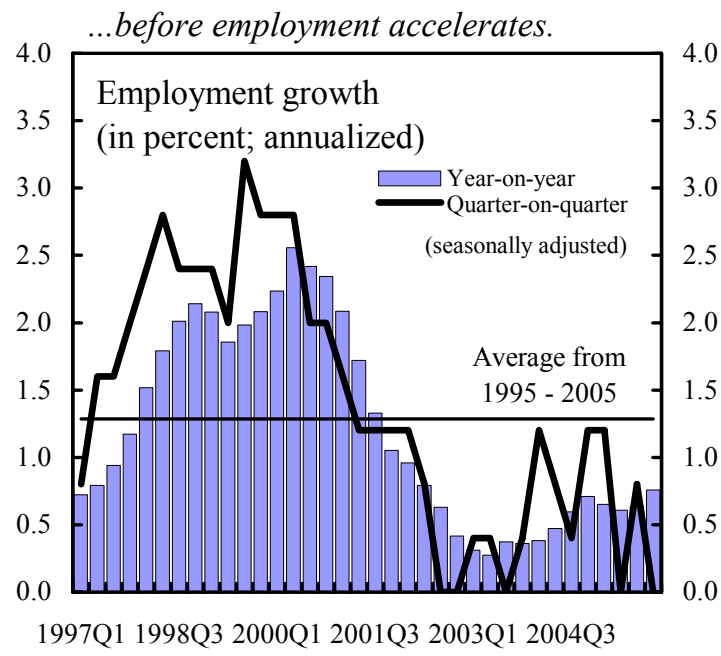

\footnotetext{
${ }^{3}$ Unemployment has edged down, but partly for statistical reasons.
} 
8. The balance of risks lies somewhat to the upside in the near term but to the downside beyond 2006. Amid cyclical and structural crosscurrents, notably strong world demand, a faster recovery this year cannot be ruled out: recent experience in the United States and Japan, for example, suggests that when the corporate sector turns from restructuring to expansion growth dynamics can improve sharply. Buoyant lead indicators - although downplayed by all interlocutors - are consistent with such a scenario and point to $2 \frac{1}{2}$ percent output growth for 2006:Q2 and Q3 (Figure 9). Furthermore, with

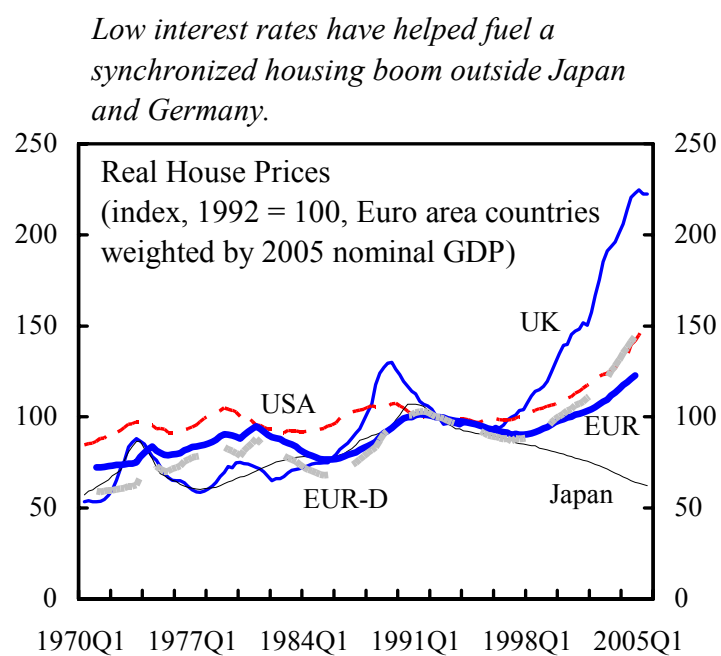
respect to domestic demand the Commission considered risks more balanced than the staff, specifically pointing to upside risks to household spending on account of pent-up consumer demand. However, moving into 2007, the risks were seen on the downside, mostly on account of the recovery's continued dependency on external demand, global imbalances and exchange rate risk, flight from risk in capital markets, volatile oil prices, and the avian flu. ${ }^{4}$ In addition, richly-valued housing stocks and high household debt in some regions pose hazards for consumption as interest rates continue to rise.

\section{B. Monetary Policy: What are the Risks to Price Stability?}

9. The ECB views the risks to price stability as skewed to the upside, and has begun to raise rates (Figures 10,11). After keeping interest rates unchanged for two and half years, the ECB raised its policy rate by 25 basis points in December, March and June, to 2.75 percent. The ECB's stance is motivated by several considerations:

- Headline inflation has been running above the ECB's close to but under 2 percent objective since 2000 and is projected to continue doing so through 2007 because of further tax (notably, VAT in Germany) and administrative price hikes as well as oil prices. While these shocks are acknowledged not to have given rise to significant indirect or second round effects so far, unions are seen to be keenly aware of the erosion of purchasing power so that the risks that such effects might materialize are mounting as the recovery broadens. Additionally, imported manufacturing goods prices are increasing as a result of the strength of the global upturn.

- $\quad$ The conditions for an ongoing economic expansion appear in place.

\footnotetext{
${ }^{4}$ Staff estimates suggest that a 10 percent hike in oil prices reduces real GDP growth by 0.2 percentage points and directly raises inflation by 0.1 percentage points.
} 
Figure 9. Euro Area: Leading Indicators
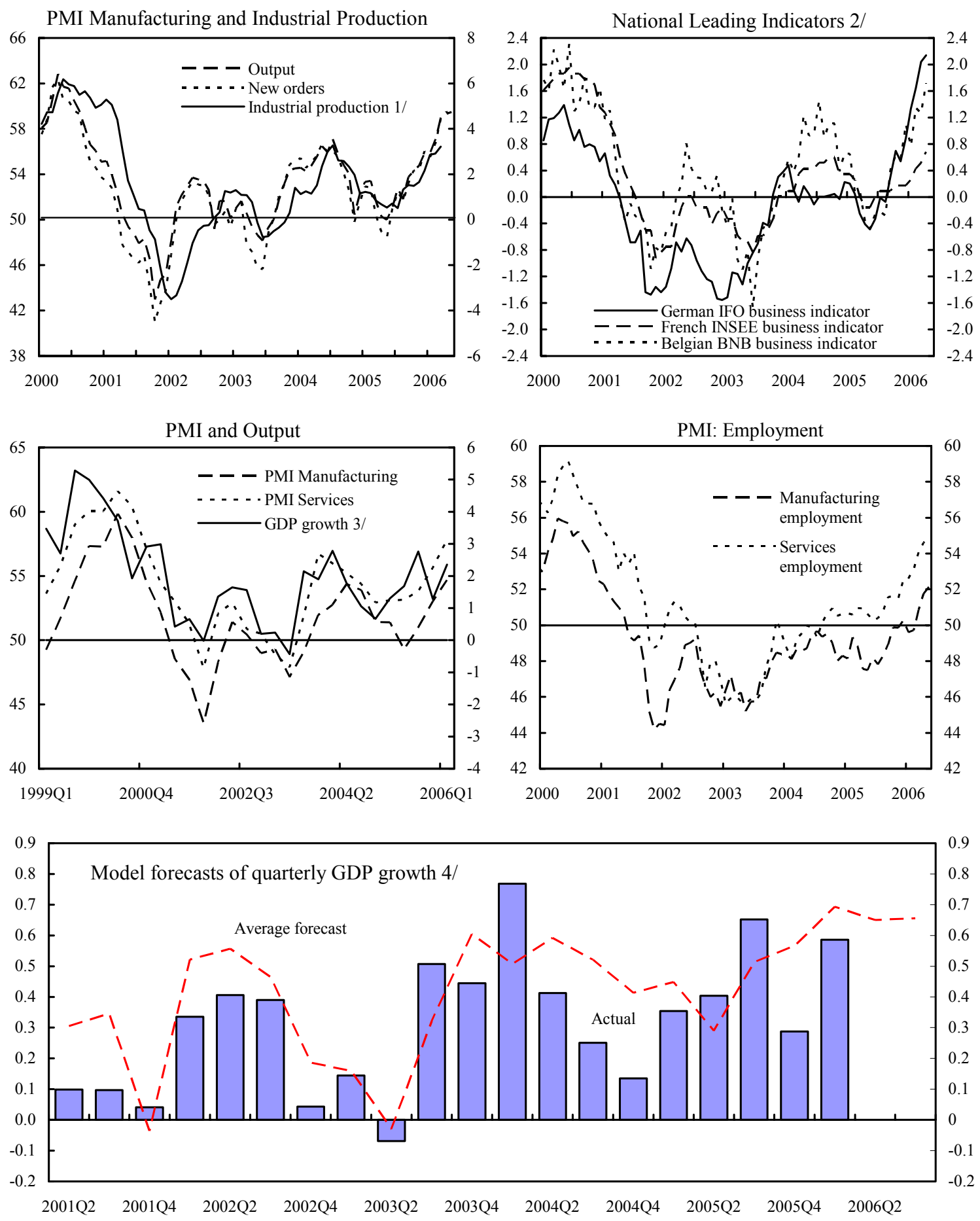

Sources: Eurostat, Reuters, IFO, INSEE, Banque Nationale de Belgique, and Fund staff calculations.

$1 /$ Year-on-year percent change, three-month moving average, right scale.

2/ Standardized over 1991-2004 period.

3/ Year-on-year growth, right scale.

4/ Quarter-on-quarter growth, right scale. 
Figure 10. Euro Area: Monetary Policy and Market Expectations, 2000-06 (in percent, unless otherwise specified)
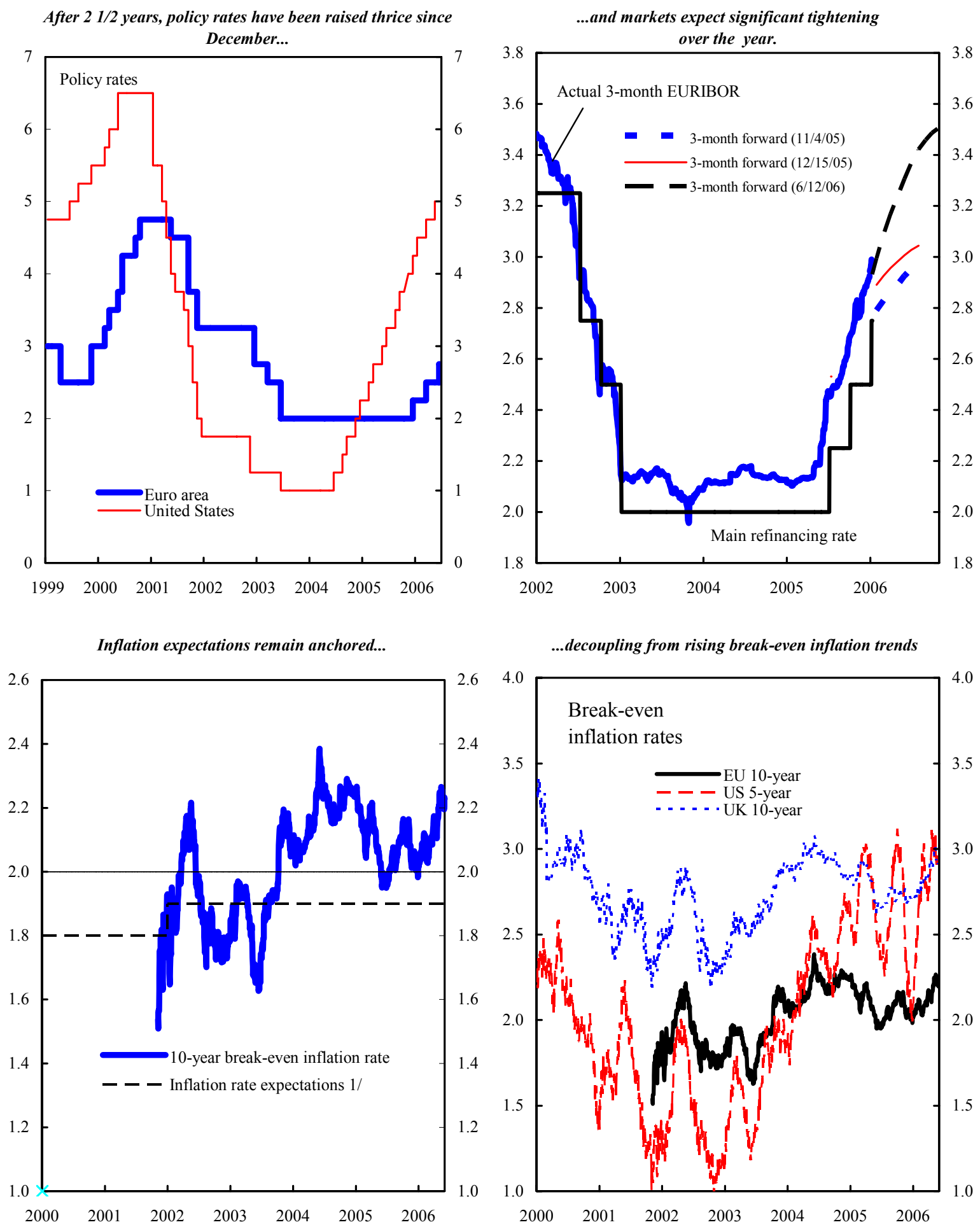

Sources: Datastream; ECB; Eurostat; and staff calculations and forecasts. 1/ Survey of Professional Forecasters. 
Figure 11. Euro Area: Money and Credit, 1980-2006 (in percent, unless otherwise specified)

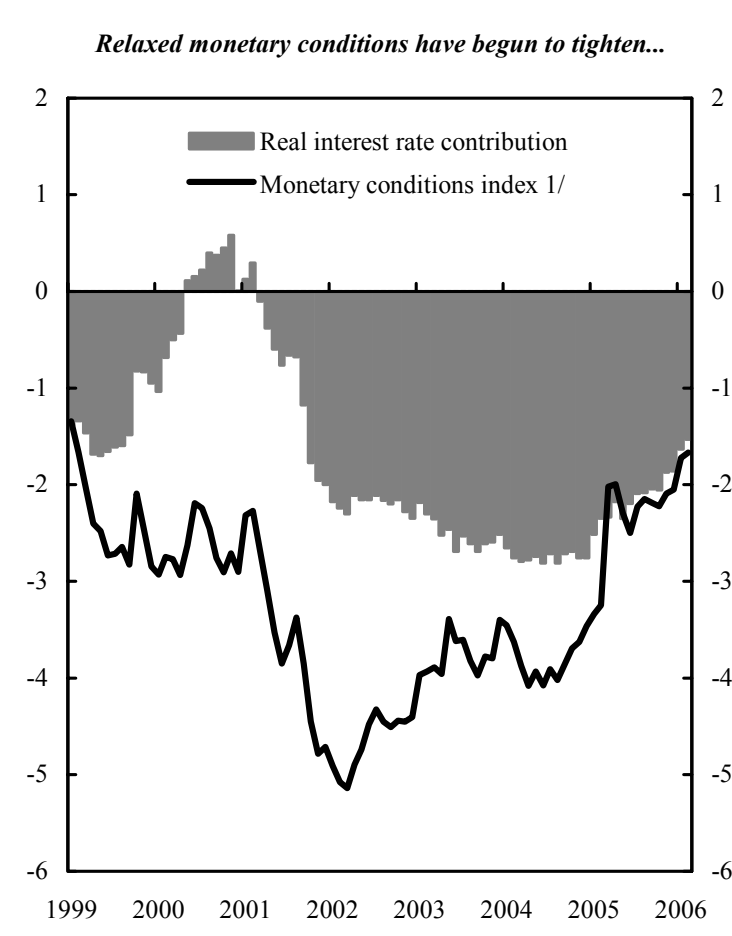

...but the ECB perceives a liquidity "overhang" as a key upside inflation risk as the recovery strengthens.

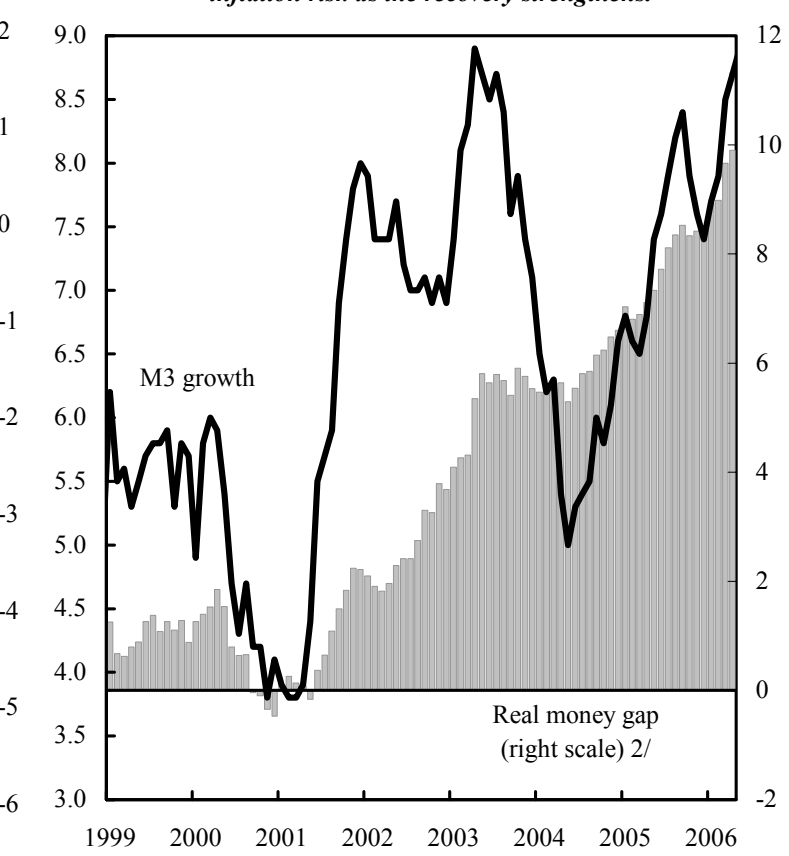

Variable declines in money velocity, however, leave inflation implications less clear.

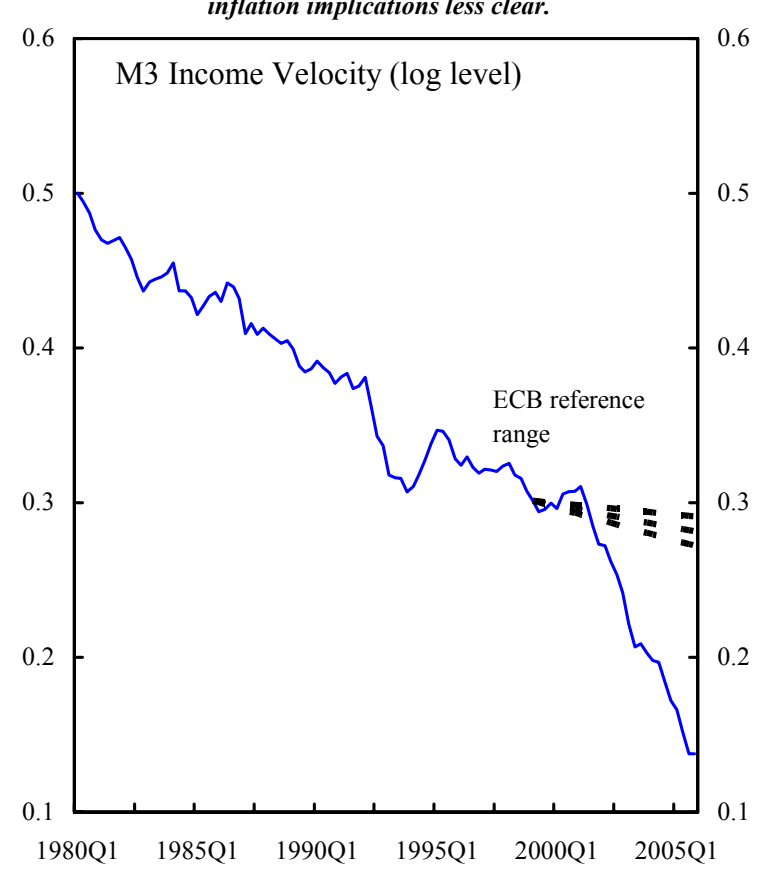

Credit growth has also been brisk, picking up across the board.

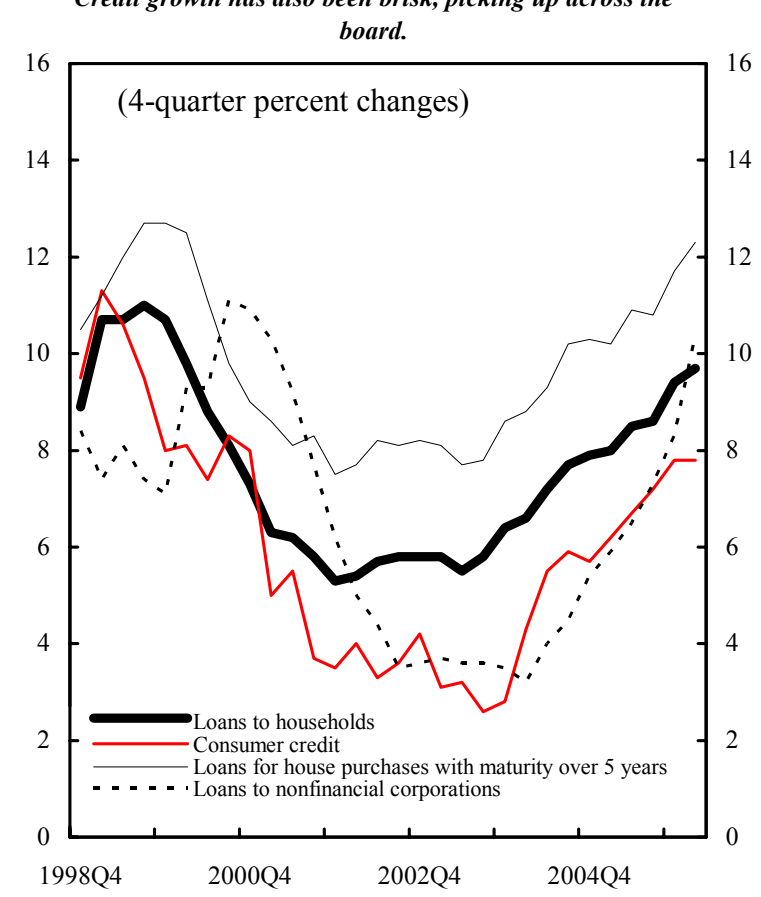

Sources: ECB; Datastream; Bloomberg; and staff calculations.

1/ Deviations from 1990-2004 mean.

2/ Deviation (in percent of the actual real stock of M3 from an estimate of the long-run real stock of M3, consistent with long-run inflation of 1.75 percent a year and assuming that the real money gap was zero in January 1999. 
- Monetary and credit dynamics are strong. Monetary aggregates are growing rapidly, even when adjusted for idiosyncratic changes, driven mainly by the expansion of the most liquid components. Private sector credit is expanding at double digit rates and becoming more broadly based across sectors, with borrowing both by households and non-financial corporations rising more strongly. These developments, together with strong asset (notably housing) price dynamics, were seen to confirm the stimulative impact of the historically low level of interest rates.

10. As the baseline scenario for prices and activity finds confirmation in the data, a progressive withdrawal of monetary accommodation would be warranted, according to the ECB. Officials explained that action Latest Inflation Projections (in percent)

was necessary to keep inflation expectations solidly anchored. Thus, while professional forecasters continue to expect inflation to average 1.9 percent over the medium run, officials noted that 47 percent of those regularly surveyed are now expecting headline inflation above 2 percent over the

\begin{tabular}{|c|c|c|c|c|c|c|c|}
\hline \multicolumn{8}{|c|}{$\begin{array}{l}\text { Latest Inflation Projections } \\
\text { (in percent) }\end{array}$} \\
\hline & \multicolumn{2}{|c|}{$\begin{array}{l}\text { EC Forecast } \\
\text { (May 2006) }\end{array}$} & \multicolumn{2}{|c|}{$\begin{array}{c}\text { Eurosystem Staff Projection } \\
\text { (June 2006) } \\
\end{array}$} & \multicolumn{3}{|c|}{$\begin{array}{l}\text { IMF WEO Projection } \\
\text { (June 2006) }\end{array}$} \\
\hline & 2006 & 2007 & 2006 & 2007 & 2006 & 2007 & 2008 \\
\hline HICP & & & $2.1-2.5$ & $1.6-2.8$ & & & \\
\hline Inflation & 2.2 & 2.2 & 2.3 & 2.2 & 2.2 & 2.2 & 1.9 \\
\hline $\begin{array}{l}\text { Assumed oil } \\
\text { price increase 1/ }\end{array}$ & 27.4 & 3.0 & $29.12 /$ & $5.12 /$ & 24.6 & 4.9 & -5.4 \\
\hline $\begin{array}{l}\text { Oil effects on } \\
\text { infl. } 3 /\end{array}$ & 0.3 & $\cdots$ & 0.3 & $\cdots$ & 0.3 & $\cdots$ & $\cdots$ \\
\hline $\begin{array}{l}\text { Admin. Price } \\
\text { effects }\end{array}$ & 0.4 & $\ldots$ & $0.4 \quad 4 /$ & $0.4 \quad 4 /$ & 0.4 & 0.4 & 0.1 \\
\hline $\begin{array}{l}\text { 1/ EC and Eurosy } \\
\text { simple average of } \\
\text { 2/ Calculated by } \\
\text { 3/ Direct effect, c } \\
\text { 4/ Fund staff estir }\end{array}$ & $\begin{array}{l}\text { staff } \\
\text { t pric } \\
\text { staff } \\
\text { lated }\end{array}$ & $\begin{array}{l}\text { casts ar } \\
\text { U.K. B } \\
\text { d on EC } \\
\text { and staf }\end{array}$ & $\begin{array}{l}\text { ased on Brent } \\
\text { projections. Dubai, and }\end{array}$ & $\begin{array}{l}\text { crude oil pri } \\
\text { West Texas }\end{array}$ & $\begin{array}{l}\text { IMF } \\
\text { rmedi }\end{array}$ & $\begin{array}{l}\text { asts a } \\
\text { ade o }\end{array}$ & ed on \\
\hline
\end{tabular}
medium run (up from about 40 percent one year ago). Surveys of Europe's purchasing managers also suggest rising price pressures.

11. Staff agreed with the ECB's baseline projection through 2007, but considered the risks to price stability over the medium run to be more balanced. An encompassing
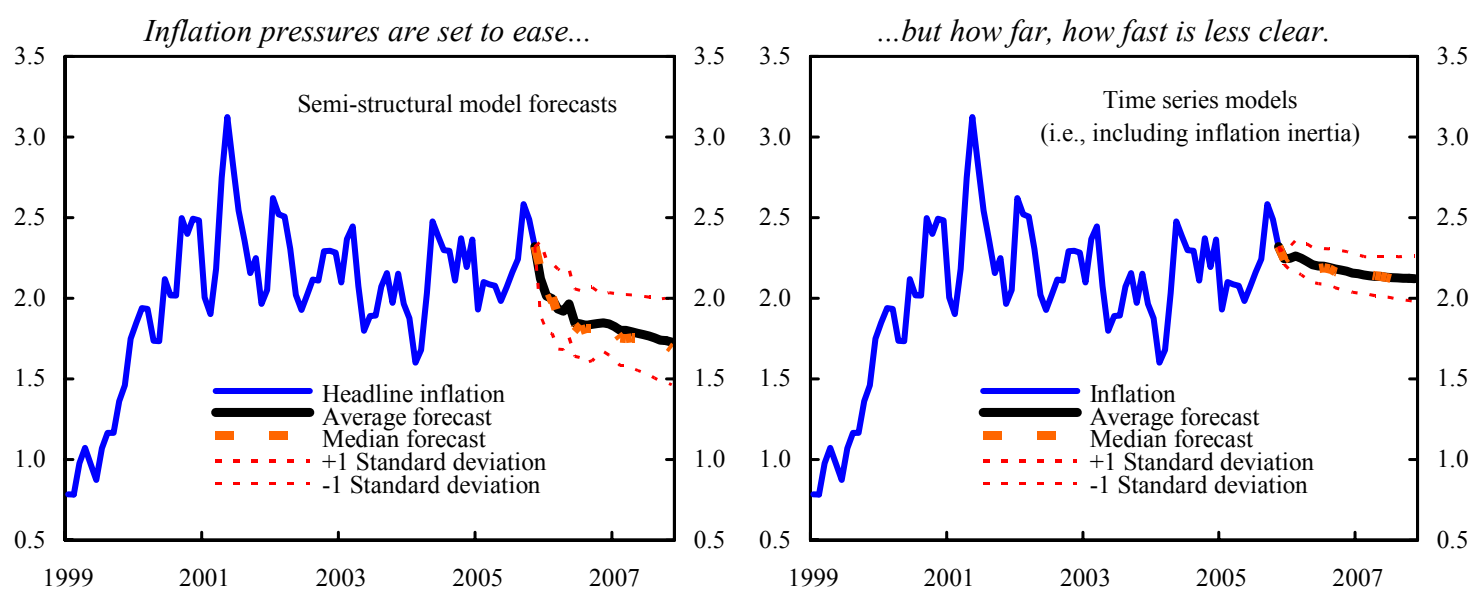

Source: IMF staff estimates. 
view - built around models that use various statistical measures of underlying inflation (e.g., core, median, trimmed mean, or cross-sectionally and dynamically-filtered inflation) as well as small structural models to forecast headline inflation - suggests that HICP inflation should moderate to just under 2 percent in 2008 and that the risks around this baseline are not significantly skewed to the upside (see charts). ${ }^{5}$ A simple but important indicator of low fundamental price pressures is subdued current and expected ULC growth, with the cyclical behavior of wages overwhelmed by trend restraint related to various structural changes. ${ }^{6}$ Moreover, in the context of continued slack, a weak labor market, and strong global competitive pressures, the growing downside risks for international and domestic activity over time also imply some downside risks for domestic prices.

12. Staff also questioned whether historical comparisons provided a good measure of current monetary policy accommodation and whether the link between $\mathrm{M} 3$ and prices was clear enough for operational purposes. While estimates of the neutral rate-in the past usually taken to have been around 4 to $4 \frac{1}{2}$ percent-are impossible to pin down, there is evidence for a downward trend, consistent with revisions to potential output growth estimates (Box 2). Also, the relation between M3 growth - which averaged $71 / 2$ percent in 2005 - and prices has been unstable of late, ${ }^{7}$ reflecting shifting money demand outside the "core" household sector.

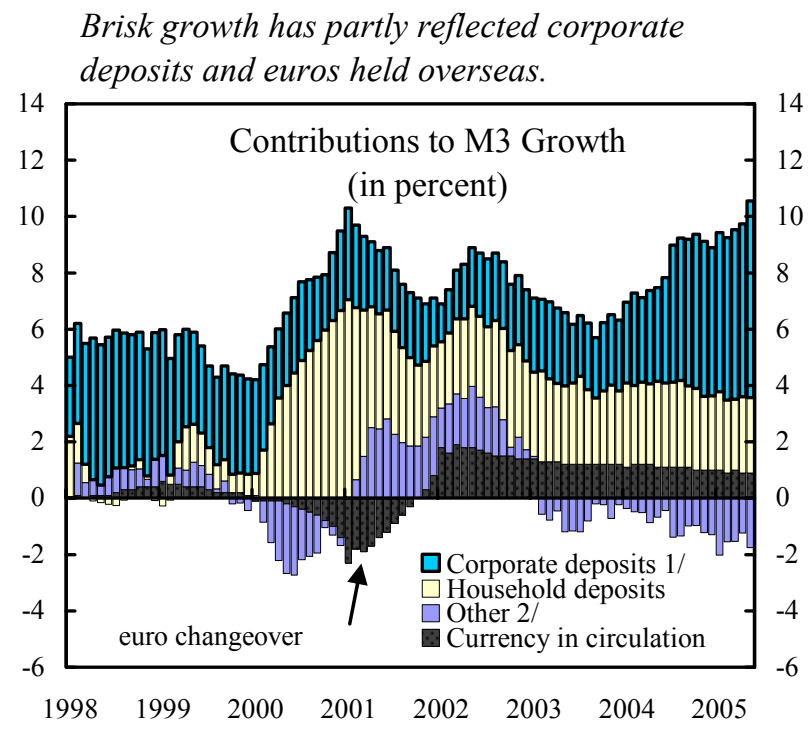

Source: Fund staff calculations, based on ECB data. $1 /$ Includes non-financial firms, insurance and other nonmonetary financial institutions.

2/ Other includes discrepancies.

\footnotetext{
${ }^{5}$ See Selected Issues paper "Measures of Underlying Inflation In The Euro Area: Assessment and Role for Informing Monetary Policy."

${ }^{6}$ Staff estimates suggest that 1 percent higher demand-driven output growth than projected would add 0.2 percent inflation contemporaneously.

${ }^{7}$ See IMF Country Report No. 05/266, Chapter II.
} 


\section{Box 2. Declining Neutral Interest Rates and ECB Monetary Policy}

Global interest rates, including those in the euro area, have shown a trend decline since the mid1980s. Explanations revolve around moderating inflation, lower macroeconomic volatility, enhanced central bank credibility, favorable economic shocks, and structural trends (technology, globalization); and potentially less benign sources such as a global "glut" of savings and loose global monetary policy as well as the legacy of the Asian financial crisis and the bursting of the ICT bubble.

Whether the decline in nominal rates also reflects a decline in nominal "neutral" rates depends on the underlying sources of the shifts. For example, declining long rates may reflect a declining term premium, which need not imply a decline in the neutral (short) rate. Simple term-structure models for the euro area, however, suggest a broadly stable term premium. However, declining long rates could partly reflect a falling euro-area growth potential. If so, then this implies lower neutral short rates in the euro area. Overall, lower macroeconomic volatility, relatively high global savings/low investment, and a falling euro-area growth potential suggest that euroarea neutral rates likely have been moving down.

Changing area neutral rates, although difficult
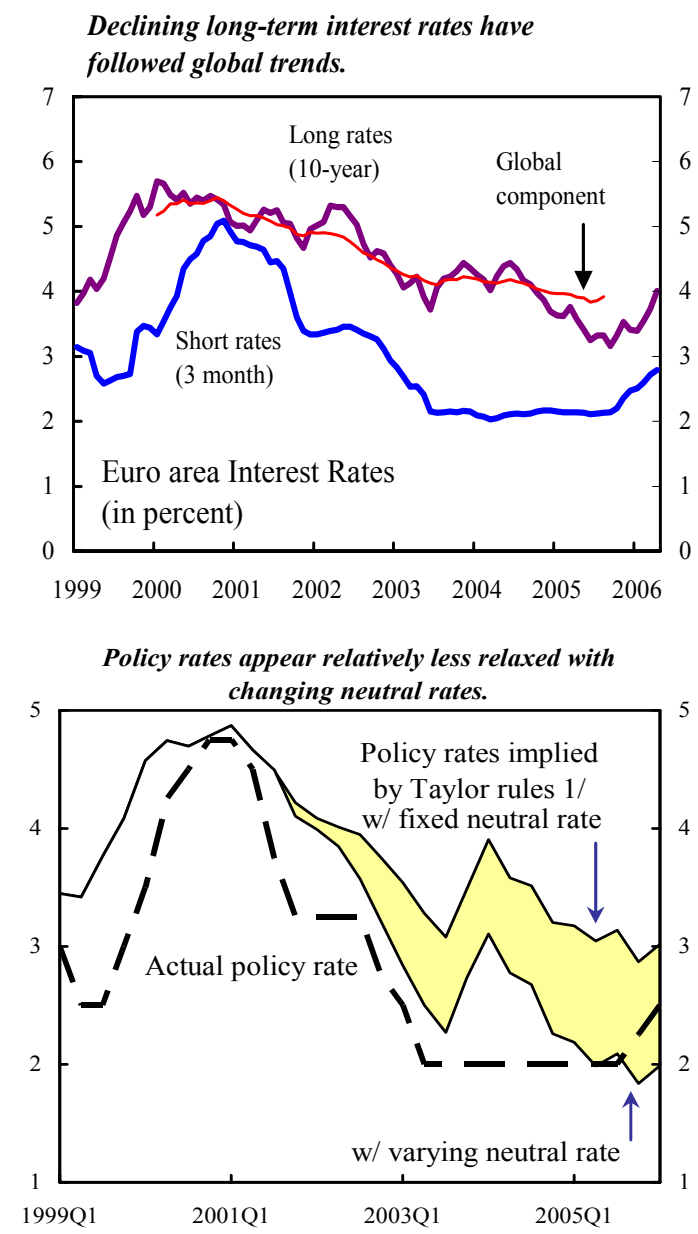

Sources: ECB; Eurostat; IMF; and staff calculations. 1/ Calculated using standard coefficients, core inflation, and fixed \& dynamic neutral rate estimates.

to pin down numerically, suggest increasing uncertainty about the extent of monetary accommodation as illustrated by a Taylor rule. The lower policy rate implied by the rule-i.e., based on a time-varying neutral rate-also suggests that the extent of policy accommodation has become less clear.

ECB staff agreed that lower area potential output growth may imply a lower neutral rate but thought that many other, international factors explained the global fall in interest rates and that their implications for the area's neutral rate were unclear. The ECB staff also stressed that the neutral rate is very difficult to estimate in real time. Moreover, they thought that the present level of rates was still below reasonable lower bound estimates for this rate. 


\section{Considering the risks to prices and the uncertain prospects for activity beyond the near term, staff argued that monetary policy needed to remain accommodative.} While the June hike - which staff considered warranted because inflation is expected to revert to its benchmark only slowly and the recovery is gaining traction-leaves rates in accommodative territory, continued tightening would, barring unexpected shocks to domestic inflationary pressures, require a further broadening of the recovery, notably better prospects for employment, of which there are as yet few concrete signs. Besides the unbalanced nature of the recovery and the downside risks beyond 2006, the evolution of neutral rates, the risks related to the exchange rate, and volatility in financial markets call for caution in normalizing rates.

\section{Structural Policy Issues and Challenges}

\section{Avenues to stronger growth}

\section{The overriding policy concern is} how to overcome the area's inability to simultaneously achieve solid employment and productivity growth (see chart). On the whole, employment growth has been remarkably strong over the past decade, broadly on a par with the United States. ${ }^{8}$ Nonetheless, unemployment remains high and labor participation rates low. Reducing unemployment and fostering labor force participation are the most direct avenues to boosting per capita incomes and easing the adjustment to aging. However, care must be taken that such policies do not trigger an offsetting slowdown in productivity, which has been the case since the mid-1990s. This slowdown is related partly to structurally moderating labor costs and reforms that have fostered the adoption of more labor-intensive production processes. Furthermore, reforms to labor markets have fostered employment of the less skilled. But there was agreement that these developments, together with cyclical factors and the regularization of "underground" employment in some area
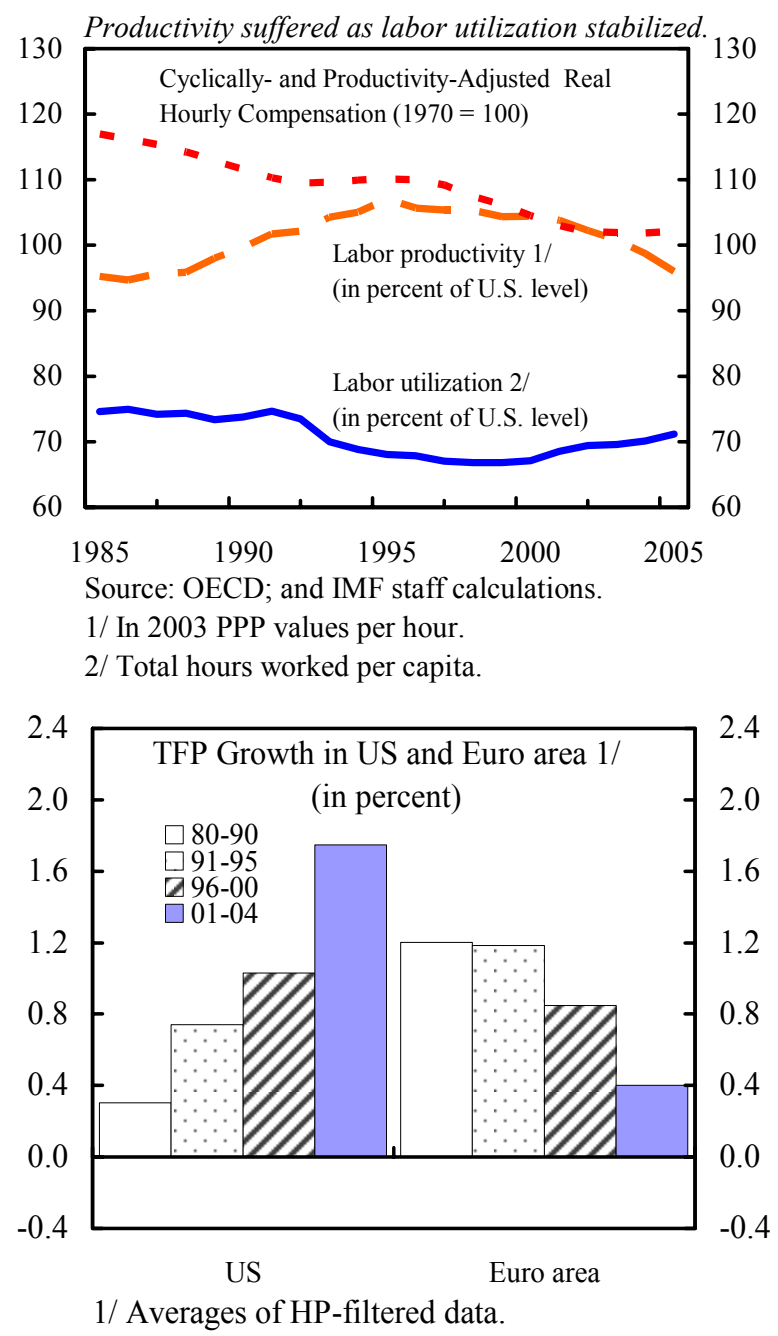

\footnotetext{
${ }^{8}$ Employment growth in the business sector amounted to15.2 percent in the euro area during 1995-2005, relative to 12.2 percent in the United States.
} 
countries, could only account for part of the deceleration in total factor productivity growth that underlies languishing labor productivity. ${ }^{9}$

\section{There was widespread agreement that the challenges posed by the productivity slowdown and imminent population decline required a strengthening and some reorientation of policy responses. Pinpointing the drivers of sluggish productivity is}

\begin{tabular}{|c|c|c|c|c|c|c|c|c|}
\hline \multicolumn{9}{|c|}{$\begin{array}{l}\text { Euro Area and US: Labor Productivity Growth per Person Employed } \\
\text { (Annual percentage changes) }\end{array}$} \\
\hline & \multicolumn{2}{|c|}{ Total economy } & \multicolumn{2}{|c|}{ Total services } & \multicolumn{2}{|c|}{ Wholesale and retail trade } & \multicolumn{2}{|c|}{ Hotels and restaurants } \\
\hline & Euro area & United States & Euro Area & United States & Euro area & United States & Euro area & United States \\
\hline $1981-1990^{1 /}$ & 1.8 & 1.3 & 0.9 & 0.6 & 1.5 & 1.9 & -1.6 & -0.3 \\
\hline $1991-2003^{2 /}$ & 1.3 & 1.5 & 0.7 & 1.6 & 1.1 & 3.9 & -1.9 & 0.5 \\
\hline \multirow[t]{3}{*}{$1996-2003^{3 /}$} & 1.0 & 1.8 & 0.6 & 2.3 & 0.7 & 5.5 & -1.6 & -0.8 \\
\hline & \multicolumn{2}{|c|}{$\begin{array}{l}\text { Transport and storage, } \\
\text { and communication }\end{array}$} & \multicolumn{2}{|c|}{$\begin{array}{c}\text { Financial } \\
\text { Intermediation }\end{array}$} & \multicolumn{2}{|c|}{$\begin{array}{l}\text { Real estate, renting } \\
\text { and business activities }\end{array}$} & \multicolumn{2}{|c|}{$\begin{array}{l}\text { Community, social } \\
\text { and personal services }\end{array}$} \\
\hline & Euro area & United States $^{4 /}$ & Euro area & United States ${ }^{4 /}$ & Euro area & United States $^{4 /}$ & Euro area & United States \\
\hline $1981-1990^{1 /}$ & 2.8 & 1.7 & 1.8 & -1.1 & -0.8 & -1.7 & -0.2 & 0.1 \\
\hline $1991-2003^{2 /}$ & 3.9 & 2.7 & 1.6 & 3.7 & -1.4 & -0.3 & n.a & -0.4 \\
\hline $1996-2003^{3 /}$ & 4.3 & 2.5 & 2.5 & 5.2 & -2.1 & -0.1 & 0.0 & 0.0 \\
\hline
\end{tabular}

Sources: OECD STAN, Groningen Growth and Development Centre Database, NCBs and ECB calculations.

$1 /$ The euro area aggregate does not include Greece.

2/ The euro are aggregate does not include Greece. Ireland is included up to 2002.

3/ Ireland is included only up to 2002 .

4/ Data for all sectors for the United States are up to 2001.

difficult but they likely feature high job turnover costs and insufficient competition in product and services markets. The underlying rigidities impede a reallocation of resources in response to changes in preferences and technologies as well as globalization. In this regard, ECB research suggests that some sectors that have been extensively deregulated recently have featured rather strong productivity growth, notably telecommunications and transport. Other sectors, for example, the wholesale and retail sectors as well as the financial sector, have lagged. More generally, there is increasing evidence for the crucial role of competition in fostering productivity-enhancing restructuring, including better management practices. ${ }^{10}$ Rigidities in labor and services markets also explain noticeable intra-area imbalances (Box 3).

\footnotetext{
${ }^{9}$ Commission studies suggest that the share of the intermediate and high-intermediate skilled in employment has risen in all euro-area countries bar Spain since the early 1990s.

${ }^{10}$ See Bloom, N. and J. V. Reenen, 2006, "Measuring and Explaining Management Practices Across Firms and Countries."
} 


\section{Box 3. Euro Area Divergences}

Intra-area imbalances have raised considerable concerns. Current growth differences in the euro area are not large by historical standards and partly reflect income convergence (see Box 3, IMF Country Report No. 05/265). However, they appear to feature a falling cyclical component, a result of closer integration and monetary union, and a growing trend component, in part related to demographics but also due to different degrees of structural reforms and productivity growth. Relatedly, crosscountry inflation differentials, while not sizable, appear highly persistent over the past several years. The persistence of inflation differentials has contributed to divergences in competitiveness and current account balances, which might take a painfully long time to unwind.
Euro Area: Persistence of Growth and Inflation Imbalances 1/

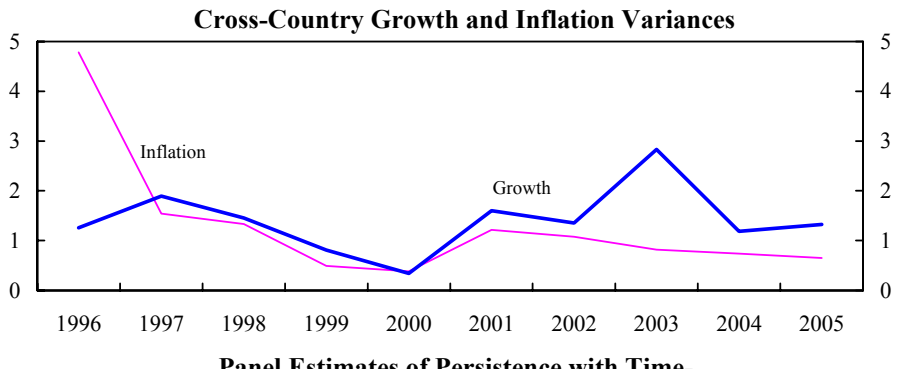

varying Slope $2 /$

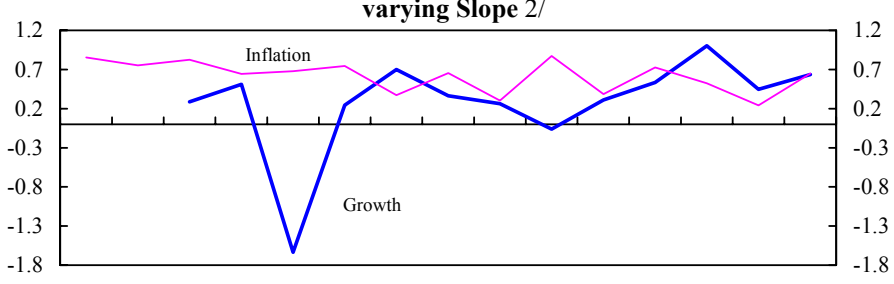

199119921993199419951996199719981999200020012002200320042005 Contribution of Cyclical and Trend Components to Cross-Country Growth Variability

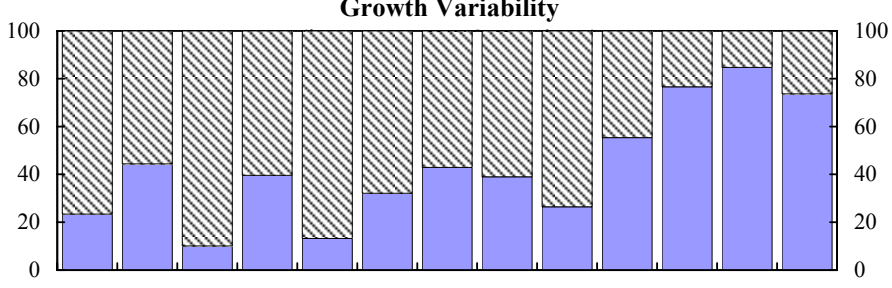

$199319941995 \quad 1996199719981999200020012002 \quad 2003 \quad 20042005$ $\square$ Variance explained by trend $\$$ Variance explained by cyclical

Sources: Eurostat; and Fund staff estimates.

1/ Excluding Ireland and Luxemboure.

2/ Estimated equation: $\quad x_{t, j}-\bar{x}_{t}=\alpha_{i}+\beta_{t}\left(x_{t-1, i}-\bar{x}_{t-1}\right)+\varepsilon_{t, i}$, where

$x_{t, i}$-growth/inflation of each member state; $\bar{x}_{t}$-euro area growth/inflation; $\beta_{t}$-persistence parameter.

There was agreement on several policy implications, notably the need for: (i) more flexible wage setting and accelerated deregulation of the services sector; and (ii) fiscal policy in booming economies to be tightened more than standard measures of structural balances suggest, given the high correlation between asset prices and government revenues. Furthermore, Fund staff noted that there was a need to coordinate prudential action if it was to effectively address potential financial system stability issues in countries with high domestic credit growth. The

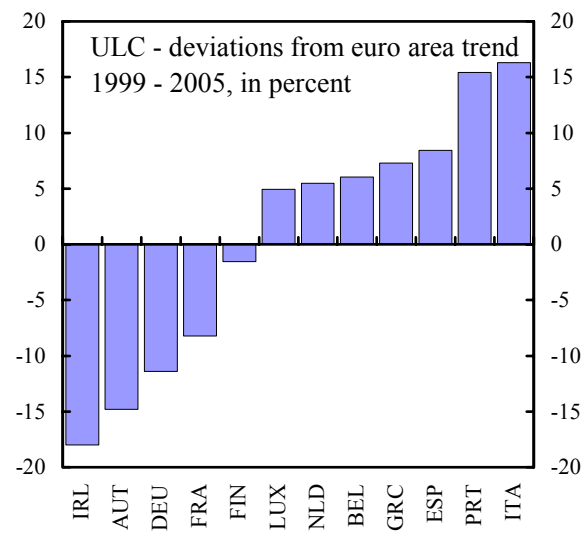
staff's interlocutors, however, questioned the benefits of such measures and observed that there was little appetite for enhanced coordination under present circumstances. 
16. A staff analysis of the experience of Europe's more successful long-term reformers suggests that more decisive progress is less a matter of social choices than of sticking to a forward-looking strategy, pursuing functionally and intertemporally consistent fiscal and structural policies. ${ }^{11}$ Fiscal adjustment in these countries has centered mainly on welfare reform and the government wage bill, using the ensuing labor supply and related revenue improvements to cut taxes and maintain the reform momentum. These steps were complemented by actions that enhanced both factor and product (goods and services) market flexibility and thereby enabled a stronger response of job creation to wage moderation while nonetheless maintaining productivity growth, with beneficial effects for household incomes. ${ }^{12}$ Importantly, reforms along these lines also proved to be compatible with broadly stable income distributions in several of the cases. By this standard, staff thought that recent fiscal and structural area-wide policy initiatives - the reformed Pact and the new National Reform Programs - offered some promise, but that bolder steps would be needed on both fronts if decisive progress was to be expected.

\section{Fiscal requirements: The SGP and the need to adjust during the upswing}

17. Outcomes were better than expected in 2005. At the time of the 2005 Article IV report, Fund staff had not expected any significant adjustment for 2005. In the event, the cyclically-adjusted fiscal balance for the euro area improved by close to $1 / 2$ percent of GDP, broadly in line with the staff's recommendation. However, the area's deficit remains large, mainly on account of imbalances in the countries that are in the Excessive Deficit Procedure (EDP) under the Stability and Growth Pact (SGP), namely France, Germany, Greece, Italy, and Portugal.

\section{The SGP is regaining some leverage over national fiscal policies. The}

implementation of the EDP is improving: a large country, Germany, has been moved to one step short of sanctions (Article 104.9) for failing to reduce its deficit below 3 percent of GDP in a timely manner; and countries are taking significant steps to abide by their SGP commitments. Moreover, in specifying their medium-term objectives (MTO), countries have

2006 Stability Program Structural Balances and MTOs (in percent of GDP)

\begin{tabular}{|c|c|c|c|c|c|c|c|c|c|c|c|c|}
\hline \multicolumn{2}{|c|}{ Euro Area } & Aus & Bel & Fin & Fra & Ger & Gre & Ire & Ita & Net & Por & Spa \\
\hline 2005 & -1.8 & -1.6 & 0.6 & 2.9 & -2.0 & -2.6 & -5.4 & 0.2 & -3.2 & -0.2 & -5.1 & 1.1 \\
\hline 2006 & -1.7 & -1.7 & 0.2 & 2.6 & -1.6 & -2.8 & -3.4 & -0.6 & -3.1 & -0.1 & -3.6 & 0.9 \\
\hline MTO & 0.1 & 0.0 & 0.5 & 1.5 & 0.0 & 0.0 & 0.0 & 0.0 & 0.0 & $\begin{array}{c}-0.5 \text { to } \cdot \\
1.0\end{array}$ & 5 & 0.0 \\
\hline
\end{tabular}

\footnotetext{
${ }^{11}$ See Selected Issues paper "Case Studies and Beyond: Lessons from Successful Labor Market Reformers in Europe and Implications for its Social Model."

${ }^{12}$ For example, staff research suggests that the pass-through of wage moderation into jobs and output in the euro area over the past two decades was about half of that in the four non-area OECD economies with the least regulated markets (see Estevão, M., 2005, "Product Market Regulation and the Benefits of Wage Moderation," IMF WP/05/191).
} 
given heavy weight to reducing public debt. The 2006-08 fiscal targets in countries' Stability Programs generally feature an average annual structural adjustment of at least $1 / 2$ percent of GDP for those countries that have not reached their MTO, which is in line with past staff advice. In particular, countries have not proposed to trade off adjustment with structural reform. And the Stability Programs now feature more prudent macroeconomic assumptions and a diminishing reliance on one-off measures. Overall, there was agreement that the functioning of Europe's fiscal framework had improved although key tests - achieving adjustment during this recovery - and new challenges to the EDP (notably Italy's difficulties in correcting its fiscal deficit) lay ahead.

\section{The impending demographic shock is the main driver behind medium-term}

fiscal requirements. In this regard, Commission officials pointed to the projections of the Aging Working Group (AWG), which feature a "no-policy change scenario" showing that aging-related spending would rise by about $3 \frac{3}{4}$ percent of GDP through 2050 . The AWG project is a major improvement over a similar project undertaken in 2001, notably adding transparency, consistency, and comparability to national projections. Staff welcomed the report as a significant step forward in forging a consensus on the seriousness of the demographic challenge. It argued, however, that some of the AWG's alternative scenarioswhich suggest that the expenditure increase could be considerably larger-appeared more plausible than the baseline "no policy change scenario" (Box 4). Commission officials agreed that the projections were subject to considerable risks and these would be taken into account in the forthcoming assessment of countries' fiscal vulnerabilities.

\section{Given these projections, the key fiscal} policy requirement is for countries to achieve structurally balanced budgets by 2010 - a task made all the more challenging by the better times seemingly ahead. Past experience is not reassuring: the 1998-2001 budgets - cast during the upswing phase-led to a structural deterioration in fiscal balances of about $1 \frac{1}{2}$ percentage points of GDP. Also disquieting is the structural weakening that is planned by nonEDP countries for 2006 (chart). While countries' proposed medium-term adjustment paths are broadly in line with the staff's recommendations, the measures to implement them remain

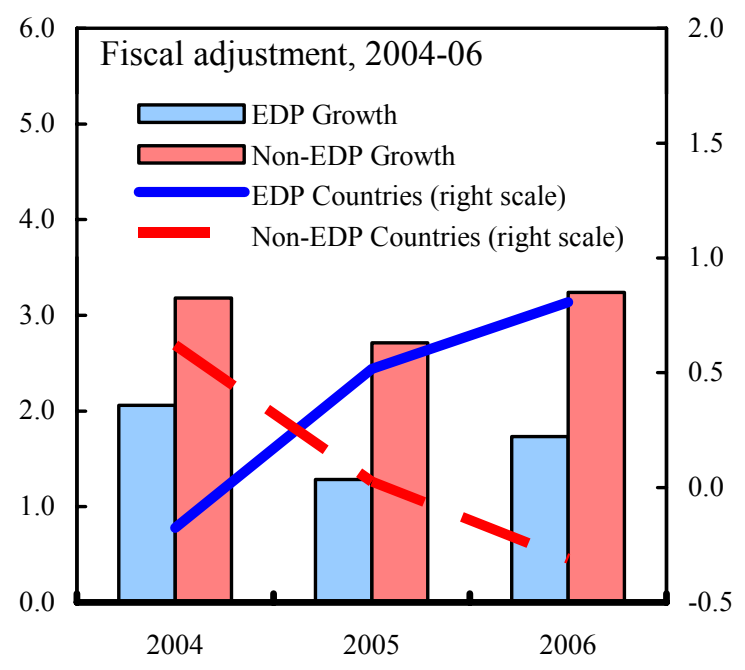
unspecified. Staff and the Commission thus project a structural balance for the area that moves broadly sideways (Figure 12). Furthermore, absent significant reductions in cyclically-adjusted deficits the EDP in some countries risks becoming open-ended and damaging the Pact - a view stressed by ECB officials. Thus, while the national authorities' commitments point to adjustment over the next few years, prospects remain uncertain. 


\section{Box 4. The Updated Demographic Perspective}

The EU's population will begin to fall around 2010. According to the "no policy change" scenario in a report by the EU Economic Policy Committee's Working Group on Ageing Populations (AWG), this would add about $3 \frac{3}{4}$ percent ( $4 \frac{1}{2}$ percent) of GDP on a net (gross) basis to public spending. Under plausible alternative AWG scenarios, however, the net increase might well be 6 percentage points of GDP.

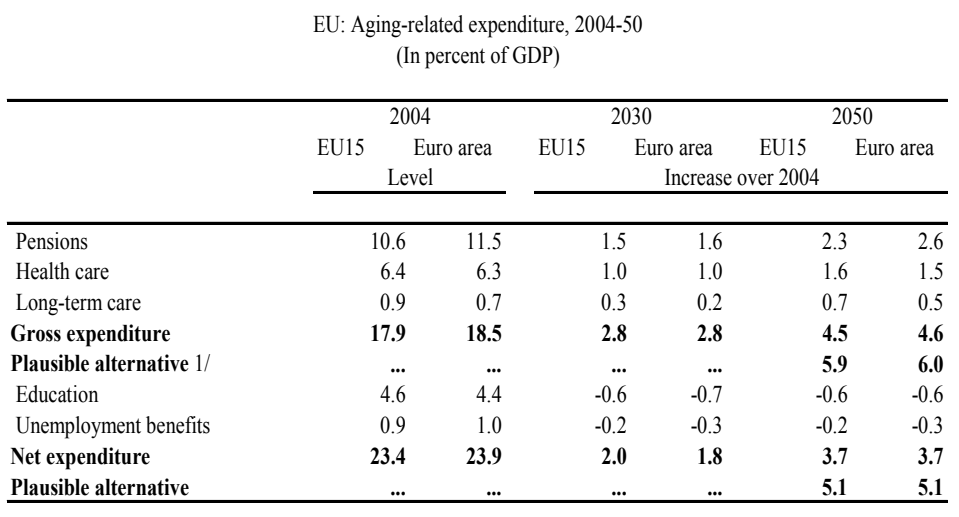

Source: AWG Report, European Policy Committee.

1/ Assumes that healthcare costs rise in line with wages rather than per-capita GDP; and that the probability of receiving formal long-term care rises gradually.

First, the "no change" projections assume a significant acceleration in TFP growth and a large sustained increase in employment, something which Europe has not mustered since the 1970s.

Second, some budgetary assumptions are particularly critical, according to the findings. For example, allowing health care costs to rise with wages (rather than prices) and assuming a slowly growing proportion of formal long-term care would add a further $1 \frac{1}{2}$ percent of GDP to spending, according to alternative scenarios in the AWG report. Furthermore, savings on education and labor market policies might not materialize, if the experience of countries with high labor utilization in Europe is relevant.

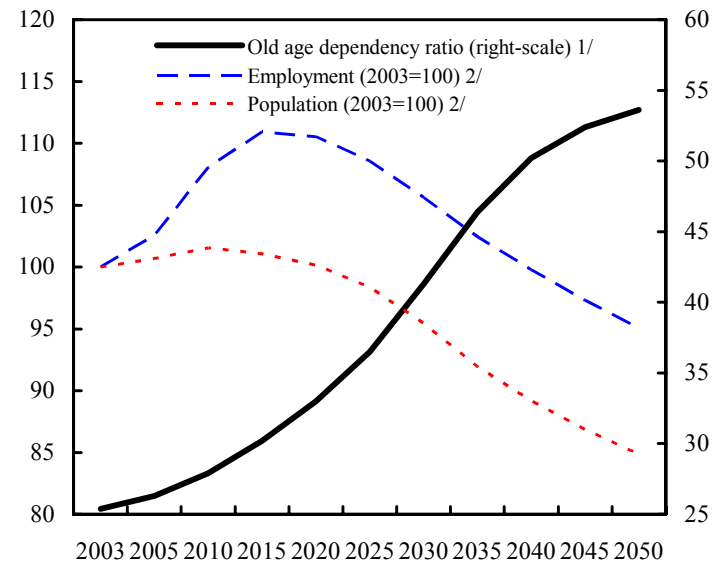

Source: AWG projections.

$1 /$ In percent of population aged 15-64

2/ Aged 15-64

Third, the interaction between real growth/employment, taxes, and debt is ignored (because it is very difficult to model consensually) and therefore downplays the policy challenge. For example, higher spending would have to be met with higher taxes - which would hold back employment and growth — or more debt and interest payments, potentially creating fiscal sustainability problems.

Lastly, member countries have made vastly differing progress in addressing aging-related costs and this could affect the smooth functioning of the union. The "no policy change" estimates suggest that the net increase in spending would range from lows of 0-2 percent (Austria, Italy) to highs of 8-10 percent of GDP (Luxembourg, Portugal, Spain). 
Figure 12. Euro Area: Fiscal Developments

(in percent of GDP, unless otherwise noted)
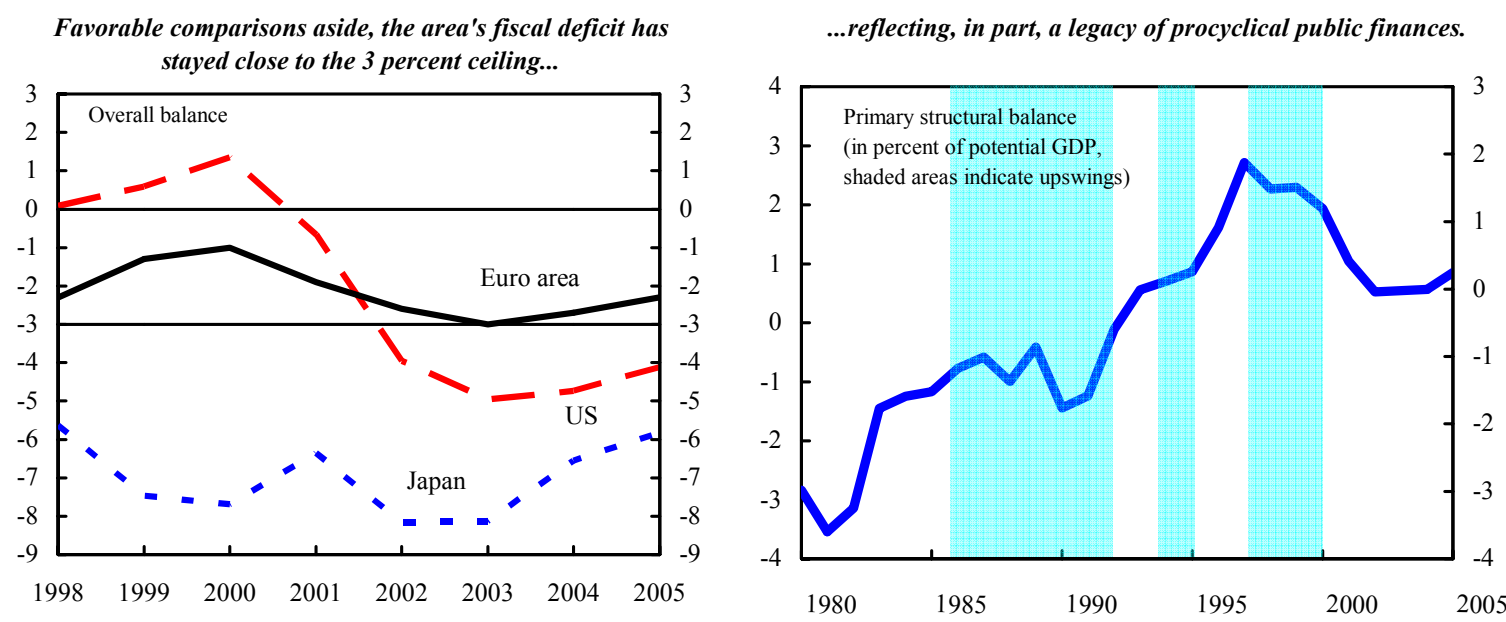

The close-to-balance criterion has proven elusive for

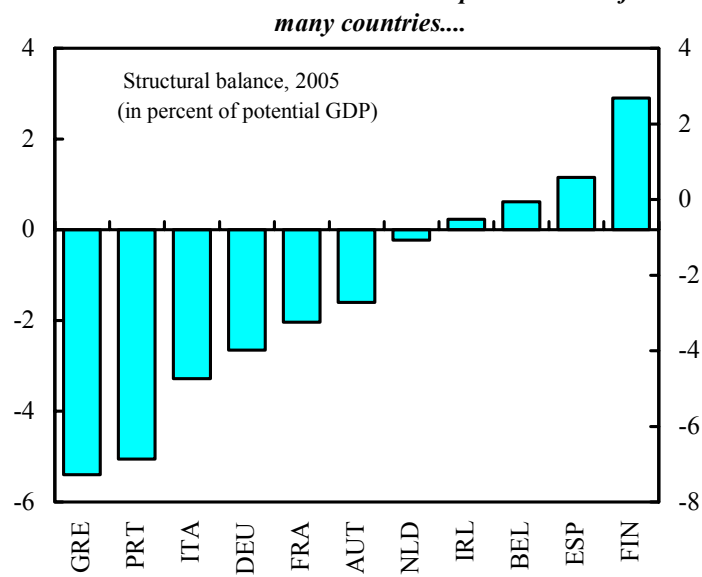

...causing public debt to remain high.

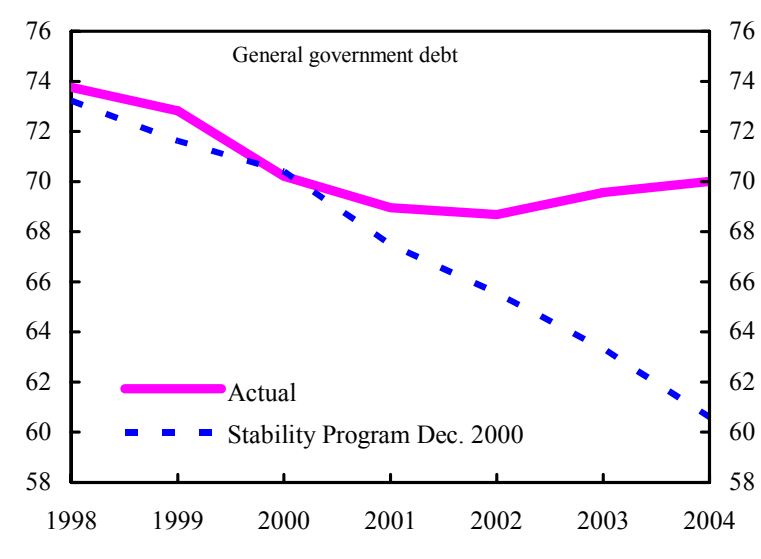

Overly-optimistic assumptions and lack of ambition have plagued Stability Programs.

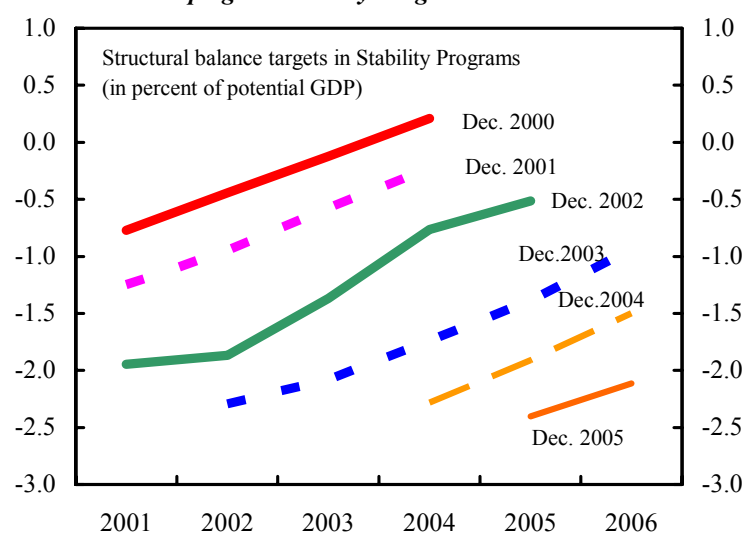

Looking ahead, countries display modest aims with few credible

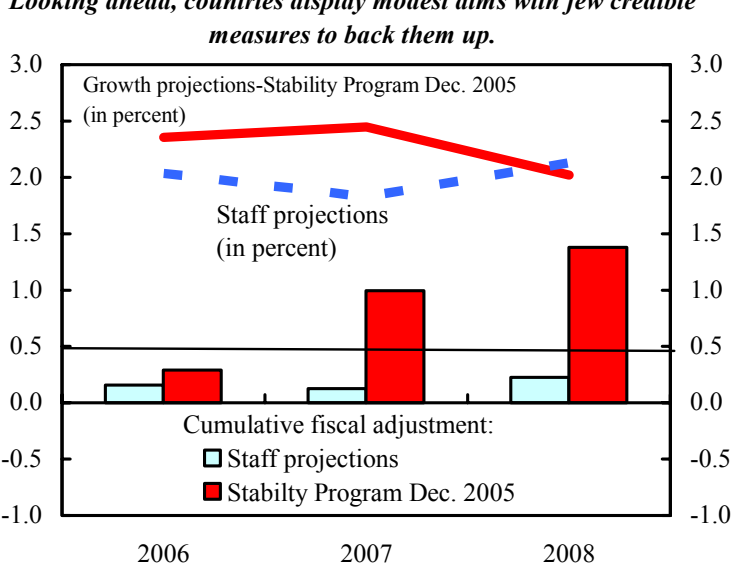

Sources: European Commission; IMF, World Economic Outlook; and IMF staff calculations. 
21. Staff argued for improving national governance mechanisms to help overcome pro-cyclical behavior during upswings and tackle the demographic challenge. The credibility and effectiveness of fiscal policies would benefit from improvements in national rules and governance mechanisms, points that had been taken up in ECOFIN Council discussions and reports. In this regard, a key issue is to overcome popular disaffection with adjustment, which requires deepening public understanding at the national level of the longer-term issues facing countries and the role of policies in addressing them. Commission officials agreed, noting that the evidence suggested that delegation of forecasting to independent institutions is an efficient way to address biases; that independent institutions have considerable impact and their advice is often followed by governments; that the quality of their analysis is mostly considered above or well above average; and that there is a general perception that they have improved fiscal discipline. National authorities are divided on this issue, with some supportive and others skeptical, notably as regards the wisdom of creating new institutions, their democratic legitimacy and accountability, and their likely effectiveness. There is agreement that such institutions of necessity need to reflect national arrangements and should eschew reaching normative (as distinct from "positive") assessments. The Finnish Presidency has made the issue a subject of discussion for the second half of this year.

\section{The reformed Lisbon Agenda: a vehicle for strengthened reform strategies?}

22. The National Reform Programs (NRP) provide a potentially promising vehicle for designing policies that tap the synergies between fiscal and structural adjustment and thereby boost productivity and employment simultaneously. On content, the NRP, which were first prepared in fall 2005, tend to be fairly comprehensive and forward looking, although they vary considerably as regards concreteness and often remain silent on complementarities - in fact, key structural policy measures entail either lower fiscal revenue or higher expenditure and therefore could complicate fiscal adjustment - and sequencing of reforms. The need for labor market reform is widely acknowledged. But, whereas programs hone in on active labor market policies and lower payroll taxation, they shun steps that might facilitate job turnover. The Commission explained that increased spending on R\&D (the target is 3 percent of GDP), including for the creation of a European Institute of Technology, and a reduction in the administrative burden on companies featured prominently in the programs and were central to efforts to reinvigorate productivity.

\section{Staff felt that boosting productivity required more concerted action, notably} around reforming the services sector, a concern which Commission and ECB officials shared. Services account for roughly two-thirds of the EU GDP. With only 8 percent of services output being traded, partly because of the many barriers at the national level, staff welcomed the adoption of the revised services directive. However, it expressed regret that the country of origin principle (CoOP) had been dropped, as this could reduce the potential output and employment gains from the directive by some 30 -odd percent (Box 6). In the staff's view, much could be gained by strengthening competition in this sector, including in exempted services such as work agencies and liberal professions. Furthermore, there was 
agreement that more progress was also needed in sectors covered under separate directives, notably energy, railway, and postal services.

\section{Notwithstanding improved ownership, concerns about NRP implementation}

linger. Commission officials noted that the NRPs had fostered greater coordination at the national level and had been reviewed in parliaments and discussed with social partners in virtually all countries. Thus, while the NRPs still needed to feature in broader reform debates, they nonetheless represented a step towards increased ownership. Another concern is that specific targets and timetables are often missing from the programs. This will make it difficult to evaluate implementation but a framework to do so in a consistent manner is under development.

\section{Financial sector: broadly healthy but still too segmented}

\section{Financial markets are generally healthy and supportive of growth, but not}

without vulnerabilities. The national authorities and staff agreed that the soundness of the euro area's financial system has continued to improve, but is subject to risks, some of which are increasing. Risks include a possible disorderly unwinding of global imbalances, potential mispricing of assets due to the hunt for yield, the exponential growth and opacity of the Credit Risk Transfer market, and the ongoing tightening of global liquidity conditions. Bank profitability has reached very high levels, but some of its current drivers are likely to become less supportive going forward. The insurance sector has continued its recovery, thanks to benign financial market developments and improving underwriting income. At the area-wide level, accelerating credit growth does not raise prudential concerns. The financial situation of the corporate sector has improved further, although there are indications that the credit cycle may have turned and interest rate sensitivity increased. Household balance sheets appear sound at the euro area level, but risks exist in countries that have seen rapid housing price inflation and widespread use of variable-rate mortgage loans in a context of high household debt levels. The Commission had some doubts about the effectiveness of using additional prudential or fiscal measures at the national level to contain such risks, as advocated by staff. The mission's counterparts had no uniform views on the extent to which credit growth in the new member states posed risks.

\section{Staff remains concerned that}

financial integration, and area-wide growth, is being slowed by entrenched interests and institutional legacies. Europe's anemic productivity growth is in good part traceable to this sector: empirical estimates suggest that about half the productivity growth gap between the area and the United States over the past decade can be traced to the

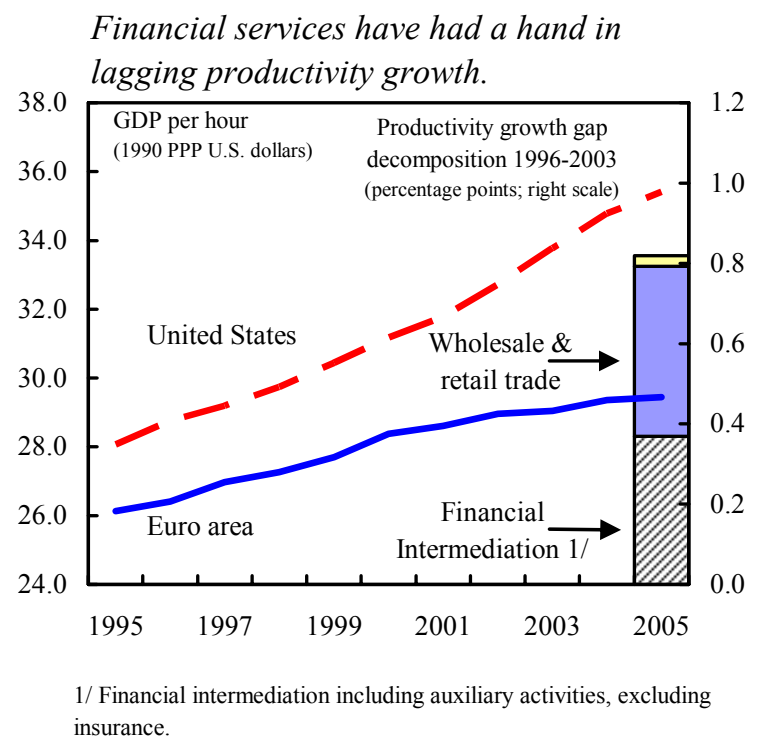


financial sector (excluding insurance).$^{13}$ While bond and money markets have largely integrated, retail banking, equity markets, and markets in collateralized securities remain segmented, thereby slowing efficiency gains and contributing to regional economic divergences. The same holds for payments as well as clearing and settlements systems, which makes cross-border business and trading expensive. More generally, wide differences in taxation procedures (very relevant for VAT on intra-group transactions), consumer protection, and contract law pose formidable obstacles to the integration and development of Europe's capital markets, notwithstanding rapid financial innovation. Specific concerns include the following:

- The integration of payments and, particularly, of clearing and settlement systems is being held up by vested interests. Given the benefits of integration (Box 6), the Commission is considering legislative action.

- There are instances of vested interests capturing legislative initiatives and the Lamfalussy process and turning integration and harmonization into something more akin to a collection of national practices rather than best practice. This is regrettable because, according to a review of EU country IMF Financial Stability Assessment Programs (IMF FSAP), the prudential infrastructure in EU countries does not fully meet international best practice. ${ }^{14}$

- $\quad$ The segmented supervisory framework stands in the way of optimization across borders of banks' operations and is not cost efficient. ${ }^{15}$ Furthermore, the centralization of risk management functions of large financial groups and their increasing presence in many countries creates tensions between home and host country supervisors that are amplified by legal and regulatory differences. Key issues revolve around the public good nature of financial stability, externalities, and asymmetric information, both at the macroeconomic (e.g., the optimal response to housing market booms) and the microeconomic (e.g., cross-border transfers of assets by large groups as well as cross-border business and deposit insurance) level.

- $\quad$ Europe's financial stability framework, including crisis management and resolution, needs to keep pace with the emergence of complex cross-border financial institutions, considering also that cross-border diversification has not lead to a decline in systemic

\footnotetext{
${ }^{13}$ Microeconomic evidence points in the same direction as macroeconomic data (see IMF Country Report No. 05/266, Chapter VI).

${ }^{14}$ See Selected Issues paper "How Good is Financial Sector Regulation and Supervision in Europe?"

${ }^{15}$ The Capital Requirements Directive, for example, allows national discretion in various areas. To avoid complex dealings with many national supervisors, some financial conglomerates are therefore considering adopting the Basel II advanced approach only at the group level, not for cross-border subsidiaries.
} 
risk. Staff considers that the dispersion of information and competencies related to financial stability over different institutions and decision-making levels hinders the timely identification of threats to financial stability and optimal policy responses. In particular, more detailed information should be made available at the central level, and coordinated prudential action should be made possible, including for problems that involve multiple, but not all, member states.

\section{Although recognizing these difficulties, the authorities viewed the EU Financial} Services Action Plan (FSAP) and Lamfalussy process as delivering significant progress towards financial market integration and prudential convergence. Integration is proving complex essentially because financial services revolve around contracts and contract law differs widely across countries and because of different rules and cultural perspectives. Accordingly, the EU FSAP entails significant legal and regulatory changes, many of which still need to be implemented on the ground and this is what the authorities' plans are now focusing on. The authorities also noted that the flexibility inherent in the Lamfalussy process made it easier to adjust in the face of changing circumstances than would be the case with Directives. Turning to supervision, the plans center on improving convergence and collaboration through the Lamfalussy process, by fostering: (i) non-binding mediation to help solve day-to-day supervisory disputes; (ii) the use (on a voluntary basis) of delegation between supervisors, particularly to help optimize the functioning of cross-border supervision, through the elaboration of guidelines for supervisors and the promotion of colleges of supervisors; (iii) a significant streamlining of reporting requirements for crossborder business; and (iv) supervisory disclosure. Staff welcomed these changes and acknowledged that progress was underway. However, considering the opportunity costs, this remained slow, particularly in key cross-border areas. It argued at a minimum for improving information flows between supervisors, notably by establishing a central repository with upto-date information on systemically-important financial institutions that could also serve as a platform to aid crisis coordination efforts.

\section{International Spillovers, Trade Policy, and Imbalances}

\section{The hesitancies about euro-area integration extend to integration with the New Member States (NMS) and the rest of the world as well:}

- Instances are the latest spat over cross-border M\&A; the watering down of the EU services directive; barriers to migration from NMS; and concerns about euro-area entry of new members even though some of these seem well-positioned to instill a greater dynamic to the area. ${ }^{16}$

\footnotetext{
${ }^{16}$ From a "half-full" perspective, it should be noted that several countries have decided to join the United Kingdom, Ireland, and Sweden in opening their job markets to workers from NMS; controversial cross-border M\&A did go ahead; a services directive with significant beneficial effects was adopted; and Slovenia was admitted into the euro area.
} 
- $\quad$ Similarly, positions on trade liberalization, including access to EU agricultural markets, are hardening, which has had direct consequences for selected emerging markets (Box 5) - as well as domestic consumers - and may also affect the outcome of the Doha Round.

\section{Box 5. EU Textiles Trade Following Expiry of Quotas in 2005}

The removal of the last, or "Phase IV," quotas on textiles and clothing (T\&C) on January 1, 2005 changed the structure of T\&C imports into the United States and EU. Based on data for January-November, U.S. and EU imports of Phase IV T\&C products from all source countries increased by 7.7 percent and 5.8 percent in 2005, while unit prices declined by 5.4 and 4.5 percent respectively. However, imports from China tripled in the United States and almost doubled in the EU. Although the surge of imports from China was mostly at the expense of other countries, U.S. and EU producers experienced strong price pressures. This has prompted a return to managed trade. In particular, in June 2005 the EU negotiated a bilateral agreement limiting China's T\&C exports (the United States negotiated a similar agreement with China in November 2005). Afterwards China's import share for products covered by the agreementwhich had increased from 8 percent in 2004 to 25 percent in January-May 2005-barely budged. Moreover, the agreement raised the prices of covered T\&C products back to pre-2005 levels.

The removal of the quotas and the subsequent restrictions on China's exports have had mixed effects on other countries' exports. Sub-Saharan Africa has been the most severely affected region, even though market losses may have been limited somewhat by the EU-China agreement. Exports from the Middle East and North Africa may also have benefited from this agreement as EU imports bounced back in June-November. South Asia is the only region, outside China, that did not suffer export losses in the EU market.

Table. US and EU imports of textiles and clothing.

\begin{tabular}{|c|c|c|c|c|c|c|c|c|}
\hline \multirow[t]{3}{*}{ Country of Origin } & \multicolumn{4}{|c|}{ Imports to the United States } & \multicolumn{4}{|c|}{ Imports to the European Union } \\
\hline & \multirow{2}{*}{$\begin{array}{r}\text { Value in } 2004 \\
\text { (mill. \$) }\end{array}$} & \multicolumn{3}{|c|}{ Value, percent change 2004-05 } & \multirow{2}{*}{$\begin{array}{r}\text { Value in } 2004 \\
\text { (mill.Euro) }\end{array}$} & \multicolumn{3}{|c|}{ Value, percent change $2004-05$} \\
\hline & & Jan-May & Jun-Nov & Jan-Nov & & Jan-May & Jun-Nov & Jan-Nov \\
\hline World & 86,738 & 11.3 & 4.2 & 7.1 & 63,715 & -9.7 & 18.3 & $\overline{4.8}$ \\
\hline World (excl. China) & 71,811 & 1.8 & -5.2 & -2.3 & 49,924 & -19.6 & 8.9 & -5.5 \\
\hline Greater China & 22,502 & 33.9 & 27.0 & 29.6 & 16,725 & 21.3 & 37.4 & 31.0 \\
\hline China (mainland) & 14,927 & 60.1 & 47.1 & 52.0 & 13,791 & 36.4 & 45.8 & 42.1 \\
\hline Latin America and Carribean & 20,634 & 2.3 & -6.9 & -3.0 & 771 & -8.9 & -16.2 & -12.9 \\
\hline South East Asia & 11,930 & 7.1 & 4.3 & 5.4 & 5,102 & -17.7 & -9.0 & -12.6 \\
\hline Cambodia & 1,431 & 17.1 & 19.0 & 18.3 & 480 & -1.9 & -13.8 & -10.0 \\
\hline South Asia & 10,293 & 20.9 & 12.6 & 16.0 & 10,683 & -2.0 & 4.9 & 1.8 \\
\hline India & 3,939 & 29.5 & 19.9 & 24.2 & 4,104 & 11.0 & 23.6 & 17.5 \\
\hline Pakistan & 2,554 & 11.9 & 13.4 & 12.8 & 2,140 & -16.8 & -8.7 & -12.3 \\
\hline Bangladesh & 1,986 & 24.3 & 15.1 & 18.6 & 3,600 & -7.2 & -6.0 & -6.5 \\
\hline MEDA (excl. Cyprus and Malta) & 4,150 & 5.9 & -4.4 & -0.1 & 15,734 & -2.7 & 1.1 & -0.6 \\
\hline Sub-Saharan Africa & 1,799 & -5.8 & -21.8 & -15.6 & 1,213 & -21.6 & -10.0 & -15.2 \\
\hline Eastern Europe & 831 & -35.4 & -41.7 & -39.3 & 7,123 & -8.3 & -4.3 & -6.0 \\
\hline
\end{tabular}

Source: US OTEXA, Eurostat, and Fund staff calculations. 
29. Staff stressed that integration in its various forms had been a lasting engine of growth for Europe, and that EU leadership on the multilateral trade negotiations provided an immediate opportunity in this regard. Concluding an ambitious Doha Round agreement remains the EU's most important trade policy priority, but the window of opportunity for agreement is closing rapidly. Effective access to EU agricultural markets is key to an ambitious Round, including sensitive product designations that remain truly exceptional and are not unduly restricting. The Commission noted that its agriculture offer would create new export opportunities in all sectors, but that any further flexibility was conditioned on the value of trade partners' offers, including effective new access for manufactures and services in the more advanced developing countries.

\section{As the EU's interest in free trade agreements (FTA) grows, it should seek} stronger international discipline in this area. Negotiations with Central America were launched in May, others with Asia are under consideration, and staff is concerned that a disappointing outcome from the Doha Round might spur a strategic shift towards FTA. This can add to the existing proliferation of such initiatives and undermine the multilateral fabric of world trade. The presence of defensive motives - i.e., reacting to others' FTA - suggests there is scope to agree mutual restraints, or the inclusion of open-access clauses for countries wishing to accede existing FTA. Simple and liberal rules of origin are crucial to avoid burdening cross-border value chains. The Commission agreed that shallow integration agreements were weakening multilateral resolve. It noted that it was seeking improved discipline on FTA as part of the Doha Round, and that its FTA were aiming for deep integration that ensured complementarity with the multilateral trading system.

31. Aid for Trade and integration initiatives are increasingly prominent tools of $\mathbf{E U}$ development policy. The Commission has defined an ambitious agenda for delivering Aid for Trade, which grew some 40 percent to almost euro 1 billion in 2005, and is examining ways to help channel stepped-up trade-related support by member countries. Economic Partnership Agreement (EPA) negotiations on intra-regional integration and free trade with the EU continue with six ACP regions (77 countries). The talks are targeted for completion at end-2007, but in some cases this timeline will be difficult to meet, e.g., due to differences over scope of the agreement and, in some cases, the related geographical configuration issues. Staff suggested that the development impact of EPA would depend partly on avoiding excessive discrimination favoring EU goods (e.g., through rules of origin) and services, and on the extent to which they supported open and competitive markets.

\section{Global imbalances}

32. Notwithstanding a broadly balanced exchange rate and external position, the euro area remains precariously exposed to a disorderly resolution of global imbalances. The authorities agreed that the exchange rate of the euro was broadly appropriate from a multilateral perspective (Box 6), aligning closely with its 1980-2005 average. An orderly market-led resolution of global imbalances was viewed to have relatively limited effect on 
activity in the euro area. Instead, concerns focused on a disorderly resolution. Indeed, given the euro's role second only to the dollar internationally, and in light of recent history, the euro remains disproportionately susceptible to a sharp, multilateral appreciation if market sentiment in the dollar were to sour. ${ }^{17}$ Staff's position has been that this would warrant an easing of monetary policy, assuming no other changes to the outlook for inflation.

\section{Box 6. Reforms in the Euro Area and Global Imbalances}

Staff estimates indicate that from a medium-term perspective the euro's exchange rate is broadly aligned on a multilateral basis. Nonetheless, the area has committed to contributing to an orderly resolution of global imbalances through enhanced structural reform. Progress, however, has been slowed by popular resistance to both labor and services market reforms.

The potential welfare gains from reform are substantial:

> According to studies by Copenhagen Economics and the Central Planning Bureau in the Netherlands, liberalization of the services sector would yield significant output and employment benefits for the euro area. Full implementation of the services directive, including the CoOP, would boost employment by 600,000-2.5 million and GDP by $0.8-1.8$ percent - the impact of the CoOP is between 10-30 percent - with the higher numbers accounting also for dynamic effects and hence more credible.

$>$ A common clearing and settlement systems would lead to lower transaction costs of up to 18 percent, increasing GDP by around 0.6 percent (European Commission).

> Integration of bond, equity, and bank markets would reduce firms' financing costs, raising GDP by 1.1 percent and employment by 0.5 percent, about one million new jobs (London Economics).

> Integrated European mortgage markets could yield a net gain of 0.9 percent of GDP over 10 years (London Economics).

> Implementing the Lisbon reform package could raise Europe's growth potential by $1 / 2$ to $3 / 4$ percentage points over the medium term.

33. The national authorities concurred that reducing imbalances must be seen as a shared responsibility, with all major regions putting in place appropriate policies. The widening of global imbalances in recent years has been driven by a diverse combination of forces, including differences in productivity growth and investor preferences, sharp declines in US savings, relatively weak domestic demand in much of Asia, exchange rate policies, and higher energy prices. Thus, action on several fronts is necessary to foster an orderly rebalancing. Regarding the euro area, measures that boost employment and productivity-

\footnotetext{
${ }^{17}$ See IMF Country Report No. 04/235, Chapter IV.
} 
particularly through reforms of non-tradables (notably services) markets-would be supportive of global growth, promote faster convergence of the NMS, ${ }^{18}$ and help facilitate an orderly unwinding of global imbalances, a point of view which the Commission and ECB officials shared. By way of example, staff argued that a rebalancing would require restraint in domestic demand in some parts of the world. To help fill the ensuing growth shortfall, implementing the Lisbon reform package could raise the EU's growth potential by $1 / 2$ to $3 / 4$ percentage point over the medium term; ${ }^{19}$ staff also pointed to more specific reforms and their estimated benefits. These reforms could prompt confidence effects that would hasten beneficial effects for area growth and could lead to some significant rebalancing, according to EC staff simulations. At a minimum, they would improve the area's resiliency to a possible disorderly resolution of imbalances.

\section{E. Other Issues}

34. The EU's AML/CFT framework is being further enhanced through increased cooperation and the development of common approaches. A new Directive on AML/CFT was promulgated in October 2005 and full implementation is expected by end-2007. To prepare for a potential pandemic, the Eurosystem is adapting its business continuity plans, focusing in particular on guaranteeing the functioning of key market operations and infrastructure. Challenges include increasing remote access facilities for ECB staff and the consistency of business continuity plans across the Eurosystem.

\section{STAFF ApPraisAL}

35. The euro area is emerging from the doldrums and needs to focus on translating a cyclical rebound into sustained growth. Economic activity appears to be finally catching up with business sentiment, and past reforms, especially in the labor market, are bearing fruit. But persistently sluggish productivity is inhibiting more sustained growth. Policies need to address this and tap the synergies of fiscal adjustment, labor supply reforms, and competitive product and services markets as well as accelerate the area's integration with the new member states of the EU and the rest of the world.

\section{The near-term outlook appears propitious but prospects for a more sustained} expansion are less assured. Buoyed by strong global growth and accommodative financial conditions, restored business confidence and rebounding profitability are finally translating

\footnotetext{
18 The catch-up process in the NMS has unquestionably benefited from further trade expansion with the EU15, greater policy discipline, and larger use of foreign savings. However, low real GDP growth in the EU15 has slowed the real convergence of NMS incomes - for the CE-5, by $1 / 2-1$ percentage point a year over 2000-04, according to staff research "Growth in the Central and Eastern European Countries of the European Union-A Regional Review,” forthcoming Occasional Paper, No. 252.

${ }^{19}$ See European Commission (2005), "The Economic Costs of non-Lisbon: A survey of the literature on the Economic Impact of Lisbon-type Reforms,” Occasional Paper, No. 16.
} 
into higher investment, and a consumption recovery appears in the works. Accordingly, GDP growth should remain around 2 percent, and could even be higher this year. But weak fundamentals are likely to dampen a more sustained recovery. And risks are firmly tilted to the downside in 2007 and beyond, in the face of an increasingly precarious external environment, notably unresolved global imbalances and the risk of further euro appreciation, although, from a multilateral perspective, the area's currency trades broadly in line with fundamentals.

37. With inflation projected to ease over the next 24 months and prospects for activity beyond the near term uncertain, monetary policy can afford to remain accommodative. Monetary conditions are appropriate. Even though inflation is running above the close to or below 2 percent benchmark, it is expected to fall back after 2007, as one-off shocks abate, and risks increasingly lean downwards. Inflation expectations also remain well anchored. Absent significant indirect or second round effects from exogenous price shocks, further tightening can await a firming of the recovery, as evidenced by accelerating employment. The risks of currency appreciation as well as the uncertainties about the extent of monetary accommodation (as a result of the decline in potential growth and relatively high savings) also warrant a cautious approach to raising rates.

\section{Boosting Europe's sagging growth potential will require steadfast pursuit of} mutually reinforcing fiscal and structural policies. Not only is productivity growth falling, populations will begin to decline around 2010 and this poses major challenges for Europe's welfare states. Adjustments to, rather than a revamping of, Europe's welfare programs may well suffice to prepare for the demographic shock, provided all policy levers are set in a manner that leverages the synergies between them. The examples of Europe's most successful reformers point the way. These countries twinned fiscal adjustment through expenditure reduction with labor supply reforms and nurtured flexible labor and product markets to allow wage moderation to translate into jobs rather than rents.

\section{The key challenge for fiscal policies and the credibility of the Stability and} Growth Pact is the need to consolidate as the recovery unfolds. The reformed Pact is regaining some traction over fiscal policies. The Excessive Deficit Procedure is being implemented in line with the rules. Some progress is also evident on the preventive side of the Pact, as countries opt for underlying balance over the medium-term, refrain from exploiting loopholes, and base programs on more realistic assumptions than before. But, at the cusp of better times and considering the looming demographic shock, countries at some distance from underlying balance need to urgently identify measures equivalent to at least $1 / 2$ percent of GDP annual adjustment over the coming years, focused on the expenditure side. Given the soft nature of the preventive arm in particular, the rules could usefully be buttressed by non-partisan national governance mechanisms that appraise policies in a forward-looking manner. 
40. The integrated National Reform Programs under the rejuvenated Lisbon process offer platforms for carrying forward the product and labor market reform agenda at the national level, but they need strengthening. Given the adverse demographics, reforms that raise labor utilization must continue to be paramount but programs also need to devote more attention to boosting productivity, not just through R\&D spending, but also by intensifying competition in the internal market, especially in the critical services sector where rents are rife. Such an approach would also support an orderly unwinding of global imbalances and limit downside risks from financial fallout in the euro area. Furthermore, ownership has been enhanced by involving national parliaments and social partners in the debate, but much more remains to be done for these plans to become a fulcrum of public debate and a stepping stone to more consistent policies at the national level.

\section{The EU FSAP and Lamfalussy process are fostering the integration of Europe's} financial markets, but the pace is too measured given the opportunity costs. Much of the euro area's lagging productivity performance can be traced directly to the financial services sector and thus policies need to hone in on removing the many remaining cross-border barriers to integration. This will require using all the tools available to competition policy and more forceful public intervention where stakeholders stymie the establishment of open, market-based solutions, notably at present in securities clearing and settlement systems. At the same time, a clarification and further integration of supervisory powers over complex groups - supported by legal and regulatory changes at the national level-will be necessary to improve the efficiency and effectiveness of financial stability policies, notably prudential policies and crisis management. While the issues are complex, postponing political decisions on key drivers, such as the fiscal dimensions of crisis resolution, could significantly slow the process of integration. In the meantime, the latest initiatives to improve supervisory collaboration and convergence are pragmatic steps forward that deserve strong support from national capitals. As in other areas, the key test will be their rapid implementation. In this regard, priority should be placed on improving information flows between Europe's supervisors, notably by establishing a central repository with up-to-date information on systemically-important financial institutions that could also serve as a platform to aid crisis coordination efforts.

42. Concerning trade policy, all parties need to redouble their efforts to bring the Doha round to a successful conclusion, and resist the temptation to resort to undisciplined bilateralism. As the window of opportunity is closing rapidly, only a serious political commitment can break the logjam at this stage of the game. For its part, the EU should endeavor to achieve the effective liberalization of agricultural market access, chiefly by keeping sensitive product designations truly exceptional and not overly restrictive. It should also try to reach agreement with other players to collectively call a halt to the proliferation of bilateral trade initiatives, which only contribute to the fragmentation of world trade, and instead renew their commitment to tried and tested multilateralism. 
43. While the external position of the euro area is broadly balanced and the euro is seen as falling within a fairly-valued range from a medium-run multilateral perspective, stronger growth is needed to facilitate orderly adjustment to global imbalances and

limit downside risks to the euro area. A positive outcome of rebalancing for the euro area hinges crucially on its ability to inspire investor confidence by increasing the relative attractiveness of holding euro assets. While this can be achieved through a variety of measures, the most effective in the current context would appear to be steps to strengthen competition in the services sector, which, besides boosting productivity, would help accelerate growth and demand.

44. Quality, availability, and timeliness of statistics are adequate for effective area-wide surveillance and have continued to improve.

45. It is proposed that the next consultation on euro-area policies in the context of Article IV obligations of member countries follow the standard 12-month cycle. 
Table 1. Euro Area: Main Economic Indicators

(in percent change)

\begin{tabular}{|c|c|c|c|c|c|c|c|c|c|}
\hline & 1999 & 2000 & 2001 & 2002 & 2003 & 2004 & 2005 & $20061 /$ & $20071 /$ \\
\hline \multicolumn{10}{|l|}{ Demand and Supply } \\
\hline Private consumption & 3.4 & 3.2 & 1.9 & 0.9 & 1.0 & 1.5 & 1.3 & 1.8 & 1.5 \\
\hline Public consumption & 2.0 & 2.2 & 2.2 & 2.6 & 1.7 & 1.1 & 1.4 & 1.5 & 1.2 \\
\hline Gross fixed investment & 6.1 & 4.9 & 0.5 & -1.5 & 0.8 & 2.3 & 2.3 & 3.5 & 3.3 \\
\hline Final domestic demand & 3.7 & 3.1 & 1.7 & 0.6 & 1.2 & 1.4 & 1.5 & 2.0 & 2.0 \\
\hline Stockbuilding 2/ & -0.1 & 0.2 & -0.5 & -0.2 & 0.1 & 0.6 & 0.1 & 0.0 & -0.1 \\
\hline Domestic Demand & 3.6 & 3.3 & 1.2 & 0.4 & 1.3 & 2.0 & 1.6 & 2.0 & 1.9 \\
\hline Foreign balance 2 / & -0.6 & 0.6 & 0.7 & 0.5 & -0.6 & 0.1 & -0.2 & 0.1 & 0.0 \\
\hline Exports 3/ & 5.0 & 12.0 & 3.6 & 1.7 & 1.1 & 6.5 & 3.8 & 7.3 & 5.8 \\
\hline Imports 3/ & 7.2 & 10.8 & 1.8 & 0.3 & 3.0 & 6.7 & 4.6 & 7.3 & 5.8 \\
\hline Real GDP & 3.0 & 3.9 & 1.9 & 0.9 & 0.8 & 2.1 & 1.3 & 2.1 & 1.8 \\
\hline \multicolumn{10}{|l|}{ Resource Utilization } \\
\hline Potential GDP & 2.3 & 2.1 & 2.2 & 2.1 & 1.9 & 1.9 & 1.8 & 1.8 & 1.8 \\
\hline Output gap 4/ & 0.3 & 1.9 & 1.6 & 0.5 & -0.7 & -0.6 & -1.1 & -0.9 & -0.9 \\
\hline Employment & 2.0 & 2.4 & 1.6 & 0.7 & 0.4 & 0.6 & 0.7 & 0.9 & 0.8 \\
\hline Unemployment rate 5/ & 9.2 & 8.2 & 7.8 & 8.3 & 8.7 & 8.9 & 8.6 & 8.0 & 7.9 \\
\hline \multicolumn{10}{|l|}{ Prices } \\
\hline GDP deflator & 1.5 & 1.3 & 2.3 & 2.6 & 2.1 & 1.9 & 1.9 & 2.0 & 2.0 \\
\hline Consumer prices & 1.1 & 2.1 & 2.3 & 2.2 & 2.1 & 2.1 & 2.2 & 2.2 & 2.2 \\
\hline \multicolumn{10}{|l|}{ Public Finance 6/ } \\
\hline General government balance 7/ & -1.3 & -1.0 & -1.9 & -2.6 & -3.0 & -2.7 & -2.3 & -2.1 & -2.0 \\
\hline General government structural balance & -1.3 & -1.7 & -2.5 & -2.7 & -2.7 & -2.4 & -2.0 & -1.8 & -1.6 \\
\hline General government gross debt & 72.1 & 69.6 & 68.3 & 68.1 & 69.3 & 69.8 & 70.8 & 70.2 & 69.6 \\
\hline \multicolumn{10}{|l|}{ Interest Rates 8/ } \\
\hline Short-term deposit rate & 3.0 & 4.4 & 4.2 & 3.3 & 2.3 & 2.1 & 2.3 & 2.9 & $\ldots$ \\
\hline Long-term government bond yield & 4.6 & 5.5 & 5.0 & 4.9 & 3.9 & 3.8 & 3.4 & 4.0 & $\ldots$ \\
\hline \multicolumn{10}{|l|}{ Exchange Rates } \\
\hline U.S. dollar per euro 9/ & 1.07 & 0.92 & 0.90 & 0.94 & 1.13 & 1.24 & 1.25 & 1.27 & $\ldots$ \\
\hline Nominal effective rate $(2000=100) 8 /$ & 112.2 & 100.0 & 101.6 & 105.1 & 117.6 & 122.0 & 121.7 & 122.9 & $\ldots$ \\
\hline Real effective rate $(2000=100) 8 / 10 /$ & 113.4 & 100.0 & 101.8 & 107.5 & 121.3 & 127.5 & 126.5 & 127.6 & $\ldots$ \\
\hline \multicolumn{10}{|l|}{ External Sector 6/ 11/ } \\
\hline Current account balance & -0.5 & -1.5 & -0.3 & 0.7 & 0.4 & 0.6 & -0.3 & -0.1 & -0.1 \\
\hline Trade balance 12/ & 0.9 & 0.1 & 1.0 & 1.8 & 1.4 & 1.4 & 0.7 & $\ldots$ & $\ldots$ \\
\hline \multicolumn{10}{|l|}{ Memorandum items 6/ 13/ } \\
\hline Current account balance & 0.4 & -0.6 & 0.2 & 0.7 & 0.5 & 1.0 & -0.1 & -0.2 & -0.2 \\
\hline Trade balance 12 / & 1.3 & 0.6 & 1.4 & 2.1 & 1.8 & 1.7 & 0.9 & 1.2 & 1.2 \\
\hline
\end{tabular}

Sources: IMF, World Economic Outlook; Eurostat, ECB Monthly Bulletin.

1/ Staff estimates and projections.

2/ Contribution to growth.

3/ Includes intra-euro area trade.

4/ In percent of potential GDP.

$5 /$ In percent.

6/ In percent of GDP.

7/ Excludes UMTS revenues.

8/ Data for 2006 are for June

9/ Data for 2006 are for June 30

10/ Based on normalized unit labor costs.

11/ Based on ECB data, which exclude intra-euro area flows.

12/ Data for goods.

13/ Calculated as the sum of individual countries' balances. 
Table 2. Euro Area: Macro-Prudential Indicators for the Banking Sector, 1999-2004 (in percent, unless otherwise indicated)

\begin{tabular}{|c|c|c|c|c|c|c|}
\hline & Dec-99 & Dec-00 & Dec-01 & Dec-02 & Dec-03 & Dec-04 \\
\hline \multicolumn{7}{|l|}{ Capital Adequacy } \\
\hline Regulatory capital to risk-weighted assets* & $\ldots$ & 11.00 & 13.78 & 11.36 & 11.61 & 11.50 \\
\hline Regulatory Tier I capital to risk-weighted assets* & $\ldots$ & 7.24 & 9.01 & 8.35 & 8.36 & 8.42 \\
\hline Capital (net worth) to assets & $\ldots$ & $\ldots$ & $\ldots$ & 3.66 & 3.68 & 3.68 \\
\hline \multicolumn{7}{|l|}{ Asset composition and quality } \\
\hline \multicolumn{7}{|l|}{ Asset composition (in percent of total assets) } \\
\hline Cash and balances & 1.21 & 1.08 & 1.16 & 1.31 & 1.39 & 1.31 \\
\hline Short-term government debt & 3.38 & 0.76 & 0.71 & 0.97 & 1.25 & 1.78 \\
\hline Loans to credit institutions & 14.39 & 19.13 & 18.18 & 17.68 & 17.21 & 16.52 \\
\hline Debt securities & 29.39 & 23.42 & 23.84 & 19.24 & 20.71 & 14.99 \\
\hline Issued by public bodies & $\ldots$ & $\ldots$ & $\ldots$ & 7.25 & 4.52 & 7.37 \\
\hline Issued by other borrowers & $\ldots$ & $\ldots$ & $\ldots$ & 11.99 & 16.19 & 7.62 \\
\hline Loans to customers & 43.73 & 46.50 & 46.37 & 49.06 & 48.40 & 48.39 \\
\hline Shares and participating interest & 2.00 & 4.56 & 4.10 & 3.35 & 3.43 & 3.41 \\
\hline Tangible assets and intangibles & 1.24 & 1.17 & 1.13 & 1.38 & 1.37 & 1.34 \\
\hline NPLs to gross loans* & $\ldots$ & $\ldots$ & 3.60 & 3.44 & 3.41 & 3.05 \\
\hline NPLs net of provisions to capital* & $\ldots$ & $\ldots$ & $\ldots$ & 19.77 & 17.94 & 13.34 \\
\hline \multicolumn{7}{|l|}{ Earnings and Profitability } \\
\hline ROA* & 0.19 & 0.29 & 0.22 & 0.30 & 0.31 & 0.42 \\
\hline $\mathrm{ROE}^{*}$ 1/ & 11.54 & 7.51 & 5.74 & 7.62 & 7.76 & 10.54 \\
\hline Operating profits (in percent of total assets) & $\ldots$ & $\ldots$ & $\ldots$ & 0.80 & 0.84 & 0.83 \\
\hline Interest margin to gross income* & 54.45 & 55.94 & 59.13 & 53.89 & 53.24 & 52.77 \\
\hline Noninterest expenses to gross income* & 61.47 & 68.60 & 72.11 & 66.86 & 64.55 & 63.67 \\
\hline Personnel expenses to noninterest expenses & 53.30 & 55.24 & 51.15 & 57.14 & 57.29 & 57.98 \\
\hline Trading and fee income to total income & 37.08 & 38.75 & 34.97 & 31.96 & 33.26 & 34.75 \\
\hline \multicolumn{7}{|l|}{ Liquidity } \\
\hline Liquid asset ratio 1 (cash and T-bills) & 4.59 & 1.84 & 1.87 & 2.27 & 2.32 & 2.60 \\
\hline Liquid asset ratio 2 (ratio $1+$ loans to credit institutions) & 18.98 & 20.97 & 20.05 & 19.95 & 19.53 & 19.12 \\
\hline Liquid asset ratio 3 (ratio $2+$ debt sec. issued by public bodies) & $\ldots$ & $\ldots$ & $\ldots$ & 27.20 & 22.66 & 22.13 \\
\hline
\end{tabular}

* Included in the "core set" of FSIs.

1/ After tax and extraordinary items. 
Table 3. Euro Area: Balance of Payments

\begin{tabular}{|c|c|c|c|c|c|c|c|}
\hline & 2000 & 2001 & 2002 & 2003 & 2004 & 2005 & 2006Q1 \\
\hline & \multicolumn{7}{|c|}{ (not seasonally adjusted; in billions of euro) } \\
\hline Current account & -99.2 & -21.5 & 53.3 & 32.4 & 49.7 & -22.6 & -10.0 \\
\hline Goods & 7.7 & 73.3 & 128.5 & 106.0 & 105.2 & 52.9 & -3.5 \\
\hline Services & -10.2 & -3.5 & 13.8 & 19.4 & 28.9 & 34.2 & 3.4 \\
\hline Income & -45.9 & -40.3 & -40.7 & -37.1 & -28.1 & -41.6 & 0.8 \\
\hline Current transfers & -50.6 & -51.2 & -48.5 & -56.0 & -56.3 & -68.3 & -10.6 \\
\hline Capital account & 11.3 & 6.2 & 10.2 & 13.2 & 17.5 & 12.5 & 2.6 \\
\hline Financial account & 31.3 & -29.2 & -13.9 & -1.3 & -11.1 & 90.0 & 36.9 \\
\hline Direct investment & -56.8 & -110.1 & 20.8 & -12.4 & -41.2 & -145.4 & -11.9 \\
\hline Portfolio investment & -102.5 & 73.3 & 139.4 & 75.0 & 60.2 & 162.6 & 31.8 \\
\hline Equity & -234.1 & 131.3 & 46.4 & 31.8 & 24.7 & 139.8 & 41.5 \\
\hline Debt instruments & 134.4 & -59.4 & 93.5 & 43.2 & 35.9 & 22.5 & -9.7 \\
\hline Financial derivatives & -10.0 & -0.7 & -11.0 & -12.8 & -5.2 & -13.5 & -7.4 \\
\hline Other investment & 186.7 & -9.6 & -160.6 & -79.1 & -37.7 & 67.8 & 18.7 \\
\hline Reserve assets & 14.7 & 18.0 & -2.5 & 28.2 & 12.5 & 18.7 & 5.6 \\
\hline \multirow[t]{2}{*}{ Errors and omissions } & 56.2 & 44.6 & -49.8 & -44.2 & -56.4 & -79.9 & -29.5 \\
\hline & \multicolumn{7}{|c|}{ (in percent of GDP) } \\
\hline Current account & -1.5 & -0.3 & 0.7 & 0.4 & 0.6 & -0.3 & -0.5 \\
\hline Goods & 0.1 & 1.0 & 1.8 & 1.4 & 1.4 & 0.7 & -0.2 \\
\hline Services & -0.2 & -0.1 & 0.2 & 0.3 & 0.4 & 0.4 & 0.2 \\
\hline Income & -0.7 & -0.6 & -0.6 & -0.5 & -0.4 & -0.5 & 0.0 \\
\hline Current transfers & -0.8 & -0.7 & -0.7 & -0.8 & -0.7 & -0.9 & -0.5 \\
\hline Capital account & 0.2 & 0.1 & 0.1 & 0.2 & 0.2 & 0.2 & 0.1 \\
\hline Financial account & 0.5 & -0.4 & -0.2 & 0.0 & -0.1 & 1.1 & 1.8 \\
\hline Direct investment & -0.8 & -1.6 & 0.3 & -0.2 & -0.5 & -1.8 & -0.6 \\
\hline Portfolio investment & -1.5 & 1.0 & 1.9 & 1.0 & 0.8 & 2.0 & 1.6 \\
\hline Equity & -3.5 & 1.9 & 0.6 & 0.4 & 0.3 & 1.7 & 2.1 \\
\hline Debt instruments & 2.0 & -0.8 & 1.3 & 0.6 & 0.5 & 0.3 & -0.5 \\
\hline Financial derivatives & -0.1 & 0.0 & -0.2 & -0.2 & -0.1 & -0.2 & -0.4 \\
\hline Other investment & 2.8 & -0.1 & -2.2 & -1.1 & -0.5 & 0.8 & 0.9 \\
\hline Reserve assets & 0.2 & 0.3 & 0.0 & 0.4 & 0.2 & 0.2 & 0.3 \\
\hline Errors and omissions & 0.8 & 0.6 & -0.7 & -0.6 & -0.7 & -1.0 & -1.5 \\
\hline \multicolumn{8}{|l|}{ Memorandum items: } \\
\hline GDP (in billions of euros) & $6,710.7$ & $6,999.9$ & $7,245.8$ & $7,453.0$ & $7,750.2$ & $7,997.6$ & $2,003.0$ \\
\hline $\begin{array}{l}\text { Reserves of the eurosystem } 1 / \\
\text { (in billions of euros) }\end{array}$ & 391.2 & 392.7 & 366.1 & 306.6 & 280.8 & $\ldots$ & $\ldots$ \\
\hline
\end{tabular}

Source: Datastream.

1/ End of period stocks. 
Table 4. Euro Area: Net Investment Position 1/ (in percent of GDP)

\begin{tabular}{lrrrrrr}
\hline & 2000 & 2001 & 2002 & 2003 & 2004 & $2005 \mathrm{Q} 4$ \\
\hline & 102.8 & 110.8 & 102.5 & 106.5 & 111.4 & 131.8 \\
Assets & & & & & & \\
& 26.0 & 29.8 & 27.7 & 28.9 & 29.2 & 32.0 \\
Direct investment abroad & 35.1 & 35.9 & 31.6 & 35.3 & 38.5 & 47.0 \\
Portfolio investment abroad & 1.6 & 1.9 & 1.9 & 2.1 & 2.1 & 2.9 \\
Financial derivatives & 34.3 & 37.7 & 36.2 & 36.0 & 37.9 & 45.9 \\
Other investment abroad & 5.8 & 5.6 & 5.1 & 4.1 & 3.6 & 4.0 \\
Reserve assets & & & & & & \\
& 110.6 & 116.4 & 112.2 & 117.3 & 123.6 & 145.0 \\
Liabilities & & & & & & \\
& 20.7 & 23.8 & 25.2 & 28.3 & 28.8 & 29.1 \\
Direct investment in the EU & 47.8 & 47.8 & 44.6 & 47.6 & 52.0 & 63.4 \\
Portfolio investment in the EU & 1.5 & 1.8 & 2.0 & 2.2 & 2.3 & 3.1 \\
Financial Derivatives & 40.6 & 43.0 & 40.4 & 39.2 & 40.5 & 49.4 \\
Other investment in the EU & & & & & & \\
& -7.8 & -5.6 & -9.7 & -10.9 & -12.2 & -13.1 \\
Net investment position & & & & & & \\
& 5.3 & 6.0 & 2.5 & 0.6 & 0.4 & 2.9 \\
Direct investment & -12.7 & -11.9 & -12.9 & -12.3 & -13.5 & -16.4 \\
Portfolio investment & 0.0 & 0.0 & -0.2 & -0.1 & -0.2 & -0.2 \\
Financial Derivatives & -6.3 & -5.3 & -4.2 & -3.2 & -2.5 & -3.5 \\
Other investment & 5.8 & 5.6 & 5.1 & 4.1 & 3.6 & 4.0 \\
Reserve assets & & & & & & \\
& & & & & &
\end{tabular}

Source: European Central Bank.

1/ Data correspond to the end of the indicated period. They are expressed as a percent of the cumulated GDP of the four quarters ending on that date. 


\section{Appendix I. Statistical Issues}

Statistics for the euro area (and the EU-25) are produced by Eurostat and the ECB, generally on the basis of data reported by member states. These statistics are of sufficient quality, scope and timeliness to allow effective macroeconomic surveillance. Nevertheless, important gaps and weaknesses remain, many of which relate to specific challenges arising from the euro area's young age, changing composition, and supra-national nature. Major progress has been made over the past year, including significant improvements to the euro area (i.e., "national") accounts and the publication of euro area accounts per institutional sector, and efforts are well advanced to fill some of the remaining gaps. A major new gap is the current non-availability of euro area accounts predating 1995. More recent and higher-frequency indicators of corporate profitability, internationally comparable and higher-frequency financial soundness indicators, housing market indicators, and improved statistics on nonbank financial intermediaries would be desirable. Ongoing work at Eurostat and the ECB gives high priority to improving the timeliness, length, consistency and quality of dataseries. Efforts to improve the monitoring of member states' fiscal accounts are not yet fully up to speed and seem hampered by insufficient effectively available resources.

- $\quad$ Two major changes were introduced in the euro area accounts at end-2005: (i) the allocation of Financial Intermediation Services Indirectly Measured (FISIM) to the final and intermediate consumption of different sectors and activities, and to net exports; and (ii) the use of chain-linked volume measures. The dataseries were revised back to 1995 and publication for earlier years was suspended. Revised pre1995 data are not likely to become available before the end of the year at the earliest. The allocation of FISIM implied an upward revision to GDP levels, amounting to about 1 percent for recent observations. Revisions to GDP growth rates were relatively small, generally not exceeding 0.1 percentage points in terms of quarter-onquarter growth.

- $\quad$ On May 31, 2006, Eurostat and the ECB released euro area (and EU-25) accounts per institutional sector, on an annual basis covering 1999-2004. These accounts provide a wealth of information on the financial and non-financial transactions between the different sectors of the economy (households, non-financial corporations, financial corporations, and general government) and the rest of the world, as well as financial balance sheets per sector. The accounts include details on disposable income and savings rates, thereby filling an important gap. Publication of quarterly euro area accounts per institutional sector is planned from spring 2007 onwards, and work on non-financial balance sheets per sector continues.

- $\quad$ A revised Nomenclature générale des Activités Economiques dans les Communautés Européennes (NACE) classification is planned for 2007, in the context of the UN's revision of the International Standard Industrial Classification (ISIC). Implementation at the member state level is planned for the 2008-2011 timeframe and will likely entail new problems with backward compatibility.

- Work continues to improve the availability of fiscal statistics and reduce the risk of misreporting by member states. Eurostat has launched a new section on Government 
Finance Statistics on its website. During the spring of 2006, Eurostat and the ECB started publishing quarterly non-financial and financial data for the general government of the euro area and EU-25, as well as most member states. Around the same time, they started publishing the underlying government sector accounts for EU member states. These accounts present the various fiscal data in an integrated framework, link them explicitly with the EDP budget balance, and provide stock-flow adjustments, thus allowing the relationship between budgetary outcomes and changes in government debt to be reconciled and tracked. In addition, Eurostat has stepped up its monitoring of member states' fiscal accounts, in part through more in-depth visits (EDP Dialogue Visits and Methodological Visits), and publishes the results on its website. To allow this stepped-up monitoring, Eurostat's resources allocated to fiscal accounts have been increased and a second internal unit was established. However, many of the new positions remain to be filled, the new structure is not yet fully operational, and the resource increase merely corrects for the loss of resources that had occurred on a per-country basis due to EU enlargement.

- $\quad$ The availability of labor market statistics has improved further in 2005 and all EU Member States are now collecting data for the continuous quarterly Labor Force Survey. Eurostat has also started publishing an improved detailed labor cost index and new national accounts-based quarterly employment data. Work is ongoing to establish a euro area series on job vacancies.

- $\quad$ As elsewhere, the accuracy and international comparability of EU labor productivity statistics are hampered by difficulties in measuring hours worked, which has become more difficult with the proliferation of non-standard labor contracts, and productivity in services. Statistics on euro area and US productivity levels are also not fully comparable due to methodological differences in the calculation of GDP, including different approaches in making quality adjustments and recording military spending.

- $\quad$ Efforts to harmonize and improve consumer price statistics continue, including through the recent harmonization of the HICP index reference period and the upcoming harmonization of the length of the price collection period. Going forward, the main priorities are quality adjustments, which are being studied on a case-by-case basis, and owner-occupied housing. Although the eventual objective is to construct a "net-acquisition" index for housing (i.e., an index of the purchase price of new dwellings, excluding the cost of land), an "all dwellings" index will be constructed first. Publication of the index is envisaged, but no decision has been made on any possible incorporation in the HICP. A pilot project is ongoing to construct an HICP at constant tax rates. During 2005, Eurostat formulated a recommendation on the statistical treatment of the Dutch health care reform, which will constitute a basis for future cases.

- Despite various initiatives, asymmetries in the intra-EU trade data reported by the different member states are growing, reflecting mounting difficulties in tracking trade flows and financial transactions. Asymmetries in the latter in particular have been increasing and tend to be more volatile. The asymmetries create difficulties in measuring the EU and the euro area's external trade, domestic demand, level of GDP, 
and household savings rates, among other variables. New efforts to reduce them include work Eurostat is planning to undertake with selected pairs of high-asymmetry countries. Eurostat is also working on increasing the transparency of the transition from statistics on trade in goods (based on data produced by customs administrations and national statistical institutes) to data related to "goods" in BoP statistics (compiled by central banks). A reconciliation table will be part of the future EU quality reports to be compiled by each member state.

- $\quad$ A limited set of macroprudential indicators for the euro area is published in the fall issue of the ECB's Financial Stability Report (Table 2). All euro area countries are participating in the Coordinated Compilation Exercise for Financial Soundness Indicators, but the ECB's consolidation approach and frequency of compilation differ from the Fund's Compilation Guide on FSIs. No harmonized and aggregated highfrequency housing market indicators (prices, housing starts) exist.

- Work to improve the Principal Economic Indicators for the euro area continues, with a focus on the coordination of release and revision policies, on seasonal and working day adjustments, and on harmonization more generally. Eurostat publishes a range of structural indicators to support the Lisbon-strategy. These structural indicators have not yet been adapted to the 2005 revamp of the Lisbon strategy, but a decision on this may be made by end-2006. The publication of the euro area accounts per institutional sector made a number of indicators of corporate sector profitability available, notably net operating surplus. However, no timely quarterly or half-yearly indicators of corporate sector profitability exist. Later this year, Eurostat plans to start publishing detailed import prices at the 2-digit NACE level, covering imports coming from outside the area.

- $\quad$ Eurostat and the ECB expect no major problems from the expansion of the euro area with new member states, since statistics for these countries are already collected. However, the compilation of backward statistical series for the expanded euro area may have to rely to some extent on estimations and will be especially challenging for pre-1995 data. 


\section{Appendix II. EU Policies Staff Research, 2003-05}

\section{Monetary Policy and Inflation}

"Measures of Underlying Inflation In The Euro Area: Assessment and Role for Informing Monetary Policy" (Emil Stavrev, 2006 Selected Issues)

- $\quad$ Proposes indicators of underlying inflation (beyond the standard "core" measures), finding that this is presently running between $1 \frac{1}{2}$ and $2 \frac{1}{4}$ percent, with most measures suggesting a figure below 2 percent. Examines a suite of inflation forecasting models, comparing their performances, and combining them to provide a quantitative view on the baseline outlook for inflation as well as the balance of risks. Projects that inflation, presently running around $2 \frac{1}{2}$ percent, is set to decline to around 2 percent during 2007 and that the risks are roughly balanced.

"Declining Money Velocity in the Euro Area: Implications for the ECB's Monetary Analysis," (Hamid Faruqee, 2005, Selected Issues).

- Shows that the nexus between inflation and money growth is more reliable over longer horizons; that velocity has experienced a variable rate of decline, challenging a robust assessment of liquidity; and that strengthening the monetary cross-check entails further disentangling the factors behind changing liquidity preferences.

"House Prices and Monetary Policy in the Euro Area," (Anthony Annett, 2005, Selected Issues).

- Shows that the relationship between credit growth and house prices depends on country-specific institutional characteristics; and that house prices do not seem to forecast consumer price inflation over the short- to medium term.

"Is Inflation Persistence Higher in the Euro Area than in the United States?" (Mads Kieler, 2003, Selected Issues).

- Analyzes inflation persistence on both sides of the Atlantic; shows that it declined significantly in the mid-1990s, and is only moderately higher in the euro area (a break with the past).

\section{Fiscal Policy}

"Enforcement and the Stability and Growth Pact: How Fiscal Policy Did and Did Not Change Under Europe's Fiscal Framework," (Anthony Annett, 2006; Working Paper and Selected Issues). 
- $\quad$ Argues that the SGP is more suited to countries that are smaller, subject to greater macroeconomic volatility, and that use a "commitment" — or more rules-based-form of fiscal governance (as opposed to "delegation," which relies on a strong agenda setter such as a finance minister); and that most of the new members share these characteristics. For the other countries, domestic governance reforms would improve the operation of the Pact.

"Reforming the Stability and Growth Pact," (Anthony Annett, Jörg Decressin, and Michael Deppler, 2005, Policy Discussion Paper).

- $\quad$ Explains the benefits of rules-based fiscal policy for Europe. Reviews the history of fiscal policy under the SGP, emphasizing weaknesses, notably lack of adjustment during good times. Argues that the SGP can be strengthened by letting the Excessive Deficit Procedure focus on policies rather than outcomes, and by fostering timeconsistent national policies, transparency, and ownership through stronger national governance institutions.

"Boom-Bust Phases in Asset Prices and Fiscal Policy Behavior," (Albert Jaeger and Ludger Schuknecht, 2004, Working Paper).

- $\quad$ Argues that output gap and revenue elasticity estimates are highly uncertain during boom-bust cycles, making estimates of fiscal positions difficult; and that these cycles exacerbate procyclical loosening and deficit biases.

\section{Structural Reforms}

"Case studies and Beyond: Lessons from Successful Labor Market Reformers in Europe and Implications for its Social Model” (Tony Annett, 2006, Selected Issues)

- $\quad$ Using both case studies (from Denmark, Ireland, the Netherlands, and the United Kingdom) and wider empirical evidence, finds that more decisive reform progress is less a matter of social choices than of sticking to a forward-looking strategy, pursuing functionally and intertemporally consistent and complementary fiscal and structural policies over many years. Successful fiscal adjustment mainly centered on welfare reform and the government wage bill, using the ensuing labor supply and related revenue improvements to cut taxes and maintain the reform momentum. These steps were complemented by actions that enhanced both factor and product (goods and services) market flexibility, enabled a stronger translation of wage moderation into jobs, and increased real incomes rather than rents. Importantly, reforms along these lines also proved to be compatible with broadly stable income distributions. 
"Product Market Regulation and the Benefits of Wage Moderation," (Marcello Estevão, 2005, Working Paper and Selected Issues).

- $\quad$ Argues that the effectiveness of wage moderation in terms of raising output and employment depends on the degree of product market regulation and that the euro area, because of overly regulated markets, has been lagging in this regard.

"Why is Productivity Growth in the Euro Area So Sluggish?" (Marcello Estevão, 2004, Working Paper and Selected Issues).

- $\quad$ Argues that wage moderation and some progress on structural reforms induced firms to shift to more labor-intensive production, reversing earlier substitution toward capital; and that the euro area did not enjoy a productivity surge in ICT-using services, especially wholesale and retail trade and financial intermediation.

"Implementing Lisbon: Incentives and Constraints," (Xavier Debrun and Anthony Annett, 2004, Selected Issues).

- $\quad$ Argues that EU countries exhibit strong status quo bias; that product market reform spurs labor market reform as rents fall; that cross-border spillovers affect reforms; and that the open method of coordination remains viable, but could be improved by streamlining and relying more on "naming and shaming."

\section{Financial Sector}

"How Good Is Financial Sector Regulation and Supervision in Europe?" (Martin Čihák and Alexander Tieman, 2006, Selected Issues)

- $\quad$ Based on a detailed analysis of information from Financial Sector Assessment Program missions (FSAPs) for EU countries, concludes that even though the EU supervisory systems are of a higher and more even quality than those of comparable non-EU countries, there are still notable gaps between the EU practices and the international standards. Highlights an issue raised by most FSAPs in the EU: the need to adjust the supervisory frameworks to meet new challenges, in particular evolving international financial integration. Notes that a fuller assessment of EU-wide regulatory and supervisory framework issues is difficult on the basis of country FSAPs.

"A Bank Business Correlation Perspective on Pan-European Supervision” (Jörg Decressin, 2006, Selected Issues)

- $\quad$ Finds that developments in balance sheet and profitability indicators of Europe's 100 largest banks do not cluster naturally around countries. From various perspectives, the EU-wide dynamics in these indicators appear as important as the country-specific 
dynamics. Hence, detecting potential risks and vulnerabilities in national financial systems and resolving instabilities are likely to require a strong cross-border perspective.

"The Integration of European Financial Markets," (Francois Haas, 2005, Selected Issues).

- $\quad$ Reviews the state of European financial market integration, pointing to remaining obstacles in retail markets, collateral-based instruments, and financial infrastructure (notably payments and securities clearing and settlement systems).

"European Financial Integration, Stability, and Supervision," (Gianni De Nicolo, Robert Corker, Alexander Tieman, and Jan-Willem van der Vossen, 2005, Selected Issues).

- Explores the impact of financial integration on system-wide risk profiles of publiclytraded European financial institutions; finds that risk profiles have converged, but not to lower risk levels. Notes that the challenge is to align incentives of supervisory bodies and to improve coordination.

"Banks and Markets in Europe and the United States," (Jörg Decressin and Beata Kudela, 2005, Selected Issues).

- Reviews the history of EU and US financial integration, showing that the European financial system offers less scope for banks and markets to leverage their comparative advantage (with, for example, far less securitization than in the United States). As a result, EU banks seem to underperform relative to US banks, although they appear to operate in a less competitive environment.

\section{Trade Policy and International Spillovers}

"EU Eastern Enlargement: Impact on Trade and FDI," (Jean-Jacques Hallaert, 2003, Selected Issues).

- $\quad$ Argues that trade and investment links between old and new EU members will deepen, with enlargement providing stimulus to intra-industry trade; that new members have most to gain, and that impact on third-country trade and investment will be limited.

"Measuring the Trade Effects of EMU," (Hamid Faruqee, 2004, Working Paper).

- $\quad$ Shows that monetary union boosted trade among member states by roughly 10 percent during the euro's existence, and that trade gains do not come at the expense of extra-area trade. Dynamic effects of EMU on trade integration rise over time. 
"Global Rebalancing of Current Accounts: A Euro-Area Perspective," (Hamid Faruqee, 2004, Selected Issues).

- Shows that a benign global rebalancing would be compatible with boosting domestic demand and potential growth in partner countries relative to the United States, while an adjustment scenario based primarily on exchange rate adjustment would be more challenging, especially with limited exchange rate flexibility in the rest of the world.

“The Changing Patterns of EU-China Trade," (Jean-Jacques Hallaert, 2004, Selected Issues).

- Describes recent growth of EU-China trade, including composition (growth in electronics exports from China, as well as textiles and clothing).

"Exchange Rate Pass-Through in the Euro Area: The Role of Asymmetric Pricing Behavior," (Hamid Faruqee, 2005, Working Paper and Selected Issues).

- $\quad$ Shows that area-wide prices display incomplete pass-through, consistent with euro currency-pricing and pricing-to-market behavior; as with the United States, "expenditure-switching" effects on the current account still operate but are generally small; and that given small effects on the trade balance, substantial exchange rate adjustment may be needed for moderate external adjustment. 
This page intentionally left blank 
INTERNATIONAL MONETARY FUND

\title{
Staff Report for the 2006 Article IV Consultation
}

\author{
Supplementary Information
}

Prepared by the European Department

Approved by Michael Deppler and Adnan Mazarei

July 25,2006

1. This supplement provides an update of economic and policy developments since the release of the Euro Area Policies staff report. The thrust of the staff appraisal remains unchanged.

\section{New data are broadly in line with staff forecasts:}

- $\quad$ Revised national accounts data show that domestic demand and net exports in the first quarter were stronger than originally reported, mainly on account of investment and exports. Consumption growth, which has been volatile, reached 2.4 percent following 0.4 percent in 2005:Q4.

- Various recently-released indicators confirm that activity in 2006:Q2 is strong and that near-term risks are on the upside. The euro area industrial new orders index increased by 2.3 percent in May 2006, while that for production grew by 1.6 percent, following smaller declines during previous months. Car sales were strong but retail trade volumes fell by 0.6 percent in May and thus continue to move broadly sideways since fall 2005. Both the manufacturing and the services PMI indicator inched up again, reaching the highest levels since summer 2000. National indicators generally increased but a few lead indicators have retreated albeit from very high levels.

- $\quad$ Financial market participants generally expect quarterly real GDP growth of around 0.6-0.8 percent in 2006:Q2 and Q3. Staff's latest forecasts and those of the Commission are at the lower end of this interval.

3. Headline inflation remained stable at 2.5 percent in June. There is no evidence of acceleration in underlying price pressures, including wages, which stood 2.1-2.2 percent above last year's level in 2006:Q1, notwithstanding a further small decline in the unemployment rate, to 7.9 percent in May. Oil prices are running somewhat above US\$70 
per barrel, the price underlying staff projections for 2007. ${ }^{1}$ Inflation expectations have remained broadly unchanged and monetary and credit growth strong.

\section{At its July 6 meeting, the ECB left interest rates unchanged but gave indications} that led market participants to expect an interest rate increase on August 3. The ECB statement said that the Governing Council will exercise "strong vigilance," which is widely interpreted as a pre-announcement of a rate hike. An August rate hike would represent an acceleration relative to the once-a-quarter tightening pace followed thus far. Market see rates at $3 \frac{1}{2}$ percent by end-year.

5. Financial integration is proceeding. Regarding securities clearing and settlement, the Commission has opted against legislative action at this stage but called on market participants to put in place a code of practice to achieve integration that would contain specific objectives and deadlines so that progress could be monitored by the Commission. The ECB has announced that it is examining the possibility of providing a cross-border securities settlement system. Meanwhile, the Commission's Competition Directorate has published an interim report that shows that European retail banking markets remain highly fragmented and characterized by a range of entry barriers. The report is intended for consultation and no enforcement or policy actions are expected in the near future.

${ }^{1}$ An increase by 10 percent per barrel would add 0.1 percent to inflation, according to staff estimates. 
Public Information Notice (PIN) No. 06/86

FOR IMMEDIATE RELEASE

August 1, 2006
International Monetary Fund

$70019^{\text {th }}$ Street, NW

Washington, D. C. 20431 USA

\section{IMF Executive Board Discusses Euro Area Policies}

On July 26, 2006, the Executive Board of the International Monetary Fund (IMF) concluded the discussion of euro area policies. ${ }^{1}$

\section{Background}

After several years of disappointment, growth has picked up and broadened. Notwithstanding significant quarterly volatility, real GDP, final domestic demand, and household consumption all grew between 13/4-2 percent in the year through 2006: Q1 and the recovery has been gaining some traction in weaker parts of the area. Nonetheless, the pick up in activity remains fragile, relying on strong global growth. Employment and consumption continue to lag.

Monetary conditions remain accommodative, notwithstanding the policy rate hikes since December 2005, and external demand is strong. The area's external current account is broadly balanced and the exchange rate, while having appreciated somewhat lately, remains below the highs reached in 2004. Nonetheless, the area remains exposed to a disorderly resolution of global imbalances.

Besides supportive external demand and financial conditions the recovery reflects in part improved fundamentals in the corporate sector. Nonfinancial corporate profitability has been strong and leverage has been brought under control. Market-based financing activities have begun to recover from recent lows and, thus far, are not expected to be set back significantly by the latest market turbulence. Bank-based borrowing, which

\footnotetext{
${ }^{1}$ Under Article IV of the IMF's Articles of Agreement, the IMF holds bilateral discussions with members, usually every year. A staff team visits the country, collects economic and financial information, and discusses with officials the country's economic developments and policies. On return to headquarters, the staff prepares a report, which forms the basis for discussion by the Executive Board. At the conclusion of the discussion, the Managing Director, as Chairman of the Board, summarizes the views of Executive Directors, and this summary is transmitted to the country's authorities.
} 
picked up more than a year ago, remains robust. While enterprise loans have largely funded restructuring and consolidation, lending surveys now indicate that capital expenditures are no longer a drag. Financial sector indicators also point to improving positions. Many banks are well capitalized and booking record profits, buoyed by low interest rates, low costs of risk, cost containment, and booming demand for mortgage loans.

Price pressures appear contained despite sharply rising oil and administrative prices. Headline HICP inflation reached 2.5 percent in May and is likely to stay above 2 percent for some time due to energy prices, further administered price hikes, and the expected VAT increase in Germany in 2007. However, core inflation is running around $11 / 2$ percent, reflecting limited indirect effects and absent second-round effects. Services price inflation is easing.

Although improving in 2005, public finances remain at a significant distance from close to balance or surplus, the area's medium-term fiscal objective given the looming demographic shock. Five countries are close to or above the Stability and Growth Pact's 3 percent of GDP limit. Moreover, absent further measures little improvement is expected for 2006-07.

Area productivity growth has been disappointing and the population is expected to begin to decline around 2010. Against this background, staff foresees actual growth around 2 percent in 2006-07. The balance of risks lies somewhat to the upside in the near term but to the downside beyond 2006.

\section{Executive Board Assessment}

Directors welcomed the broadening and strengthening of the recovery in the euro area, supported by accommodative financial conditions and strong global growth, restored business confidence, and improved financial positions. Price pressures have been contained notwithstanding sharply rising oil and administrative prices. Directors were also encouraged that the reformed Stability and Growth Pact is regaining traction over fiscal policies, and welcomed the better-than-originally projected fiscal outcomes for 2005 . Equally, they welcomed the ongoing progress with the reform of product and services markets and financial integration.

Looking ahead, Directors considered the balance of risks in 2006 to be on the upside, but for 2007 and beyond, however, they saw the risks tilting to the downside.

In particular, they noted that the recovery of employment and consumption has yet to be firmly established, productivity growth continues to be sluggish, oil prices are volatile, and global imbalances remain unresolved. In light of these considerations, and more fundamentally reflecting the sluggish growth performance of the past few years and the looming demographic shock, Directors underscored the need for accelerated fiscal consolidation and further structural reforms that aim at strengthening incentives to work and invest. 
Directors commended the deliberate pace of monetary withdrawal in the face of large exogenous price shocks that continued to keep the headline inflation above the ECB target, considering it in line with the ECB's mandate. Many Directors observed that inflationary expectations remain well anchored, wage growth is subdued, signs of second-round effects from oil and administrative price hikes are absent, and inflation is projected to ease over the next two years. Accordingly, these Directors generally saw a need for caution in raising rates further until a more balanced recovery takes firm hold. Several other Directors saw the timing of further tightening as unclear, but some Directors were more concerned about the upside risks to inflation, and urged the authorities to monitor developments closely and respond flexibly with a view to keeping inflation expectations well anchored.

On the structural front, Directors agreed that significant progress has been made over the years, as evidenced by the buoyancy of employment over the past decade. Nonetheless, much remains to be done as regards both labor utilization and productivity. Steadfast pursuit of mutually reinforcing fiscal and structural policies continues to be essential to strengthen growth and stimulate employment, prepare for aging, and facilitate the orderly unwinding of global imbalances.

In this regard, Directors thought that the key fiscal challenge is to achieve broadly balanced fiscal positions by 2010 , when the area's population is projected to begin declining. Notwithstanding the recent improvements, however, Directors remained concerned about prospects for achieving the necessary adjustment toward balance during the upswing. They, therefore, encouraged countries to press ahead with fiscal consolidation. Countries at some distance from underlying balance need to identify measures equivalent to at least $1 / 2$ percent of GDP annual adjustment over the coming years, focused on the expenditure side. Indeed, given the soft nature of the Pact's preventive arm, many Directors reckoned that the Pact could usefully be buttressed at the country level by strengthening non-partisan national governance mechanisms that spell out the implications of policies in a forward looking manner.

Directors pointed to the integrated National Reform Programs under the reformed Lisbon process as useful platforms for fostering ownership and carrying forward national product and labor market reforms. They observed that reforms that raise labor utilization continue to be paramount but that policies also need to devote more attention to boosting productivity, not just through R\&D spending, but also by intensifying competition, especially in the services sector.

Directors welcomed the progress in integrating Europe's financial markets. However, with the area's lagging productivity, rooted in good part in the financial sector, policies need to become more proactive in removing the many remaining cross-border barriers to integration. This would require a forceful competition policy and public intervention in areas in which stakeholders stymie the establishment of open, market-based solutions. Directors welcomed the latest initiatives to strengthen crossborder collaboration among prudential authorities but thought that further integration of supervision over complex groups would be necessary to improve the effectiveness of area-wide prudential policies and crisis management. Directors welcomed the new Directive on AML/CFT and looked forward to its full implementation. 
Directors also stressed the role of trade liberalization in boosting productivity. Expressing disappointment about the recent developments in the Doha round, they noted an urgent need to reconsider entrenched positions, and called for resistance to the temptation to resort to undisciplined bilateralism. For its part, the EU should endeavor to achieve the effective liberalization of agricultural market access. Several Directors also commended the EU's ambitious Aid for Trade agenda.

While the external position of the euro area is broadly balanced and the euro is seen as falling within a fairly-valued range from a medium-run multilateral perspective, most Directors noted that growth-enhancing structural reform is needed to limit downside risks to the euro area and facilitate orderly adjustment to global imbalances. While this could be achieved through a variety of measures, the most effective in the current context appear to be steps to strengthen competition in the services sector, which, besides boosting productivity, would help accelerate growth and demand. In this context, Directors welcomed the authorities' acknowledgment that reducing global imbalances is a shared responsibility, and welcomed their commitment to contribute to this outcome through enhanced structural reform.

Public Information Notices (PINs) form part of the IMF's efforts to promote transparency of the IMF's views and analysis of economic developments and policies. With the consent of the country (or countries) concerned, PINs are issued after Executive Board discussions of Article IV consultations with member countries, of its surveillance of developments at the regional level, of post-program monitoring, and of ex post assessments of member countries with longer-term program engagements. PINs are also issued after Executive Board discussions of general policy matters, unless otherwise decided by the Executive Board in a particular case. 
Table 1. Euro Area: Main Economic Indicators

(in percent change)

\begin{tabular}{|c|c|c|c|c|c|c|c|c|c|}
\hline & 1999 & 2000 & 2001 & 2002 & 2003 & 2004 & 2005 & $20061 /$ & $20071 /$ \\
\hline \multicolumn{10}{|l|}{ Demand and Supply } \\
\hline Private consumption & 3.4 & 3.2 & 1.9 & 0.9 & 1.0 & 1.5 & 1.3 & 1.8 & 1.5 \\
\hline Public consumption & 2.0 & 2.2 & 2.2 & 2.6 & 1.7 & 1.1 & 1.4 & 1.5 & 1.2 \\
\hline Gross fixed investment & 6.1 & 4.9 & 0.5 & -1.5 & 0.8 & 2.3 & 2.3 & 3.5 & 3.3 \\
\hline Final domestic demand & 3.7 & 3.1 & 1.7 & 0.6 & 1.2 & 1.4 & 1.5 & 2.0 & 2.0 \\
\hline Stockbuilding $2 /$ & -0.1 & 0.2 & -0.5 & -0.2 & 0.1 & 0.6 & 0.1 & 0.0 & -0.1 \\
\hline Domestic Demand & 3.6 & 3.3 & 1.2 & 0.4 & 1.3 & 2.0 & 1.6 & 2.0 & 1.9 \\
\hline Foreign balance $2 /$ & -0.6 & 0.6 & 0.7 & 0.5 & -0.6 & 0.1 & -0.2 & 0.1 & 0.0 \\
\hline Exports $3 /$ & 5.0 & 12.0 & 3.6 & 1.7 & 1.1 & 6.5 & 3.8 & 7.3 & 5.8 \\
\hline Imports $3 /$ & 7.2 & 10.8 & 1.8 & 0.3 & 3.0 & 6.7 & 4.6 & 7.3 & 5.8 \\
\hline Real GDP & 3.0 & 3.9 & 1.9 & 0.9 & 0.8 & 2.1 & 1.3 & 2.1 & 1.8 \\
\hline \multicolumn{10}{|l|}{ Resource Utilization } \\
\hline Potential GDP & 2.3 & 2.1 & 2.2 & 2.1 & 1.9 & 1.9 & 1.8 & 1.8 & 1.8 \\
\hline Output gap 4/ & 0.3 & 1.9 & 1.6 & 0.5 & -0.7 & -0.6 & -1.1 & -0.9 & -0.9 \\
\hline Employment & 2.0 & 2.4 & 1.6 & 0.7 & 0.4 & 0.6 & 0.7 & 0.9 & 0.8 \\
\hline Unemployment rate $5 /$ & 9.2 & 8.2 & 7.8 & 8.3 & 8.7 & 8.9 & 8.6 & 8.0 & 7.9 \\
\hline \multicolumn{10}{|l|}{ Prices } \\
\hline GDP deflator & 1.5 & 1.3 & 2.3 & 2.6 & 2.1 & 1.9 & 1.9 & 2.0 & 2.0 \\
\hline Consumer prices & 1.1 & 2.1 & 2.3 & 2.2 & 2.1 & 2.1 & 2.2 & 2.2 & 2.2 \\
\hline \multicolumn{10}{|l|}{ Public Finance 6/ } \\
\hline General government balance 7/ & -1.3 & -1.0 & -1.9 & -2.6 & -3.0 & -2.7 & -2.3 & -2.1 & -2.0 \\
\hline General government structural balance & -1.3 & -1.7 & -2.5 & -2.7 & -2.7 & -2.4 & -2.0 & -1.8 & -1.6 \\
\hline General government gross debt & 72.1 & 69.6 & 68.3 & 68.1 & 69.3 & 69.8 & 70.8 & 70.2 & 69.6 \\
\hline \multicolumn{10}{|l|}{ Interest Rates 8/ } \\
\hline Short-term deposit rate & 3.0 & 4.4 & 4.2 & 3.3 & 2.3 & 2.1 & 2.3 & 2.9 & $\ldots$ \\
\hline Long-term government bond yield & 4.6 & 5.5 & 5.0 & 4.9 & 3.9 & 3.8 & 3.4 & 4.0 & $\cdots$ \\
\hline \multicolumn{10}{|l|}{ Exchange Rates } \\
\hline U.S. dollar per euro 9/ & 1.07 & 0.92 & 0.90 & 0.94 & 1.13 & 1.24 & 1.25 & 1.27 & $\ldots$ \\
\hline Nominal effective rate $(2000=100) 8 /$ & 112.2 & 100.0 & 101.6 & 105.1 & 117.6 & 122.0 & 121.7 & 122.9 & $\ldots$ \\
\hline Real effective rate $(2000=100) 8 / 10 /$ & 113.4 & 100.0 & 101.8 & 107.5 & 121.3 & 127.5 & 126.5 & 127.6 & $\ldots$ \\
\hline \multicolumn{10}{|l|}{ External Sector 6/ 11/ } \\
\hline Current account balance & -0.5 & -1.5 & -0.3 & 0.7 & 0.4 & 0.6 & -0.3 & -0.1 & -0.1 \\
\hline Trade balance $12 /$ & 0.9 & 0.1 & 1.0 & 1.8 & 1.4 & 1.4 & 0.7 & $\ldots$ & $\ldots$ \\
\hline \multicolumn{10}{|l|}{ Memorandum items 6/ 13/ } \\
\hline Current account balance & 0.4 & -0.6 & 0.2 & 0.7 & 0.5 & 1.0 & -0.1 & -0.2 & -0.2 \\
\hline Trade balance $12 /$ & 1.3 & 0.6 & 1.4 & 2.1 & 1.8 & 1.7 & 0.9 & 1.2 & 1.2 \\
\hline
\end{tabular}

Sources: IMF, World Economic Outlook; Eurostat, ECB Monthly Bulletin.

$1 /$ Staff estimates and projections.

2/ Contribution to growth.

3/ Includes intra-euro area trade.

4/ In percent of potential GDP.

$5 /$ In percent.

6/ In percent of GDP.

7/ Excludes UMTS revenues.

8/ Data for 2006 are for June

9/ Data for 2006 are for June 30.

10/ Based on normalized unit labor costs.

11/ Based on ECB data, which exclude intra-euro area flows.

12/ Data for goods.

13 / Calculated as the sum of individual countries' balances. 
This page intentionally left blank 


\section{Statement by Tuomas Saarenheimo, Executive Director for Euro Area July 26, 2006}

Since July $1^{\text {st }}$, Finland has been holding the Presidency of the euro area. I therefore have the honor of giving this statement reflecting the common view of the euro-area Member States and the European Community in their respective fields of competence.

The authorities of the euro-area Member States welcome the IMF Staff's assessment of economic developments and prospects in the euro area. While the authorities broadly concur with the findings of the IMF, on some issues views differ, as outlined below in this statement. I will also update the Board on recent economic developments.

\section{Short-term economic outlook}

Since the beginning of the year, the euro-area economy has returned to a robust growth path. Domestic demand has been picking up and GDP has been growing above potential in the first quarter. Private consumption has shown clear signs of recovery and made a strong contribution to economic growth. This reflected strengthening household confidence and a gradual firming of the labor market. Moreover, the underlying momentum of private investment growth remains strong despite somewhat subdued construction activity in the first months of the year resulting from poor weather conditions. Finally, the euro area continued to benefit from robust global demand, resulting in a positive contribution from net trade to growth.

The strengthening of domestic demand in the euro area has been awaited for some time. According to survey or "soft" data, consumer and business confidence have already been on a steady increase since the second half of 2005 and lie well above the low levels recorded in 2002 and 2003. It is a fact that it has taken longer than usual for the "hard" economic data to reflect the higher confidence of households and businesses. Statistical factors have certainly played a role here. But given the strong performance in the first quarter, hard data are now starting to trail the upward trend in the soft data, and business and consumer confidence has continued improving in recent months.

Nevertheless, there are also downside risks to growth among which the most important stem from higher energy prices, a possible disorderly correction of global imbalances, or pressure for increased protectionism. Finally, the recent turbulence on global financial markets is an additional source of uncertainty, especially in the light of these global imbalances. At this stage there is no reason to be overly worried about the consequences of this turbulence for the euro area: the effects have been largely confined to equity markets and financial markets in emerging market economies and some correction in stock markets may have been necessary in the light of earlier exuberance. Nevertheless, these developments should be kept under close review. 
The euro-area authorities share the staff's view that real GDP growth is to remain around 2\% in the baseline scenario in 2006 and 2007. Moreover, there is agreement that the risks to growth seem to be tilted to the upside in the near term and that the risks to growth start to weigh on the downside in 2007. However, while the euro-area authorities see a gradual strengthening of domestic demand (and its contribution to 2006 and 2007 growth should remain larger than external demand), the IMF staff sees a continued strong dependence of the euro area on external demand. As a result, the staff seems to be more concerned about the balance of risks to growth in 2007.

\section{Monetary policy}

The euro area authorities welcome the assessment by the IMF staff that the recent increases in the ECB's key interest rates, which reached $2.75 \%$ in June 2006, were warranted. The ECB also agrees with the staff that, after these increases, the ECB's monetary policy stance still remains accommodative. However, the ECB disagrees with some of the conclusions contained in the staff report, notably as regards the view expressed on the outlook for risks to price stability over the medium term and, consequently, the appropriate orientation of the monetary policy stance going forward in order to contain such risks. Specifically, the staff argues that the ECB should wait for a broadening of the upswing or signs of accelerating underlying price pressures before further withdrawing accommodation, since they regard the recovery in the euro area as still fragile and not sufficiently broad-based and consider risks to price stability to be relatively balanced over the medium term. In this context, it should be recalled that, consistent with its mandate, the ECB's primary objective is to maintain price stability in the euro area, and that price stability is defined on the basis of headline inflation, rather than using measures of so-called core inflation emphasised by the IMF staff.

The assessment of the ECB's Governing Council is that upside risks to price stability over the medium term continue to prevail. The Governing Council also considers that economic activity in the euro area accelerated and became more broadly based in the first half of 2006, with economic growth projected to continue at rates around potential on a sustained basis, although downside risks to the growth outlook do exist over longer horizons.

As regards the Governing Council's assessment of risks to price stability on the basis of the economic analysis, oil price rises in particular have brought annual HICP inflation rates to levels above $2 \%$, levels that have now persisted over several quarters. Inflation rates are likely to remain above $2 \%$ during the second half of 2006 and, on average, in 2007. While the moderate evolution of labour costs in the euro area is expected to continue in 2007, the indirect effects of past oil price increases and changes already announced in indirect taxes are expected to exert a significant upward effect on inflation in the course of next year. Over the medium term, risks to price stability are clearly on the upside and include: further increases in oil prices; a stronger than expected pass-through of oil price rises to consumer prices; additional increases in administered prices and indirect taxes; and, more fundamentally, stronger than expected wage and price developments owing to second-round effects of past oil price increases. 
The ECB's monetary analysis provides further insight into inflation prospects over medium to longer-term horizons. Monetary developments point to increased upside risks to price stability at these horizons and therefore require enhanced monitoring. In an environment of already ample liquidity, money and credit growth have strengthened further over recent quarters, reaching, in terms of annual growth, the highest rates observed since the introduction of the euro - and in fact, the highest rates since the early 1990s. Loans to the private sector have been expanding at double-digit rates and have become broadly based across sectors, with borrowing both by households (in particular for house purchase) and by non-financial corporations rising more strongly. These developments confirm the stimulative impact that the low level of interest rates in the euro area is having on money and credit expansion. They also emphasise the need to closely monitor price dynamics in a number of housing markets.

Cross-checking the outcome of the economic analysis with that of the monetary analysis supports the assessment that upside risks to price stability prevail over the medium term. On this basis, the Governing Council of the ECB reached the conclusion that a progressive withdrawal of monetary accommodation remains warranted. The continued solid anchoring of inflation expectations in the euro area at levels consistent with price stability requires that the markets and the public be firmly assured that the ECB will act in a timely manner to ensure that risks to price stability do not materialise. In turn, the continued solid anchoring of inflation expectations is a prerequisite for monetary policy to make an ongoing contribution towards supporting sustainable economic growth and job creation in the euro area.

\section{Fiscal developments and fiscal policy}

The euro-area authorities share the staff's view that there are important fiscal challenges for the euro area. First, the average debt-to-GDP ratio exceeds $70 \%$ and 7 out of 12 Member States have debt levels above the $60 \%$ reference value of the Treaty. Second, the population of the euro area is ageing. This will put further pressure on public finances by significantly lowering the euro area's growth potential and by substantially raising ageing-related expenditures. Progress has nevertheless been made towards securing more sustainable public finances in many member states, not least with respect to pension reform.

In this context, the staff's positive overall assessment of the reformed Stability and Growth Pact is welcomed. Authorities agree that the first year of the application of the reformed Stability and Growth Pact (SGP) can be judged positive. While remaining a rules-based system, the reformed SGP has stimulated a constructive and transparent economic policy dialogue. The reformed Pact resulted in more national ownership of the budgetary rules as a result of a stronger economic rationale which ensures that economic differences between countries are better taken into account. Budgetary adjustment in the EU has resumed and budgetary positions in 2005 have improved in structural terms by $0.8 \%$ of GDP in the euro area. 
Although these developments warrant some optimism on the future implementation of the SGP, euro-area authorities agree with the staff that further progress needs to be made to ensure compliance with the 'preventive arm' of the Pact which governs the attainment of sound budgetary balances in the medium-term. The long-term fiscal sustainability challenges stemming from ageing populations should be at the heart of policy making.

Budgetary authorities are committed to making use of the positive budgetary developments in 2005 and the benign economic outlook to speed up the pace of deficit and debt reduction so as to reach their medium-term objective. Taking advantage of the current window of opportunity to improve the budgetary position will contribute to a better policy mix with possibly lower long-term interest rates than otherwise. It will also create more room for manoeuvre in the next downswing and contribute to reducing debt levels significantly before the budgetary effects of ageing set in.

On the staff's suggestion that fiscal governance mechanisms at the national level could possibly contribute towards a more forward-looking approach to budgetary policy, euro-area authorities agree that well-designed national fiscal rules and institutions may facilitate budgetary consolidation strategies as well as help avoiding pro-cyclical policies.

\section{Structural policies}

The euro-area authorities welcome the staff's positive recognition of the progress made in the area of structural reform, regarding both the new organisation of the Lisbon process and the reforms that so far have been implemented. The new process, including National Reform Programmes, has indeed contributed to improve national ownership of - and support for the objectives of the Lisbon agenda. Moreover, national parliaments and social partners have started to become more involved in the process. Further improvements in the governance of the Lisbon process are under way. The Commission and the Member States are now in the process of developing a methodology with which the progress made in implementing the proposed measures can be assessed.

The structural reforms undertaken so far have had positive effects. Active labor market policies, mainly focusing on the labor supply side, have contributed to employment growth. Indeed, the employment rate in the euro area has risen significantly since the turn of the century. Pensions systems and social security systems are being reformed. Progress is being made in improving the Internal Market's legal and regulatory framework and in reducing administrative burdens. Finally, all Member States have been reforming their product markets to enhance the business environment and stimulate entrepreneurship.

Despite the progress that is being made - job creation has improved and it is comparable to that of the US in boom times -, much remains to be done to reach the Lisbon objective for the participation rates and to increase the flexibility needed to enhance the efficiency of adjustment mechanisms in the euro area. Labor market reform must indeed continue to be 
paramount in the reform programmes of the euro-area Member States . The euro-area's recent performance with respect to labor productivity growth, which in the light of an ageing euroarea population will become an essential source for economic growth in the long run, has been disappointing. Labor productivity growth has been on a secular declining trend and in the past decade it has been below US productivity growth. The staff therefore rightly points out that the reform programmes need to devote more attention to boosting productivity. In the light of an ageing euro-area population, however, productivity growth will become essential for economic growth in the long run.

Productivity strengthening is most necessary in the services sector which accounts for $70 \%$ of the euro-area's current economic activity and which has low overall productivity growth. This low productivity growth in the services sector seems related to the insufficient exploitation of ICT. But there also appears to be a link to the lack of competition in some services sectors, with the latter reflecting the limited tradability of many services, the extensive domestic regulation and the lack of a fully integrated single market for services in the euro area. Therefore, policy measures are needed that increase competition in, and integration of, the euro-area services markets, favour the spread of new technologies and enhance human capital. The euro-area authorities agree with the staff's assessment that stronger competition in the services sector - by means of boosting productivity - would help to accelerate growth and demand, thereby facilitating an orderly adjustment to global imbalances and limiting downside risks to the euro area. In this light the Services Directive is a step in the right direction and the euro-area authorities are committed to ensure full and rapid implementation.

\section{Financial sector issues}

The euro-area authorities share the staff's positive assessment of the health of the euro-area financial sector. The performance and soundness of the sector has been improving for several years and is likely to strengthen further in line with the recovery in the real economy. Nevertheless, significant risks to the financial sector persist and continued vigilance is required on the part of policymakers. While these risks have a global dimension, their implications will vary among euro-area Member States depending on local economic and financial conditions. In this context, the staff has drawn attention to these differences and highlighted the specific risks facing those Member States where house prices and/or household debt have risen sharply. While there is no evidence of a major risk to economic growth or financial stability in the Member States concerned, developments are being monitored carefully at both the national and euro-area level.

The euro-area authorities agree that financial sector integration would bring about important area-wide productivity gains. On these grounds, financial integration has become one of the key elements of the EU strategy for economic reform. While it is understandable that the staff should express concern about the measured pace of integration, it must be recognized that the integration of so many national financial systems is a highly complex operation. In 
this context, it is important that deadlines in the integration process are realistic, if suboptimal outcomes are to be avoided. Moreover, one should not underestimate the extent of progress that has already been achieved. For example, money markets, government bond markets and derivatives markets in the euro area are now either unified or substantially more integrated than it was the case before the introduction of the euro in 1999, while the corporate bond market and the market for investment funds have grown rapidly. In light of the progress achieved, we find the staff assessment of progress in financial integration (para. 26) somewhat unbalanced.

The process of financial integration is set to intensify in the coming years, as a common regulatory framework largely is progressively put in place through implementation of the Financial Services Action Plan. The FSAP is now implemented at the EU level and Member States are in the process of transposing the various legislative elements into their national laws. The Lamfalussy framework will assist in this process by helping to deliver consistent implementation across Member States. While a degree of discretion in transposition has been left to the Member States, the description of the FSAP and Lamfalussy process by the staff as being captured by vested interests (para. 26, second bullet) seems exaggerated.

Despite the progress achieved, the staff rightly draws attention to several important areas where efforts to promote integration must be stepped up, notably clearing and settlement arrangements and cross-border consolidation in banking. The obstacles to integration in both of these areas have been identified and analyzed, and appropriate policy reforms will be announced soon. The Staff also highlights the financial stability framework and is concerned that current arrangements for oversight of cross-border transactions may not be adequate to the task. Although much improved in recent years, the arrangements for cross-border supervision - from both efficiency and stability perspectives - have been identified as priorities for action in EU financial services policy for the period 2005-2010. A series of pragmatic initiatives - such as mediation, delegation, harmonized reporting etc. - have already been proposed and clear deadlines for delivery have been set by the Council. In this context, the so-called level-3 committees in the Lamfalussy framework will play an essential role in fostering the necessary convergence in supervisory practices and procedures. At the same time work to further refine arrangements for financial crisis prevention and management is ongoing. In April 2006, a crisis management exercise was organized involving all relevant players at EU level. On the basis of the experience with this exercise, further priorities will be set aiming at further improving the current framework.

\section{Euro area integration}

We do not share the staff's assessment concerning EU integration (see paragraph 28), in particular that the euro area is not open. Indeed, on 11 July 2006, the euro area welcomed Slovenia as new member and remains open to all EU member states fulfilling the criteria as defined in the Treaty. More broadly, we agree that the integration of labour, product and 
financial markets in the euro area need to be deepened further to enhance their flexibility to adjust to economic shocks.

\section{International economic relations}

Like the IMF staff, the euro-area authorities regret the insufficient political readiness in some countries to come to a successful and timely conclusion of the Doha Development Agenda. The European Union has taken the lead in all areas of the negotiations, including in agriculture where the EU made substantive proposals on market access, reduction of domestic support and where it committed to eliminate its export subsidies by 2013 . The EU offer in agriculture would create significant new export opportunities for third countries into European markets. Moreover, the EU would have been ready to improve its offer. However, this would have needed to be concurrently reciprocated by the United States in the field of domestic support and by the emerging market economies as regards industrial market access and services.

The authorities also share the staff's concern that the proliferation of bilateral and plurilateral free and regional trade arrangements could contribute to undermining the multilateral fabric of world trade. However, it should be added that one-sided restraint in Europe is no option, given the growing concern within the euro area about loss of global market share and the recent bilateral deals signed between other major trading blocs.

Finally, the staff's positive assessment of the EU's Aid for Trade and Economic Partnership Agreements is welcomed as the EU's recent efforts in these areas have indeed been ambitious and successful. 